Elsevier Editorial System(tm) for Energy

Manuscript Draft

Manuscript Number: EGY-D-08-00110R2

Title: Systematic Approach to Natural Gas Usage for Domestic Heating in Urban Areas

Article Type: Full Length Article

Keywords: Natural Gas; Settlement; Gas Distribution; District Heating; Urbanism

Corresponding Author: Mr Dejan Brkic, Master of Sc. in petroleum eng. PhD stud

Corresponding Author's Institution: Ministry of Science

First Author: Dejan Brkic, Master of Sc. in petroleum eng. PhD stud

Order of Authors: Dejan Brkic, Master of Sc. in petroleum eng. PhD stud; Toma I Tanaskovic, PhD in mining engineering 


\section{SUBMISSION CHECKLIST}

Please read this list and answer the questions only after you have examined them carefully. Do not submit the paper unless you can truthfully answer 'yes' to questions 1-14 (or 'not applicable' for question 8 if your paper does not include computation or experiments) for new papers, and 'yes' also to question 15 for revised papers.

Make sure you check each item carefully before submitting your manuscript.

1. yes

2. yes

3. yes

4. yes

5. yes

6. yes

7. yes

8. yes

9. yes

10. yes

11. yes

12. yes

13. yes

14. yes

15. If this is a REVISED version of a previously-reviewed paper, have you included all of the materials requested by the Editor, including:

() yes

( ) yes

( ) yes 
Dear Prof. Lior,

We are grateful to referees for their suggestions. According to referees' comments, we have modified our paper "Systematic Approach to Natural Gas Usage for Domestic Heating in Urban Areas"- EGY-D-08-00110R1. We are returning our rewritten manuscript. This paper has not been published previously, it is not under consideration for publication elsewhere, and if accepted it will not be published elsewhere in substantially the same form, in English or in any other language, without the written consent of the Publisher. Also, don't forget we want to attach Electronic annex refer to our work - MS Excel file (annex DB ver3). We hope that English expression in our paper is now improved.

Beograd, 11.08.2008.

Yours Sincerely, Dejan Brkic

Toma Tanaskovic 


\title{
Systematic Approach to Natural Gas Usage for Domestic Heating in Urban Areas Dejan Brkića ${ }^{\mathrm{a}}$, Toma I. Tanasković ${ }^{\mathrm{b}}$
}

${ }^{\mathrm{a}}$ Ministry of Science and Technological Development, Đušina 7, 11000 Beograd, Serbia, ${ }^{b}$ Faculty of Mining and Geology, University of Belgrade, Đušina 7, 11000 Beograd, Serbia Received: 22 February 2008; received in revised form:

\begin{abstract}
Natural gas can be used for satisfying population needs for heating, either directly by bringing the gas to the dwellings through the gas distribution system and combusting it in the domestic boiler (gas distribution system-G), or indirectly by combusting the natural gas in the heating plant and distributing the heat energy to the dwellings through the district heating system (district heating system-DH). The selection of a certain type of heating system is made according to the disposition of buildings in the area, their number, size, insulation quality, etc. Based on these characteristics, calculations of investments and exploitation costs have been made for both heating systems and a comparison has been made for all of the 96 presented cases. Almost each type of real settlement can be represented by one of the types of the conditional urban area which are introduced in the paper. The main goal of this paper is to establish a general model to achieve coordinated development of centralized energy supply systems fueled by natural gas, based on defined and accepted criteria. A structure analysis of centralized systems for energy supply has been done with accent on their pipelines.
\end{abstract}

Keywords: Natural Gas, Settlement, Gas Distribution, District Heating, Urbanism

*Corresponding author, Tel./fax: +381113243457, e-mail: dejanrgf@tesla.rcub.bg.ac.yu, (D. Brkić) 


\section{Nomenclature}

$\mathrm{y}$ - number of "Conditional Dwellings" per building [-]

$\mathrm{N}$ - number of buildings per "Conditional Urban Area" [-]

X - Peak load densities or "Heat Load" [MW/km²]

$\mathrm{DH}-$ costs of district heating system [€]

$\mathrm{G}$ - costs of local gas heating system (domestic boiler in each dwelling) [€]

DHN - costs of district heating network, i.e. costs of building/civil works, costs of materials (insulated pipes, pumps, accessories, etc.) and telemetry systems, etc [€]

HE - costs of heat exchanger stations located in buildings [€]

$\mathrm{HP}$-investment in new heating plant $[€]$

DHOC - annual costs of maintenance calculated as percentage of investment, network, heat exchanger station, annual natural gas consumption and annual electricity consumption for pumps drive $[€]$

MPRS - costs include costs of main pressure reduction stations [€]

PRS - costs of pressure reduction stations [€]

DN - costs of natural gas distribution network [€]

DS - costs of domestic measurement sets [€]

B - costs of domestic boilers [€]

GOC - annual costs of maintenance calculated as percentage of investment; in gas distribution network, in pressure reduction station, in measurement set, domestic boiler and annual natural gas consumption $[€]$

dr - "Discount Rate" [\%] 
NPV - "Net Present Value of Costs" [€]

$\mathrm{t}$ - Time [years]

\section{Introduction}

If a gas based system in a settlement is planned, the decision can be done among two conflicted options:

1. Indirect system; natural gas is being combusted in a heating plant and household heat supply is provided by a District Heating System (DH),

2. Direct system; dwellings are being heated by natural gas brought through a gas distribution system and then combusted in domestic gas boilers in each dwelling, individually (G).

The initial decision on choosing one of two systems is based on the number and size of buildings in a settlement, the size of the settlement itself and the heating insulation of buildings [1]. In boundary cases, if it is possible to achieve both options it is also possible to introduce a sort of hybrid system which is not considered in this paper. The economic analysis of the renovation of small-scale district heating systems in Lithuania is available [2]. District heating systems using cogeneration, as well as the local fuel-based and electric heating systems for detached houses, are analyzed by L. Gustavsson and A. Karlsson [3]. Their analysis includes the whole energy system, from the natural resource to the end user, with respect to the primary energy use, emission and cost. They found that natural gas based systems are less expensive than the corresponding wood-fuel based systems, except the matter of ecology. In the future, green energy sources or fossil energy sources such as oil and natural gas will be more used in industrial 
processes in order to decrease the ratio of greenhouse gases released from the coal-based local and industrial processes [4].

The goal of the model introduced in this paper is to determine the connections among urban and energy characteristics of settlements in cities and to be benefit from more rational usage of natural gas as non-renewable fossil fuel. Energy demands for heating are shown for the Canadian case [5], from the economical point of view. The introduction of natural gas in the Greek energy market has broadened the options in the field of space heating [6]. The paper by C. Dinca, A. Badea, P. Rousseaux, and T. Apostol [7] aims to select the optimal energetic scenario applied to a consumer with 100000 inhabitants from the residential-tertiary sector in Romania (series of seven scenarios based on natural gas have been analyzed). The natural gas in optimized bivalent heating systems is shown in the paper of SI. Gustafsson and BG. Karlsson [8]. The study of MS. Torekov, N. Bahnsen, and B. Qvale [9] is in correlation with this paper and strives to clarify to what extent the improved insulation of new buildings affects the economically rational choice of heating supply. District heating should be advocated only for areas with a strong heat demand, primarily for areas with apartment buildings [9]. R. Lazzarin and M. Noro [10] have done analyses of local or district natural gas heating from energetic, environmental and economic points of view. The legal and policy aspects of the utilization of different energy supply systems in households sector can also be found in the available literature [11]. Some German studies with subject relevant for development of district heating systems in urban environment are also useful and highly evaluated, but this literature is available only in German language [12-14], with related papers presented in scientific journals [15]. The main achievement of these German researches is the establishing of interaction between heating systems, settlement structure and 
urban planning at the local level. The study analyses options for heat supply in up to 10 types of built up areas [12] - from densely populated urban areas to villages. A new German study 20 years later_refers to this work [13], with projection to 2020 [14].

Considering the selection of heating systems and the utilization of the existing capacities in the systems for centralized energy supply, the present practice in many cities is that every single case must be considered separately and, very often, the selection is done without clear criterions. The proposed model could be useful to urban planners, municipal officials, public utility companies, etc., as a first step in system selection (see Electronic Annex in the online version of this article).

The most suitable option for satisfying heating demands in urban areas is by using a centralized system. The centralized energy supply from heating plants has many advantages: saves primary energy (due to the modern construction of boilers in heating plants as well as the utilization of modern energetic and ecological ways of combustion, the primary energy sources are better used during the transformation of primary energy into heat energy), the distribution of hot water consumption (the centralized hot water distribution is the way to avoid the transformation of primary energy, mostly from heat to electric energy, and then again, from electric to heat energy), the possible utilization of low quality fuel, the possible utilization of some alternative kind of fuel, the centralized storage for fuel, less expenses for the standard discontinuous transportation of fuel (saving motor vehicles' fuel), due to the centralized and highly controlled heating, there is less danger from fire. There is also a well organized, professional fire protection. There are also some negative aspects of the heating systems from heating plants: high investments during the initial phase of building of heating sources and pipeline structure, 
possible quitting with heat energy supply caused by the damage in heating plant or distribution network, in some cases, heating expenses are measured by squaring, not by consumption. The advantages of the systems for the individual consumption of gas in households by using the gas distribution network are the following: the gas consumption is being measured separately for each apartment and the paying of costs depends on consumption (which is not always the case when DH systems are being used), gas saving for hot water supply and cooking (these demands are being satisfied directly by the transformation of chemical energy of natural gas into heat energy, that is how the gas used for transformations of primary energy into electric energy is saved), there is no need for storehouses in households, less costs for the standard fuel distribution (the fuel is saved for motor vehicles), relatively small investments in the construction of distribution network in relation to thermal network, less possibility for quitting of supply. The disadvantages of the centralized natural gas supply systems are: an increased fire danger, explosions, or possibility of suffocation caused by damaged installations for different reasons, the combustion is taking place in the apartment, the possible lack of gas or an interrupted distribution pipeline, etc.

Life comfort [16] is the same in both options; every individual dwelling has the same network of conduits and radiators. The main intention of this model approach is to find a way to distribute heat energy in each dwelling using the existing capacities (not to make strategy for a city planning, but to exploit most possible rationally existing capacities). The primary goal of this paper is not to investigate district heating or gas distributive infrastructure, but to compare investments in both systems with their specific details (pipelines with included costs of domestic boilers for the G system or costs of heat exchanger for the DH system, investment in new 
capacities in heating plant, etc.). The main subject of the examination is in the "Conditional Urban Areas". The comparison of investments in pipelines for both systems is the most important parameter of this analysis. In the most detailed heating analyses in one town, the other types of fuel for heating plants, the alternatives for heating in the cases of the lack of natural gas, etc. must also be taken into consideration.

The model which is presented here is developed as a tool for solving some of the misunderstandings in the strategy of urbanism correlated to natural gas heating in Serbian towns. This project has been supported by the Ministry of Science of Serbia. All the values in this paper refer to conditions in Serbia, but readers also have an access to the relevant file (see Electronic Annex 1 in the online version of this article), and can change all the values (green tones in excel file can be changed). According to that possibility, this model can be applied for conditions anywhere in the world.

The strategy for heating of dwellings in urban areas of Serbia, since the communist period, had been made to favor district heating systems in towns. The consumer area of Belgrade is being supplied with thermal energy by district heating system consisting of 15 heating plants which use gas $\left(83 \%=265 \cdot 10^{6} \mathrm{~m}^{3} /\right.$ year [1]) and crude oil as basic fuel. Statistical data show that $38 \%$ of the buildings are connected to the district heating system, which represents 240000 flats and 7500 business offices heated in that way. The construction projects of thermal network and gas distribution network in downtown areas take an important place in the scope of the Belgrade environmental protection program, so approximately 800 individual solid fuel boilers have been shut down so far. Nowadays, most of these plants are being fueled by natural gas, but in the past 
they were fueled by liquid fuels or by coal (in some smaller and obsolete plants). All of these mini plants have to be closed. According to the new strategy, the heat supply for relevant dwellings will be provided by some sort of natural gas heating. The government has the strategy to connect almost all dwellings to some form of natural gas heating system. The goal is not to use solid fuel heating, especially not electric energy. They should be used only in some rare cases. There are 42 city heating plants in Serbia with heat energy capacity of 5.5GW. However, Serbia does not have sufficient energy production or funds for their procurement. The main characteristics of Serbia's heating plants are low operating readiness due to insufficient maintenance and outdated equipment, financial exhaustion and an inability to perform urgent intervention on sources and grids. Heating is poor and there is a need for additional capacity, mostly fueled by natural gas. Serbia doesn't have enough gas production reserves from its own fields or to satisfy the demands (the annual peak of the production was $600 \cdot 10^{6} \mathrm{~m}^{3}$ and now it is several times lowers $\left.\left(285 \cdot 10^{6} \mathrm{~m}^{3}\right)[1]\right)$. The imported gas is available for Serbia since 1979. from one direction (from north, through Hungary). Serbia also has the EU perspective [17, 18], and the Government's strategy is to make Serbia a transient country for the export of Russian gas to the western countries of EU countries (from the second direction, through Bulgaria). Due to the European obligation to reduce greenhouse gas emissions in the framework of the Kyoto Protocol, the trend towards the use of natural gas is expected to continue in the future. The increased consumption and comparably low indigenous gas resources within Europe are expected to increase the Europe's dependency on gas imports from abroad in the future. In addition to the existing supply sources from Russia [19] and Algeria, gas resources from the Middle East and the Caspian and Central Asian regions could be the possible supply options to cover Europe's gas demand in the future. Today, natural gas heating in Serbia has a great perspective [20-23]. 
A hypothetical equivalent within a model has been made for every type of settlement. The investment costs were calculated and the comparison has been made for each (of a limited number) of hypothetical settlements. The system with the smallest investments (including exploitation and the maintenance in the next 25 years), depending on the city planning parameters, is more cost effective and adopted. This creates a direct link between the city planning parameters and the choice of one of the systems.

\section{The concept of conditional urban areas}

The model upon which the decision on choosing one of two systems is made (DH vs. G) is based on the introduction of hypothetical urban settlements. By introducing this practice, it is not necessary to perform the entire calculation for both systems and after which the choice of a heating system in the settlement is made. The application of this model makes easier the job for energy and city planners. People with higher living standard often do not take economic parameters into consideration when deciding between gas or district heating system. The decision is based on a personal affinity (and often, prejudice) [24].

The parts of a city with residential and other buildings within real settlements are called „Real Urban Area“. They can be divided into several zones based on the same or similar urban characteristics. The zones divided like this, for the model purposes, need to have an area of 0.05 $\mathrm{km}^{2}$ - "Basic segment" (Fig. 1.). Further on, real urban parameters of a real settlement can be copied onto the selected "Basic segment" (Fig. 2.). "Basic segment" with rectangular size with 
dimension approximately $160 \mathrm{~m} \cdot 315 \mathrm{~m}=0.05 \mathrm{~km}^{2}$ is adopted for this purpose [1]. Based on the spatial disposition within the model, there are 6 different versions of "Basic segments": 4, 8, 16, 32, 64 and 128 buildings per "Basic segments": (Fig. 1). "Examination segment" (Fig. 3.) consists of ten "Basic segments" with an added pipeline (gas and district heating). Only one type of "Basic segment" can exist in one "Examination segment". Real zone formed like this can be joined with one of the 96 „Conditional Urban Areas“(Fig. 4. and Table 1.). Each particular "Conditional Urban Area" consists of ten "Basic segments" (all the ten belong to one of the six types shown in fig 1.), buildings (all the buildings are the same in one regarded segment) and pipeline (district heating pipeline or gas distribution pipeline) - Table 2. Every real situation in town has to be joined to one of the best fitted „Conditional Urban Areas”. A different heat load (peak load density) can be given to each one of these basic types of "Examination segment", which is based on the size of buildings. There are 8 different heat loads in this model: 10 $\mathrm{MW} / \mathrm{km}^{2}, 20 \mathrm{MW} / \mathrm{km}^{2}, 30 \mathrm{MW} / \mathrm{km}^{2}, 40 \mathrm{MW} / \mathrm{km}^{2}, 50 \mathrm{MW} / \mathrm{km}^{2}, 75 \mathrm{MW} / \mathrm{km}^{2}, 100 \mathrm{MW} / \mathrm{km}^{2}$ or $125 \mathrm{MW} / \mathrm{km}^{2}$ (Fig. 2). These values are chosen for the analysis in order to include a wide range of possible real urban situations.

Every settlement, found in reality, corresponds to one of the 96 hypothetical settlements included in the model (Table 1). They are called "Conditional Urban Area" (six "Basic segment" multiply by eight "Heat Loads" multiply by two types of insulation) [1]. According to a variety of possible settlements (in density, size and layout of buildings) a model which has the ability to represent their different characteristics is formed. With six types of "Basic segments" (Fig. 1) all the possible densities of built up areas in settlements can be described. Different sizes of buildings can be found in each particular urban area from small houses to skyscrapers, i.e. with 
eight types of buildings graduated by size all situations can be described (eight different "Heat Loads"). Each of the 96 proposed hypothetical settlements can be joined with different city planning parameters such as: the number of buildings reduced to the unit value of surface, the size of buildings, the number of dwellings within the buildings, the number of floors within buildings, the spatial disposition of buildings within the settlement, the quality of heat insulation of dwellings etc [25-27]. If there are several types of buildings or density of built up areas within the settlement, settlements need to be divided into several „Conditional Urban Areas“. Every single type of building can be very good or poor insulated (older buildings versus newer buildings) [28]. Numbers of "Conditional Dwellings" per building are shown in Table 1.

For every "Conditional Urban Area", it is possible to calculate the entire investment costs for the implementation of gas distribution and district heating systems (Table 3). The investment's calculations are based on the detailed estimate of distribution network for both systems with all the equipment included as well as the labor expenses and the spare parts for replacement in the first 25 years. Thus, the investments for all the 96 cases can be calculated (one of these cases is shown in Table 4). After that, the values of gas distribution costs are being subtracted from the investment costs of the district heating system (Table 5) and then they are being discounted (Table 6). For cases with positive values the option of gas distribution is more favorable than the district heating system (negative values).

The disposition of networks for all cases is shown in figure 3 ("Examination segment"). The disposition designates the pipeline length, but not structure of diameters of conduits in the pipeline composition. The determination of structure of diameters of conduits the pipeline 
composition can be done only after the "Conditional Urban Area" is formed. A structure of pipes diameters depends on building size. The "Examination segment" has ten times bigger area surface than the "Basic segment" because of the network sensitivity exploration. Note that in fig. 3 ("Examination segment") pipeline network exists, while in Fig. 1 or in Fig. 2 it doesn't ("Basic segment").

So, the similarity between "Conditional Urban Area" and "Real Urban Area" can be determined by two different independent quantities [1].

1) Number of buildings in an urban area (the number of buildings on $0.05 \mathrm{~km}^{2}-5$ hectares); (Fig. 1),

2) A heat demand [29] of an urban area ("Heat Load" or peak load densities of all buildings heated in a zone divided by the size of an area), MW/km²; (Fig. 2),

The term "building" is used here for family houses also, as well as for the similar smaller constructions with the same meaning as e.g. skyscrapers. In all analyses, "Conditional Residential Unit" [1], i.e. "Conditional Dwelling” [1] with net heating surface area of $60 \mathrm{~m}^{2}$ is observed. "Conditional Dwelling" has, for the purpose of the model approach, a heat demand of $142 \mathrm{~W} / \mathrm{m}^{2}$ (heat peak load for lower insulated dwelling) in case of a low (bad) insulation, and in case of better (good) insulation it has a heat demand of $95 \mathrm{~W} / \mathrm{m}^{2}$ (heat peak load for better insulated dwelling). Each combination of a defined number of buildings and peak load density corresponds to a different number of average dwellings in the building (Table 1). An average dwelling $\left(60 \mathrm{~m}^{2}\right)$ is practically "Conditional Dwelling”. 
The concept of the "Examination segment" is regarded only for the purpose of exploration on realistic values of diameters in the pipeline structure, but values of $\mathrm{N}$-number of buildings presented in this paper are nominally per "Basic segment". "Heat load" is expressed in MW/km² (not in MW/0.05 $\mathrm{km}^{2}$ or in MW/0.5 $\mathrm{km}^{2}$ ) and it is nominally equal for both "Examination segment" and "Basic segment".

\section{The model of rational natural gas usage based on city planning parameters}

Based on the introduced "Conditional Urban Area", a techno-economical model of rational natural gas usage has been made. For each of the 96 cases investment, a calculation has been made in both of the proposed heating systems (Gas Distribution [30] vs. District Heating [31]) including the exploitation in the next 25 years (investments). For each case, a comparison of costs has been made so that the heating system with the smallest cost has an advantage in the implementation. The number of dwellings per buildings, i.e. the identification of all the 96 cases shown here is shown in Table 1.

Both of the heating types in the model have special costs since both of them have special elements; e.g. the district heating system is made of steel conduits, pumps and heat exchangers, on the contrary, the gas distribution system is made of cheaper polyethylene conduits and has stations for measuring and regulation with internal gas equipment (each dwelling has domestic gas boiler etc). The investment in new capacities for heating plant is included in the model in a directly i.e. by increasing the price of natural gas for district heating, or can be added by 
including the new cost indirectly. The investments in a new heating plant fueled by natural gas are: $80000 € / \mathrm{MW}$ (for heat plant capacity <50MW), $65000 € / \mathrm{MW}$ (for heat plant capacity 50$100 \mathrm{MW}$ ) and $52000 € / \mathrm{MW}$ (for heat plant capacity 100-200 MW) [1]. That means additional costs of 450-680€ per "Conditional dwelling". It implies that this kind of additional costs is not essential for this kind of analyses (Fig 5.). The changes in the slope of borderline in the model $\operatorname{diagram}^{2}$ are caused the discount rate changes (Fig 5.) or by differentiation in the structure of diameters of conduits in the pipeline ${ }^{3}$. Same conclusion can be made with price variations of domestic boiler (see Table 5 and Fig 5). L. Gustavsson and A. Karlsson [3] estimated the DH investment and maintenance costs. An increasing price of domestic gas boilers simultaneously with the introduction of the same amount of investments in a heating plant are to be annulled (Fig 5.) (for detailed analyses consult electronic annex 1).

A relative amount of investments (per "Conditional Dwelling" included annual costs) in district heating - DH and in local gas heating system - G (each "Conditional Dwelling" is equipped with domestic boiler fueled by natural gas) can be calculated after following eqs. (1 and 2).

$$
\mathrm{DH}=\frac{\mathrm{DHN}+\mathrm{HE}+\mathrm{HP}+\mathrm{DHOC}}{\mathrm{y}}
$$

Where there are: DH - costs of District Heating System [€], DHN - costs of District Heating Network, i.e. costs of building/civil works, costs of materials (insulated pipes, pumps, accessories, etc.) and telemetry systems, etc [€], HE - costs of Heat Exchanger stations located in buildings [€], HP -investment in new heating plant [€], DHOC - annual costs of maintenance

\footnotetext{
${ }^{2}$ See also Fig 11.

${ }^{3}$ See also Fig 12 in case study
} 
calculated as a percentage of investment, in network, heat exchanger station, annual natural gas consumption and annual electricity consumption for pumps drive $[€]$ and $y-$ number of "Conditional Dwellings" per building [-].

The annual maintenance costs calculated as a percentage of investment (eq. 1), in network (2,5\%); lifetime of 25 years, heat exchanger station (1,5\%); lifetime 12 years, annual natural gas consumption - 10\% more than in the system with domestic boiler in each "Conditional Dwelling") $\left(942,7 \mathrm{~m}^{3}\right.$ per “Conditional Dwelling” $\left.-0.12 € / \mathrm{m}^{3}\right)$ and the annual electricity consumption for pumps drive $\left(250 \mathrm{kWh}-0,035 € / \mathrm{kWh}^{2}\right)$. The estimated heat losses in the district-heating network are $10 \%$.

$\mathrm{G}=\frac{\mathrm{MPRS}+\mathrm{PRS}+\mathrm{DN}+\mathrm{DS}+\mathrm{B}+\mathrm{GOC}}{\mathrm{y}}$

Where there are: G - costs of Local Gas Heating System (domestic boiler in each dwelling) [€], MPRS - costs include costs of Main Pressure Reduction Stations [€], PRS - costs Pressure Reduction Stations [€], DN - costs of natural gas Distribution Network [€], DS - costs of Domestic measurement sets [€], B - costs of domestic boilers [€],GOC - annual costs of maintenance calculated as a percentage of investment; in gas distribution network, in pressure reduction station, in measurement set, domestic boiler and annual natural gas consumption [ $€]$ and y - number of "Conditional Dwellings" per building [-].

The annual maintenance costs calculated as a percentage of investment (eq. 2); in gas distribution network (2,25\%); lifetime of 25 years, in pressure reduction station (2,25\%); lifetime of 25 years, in measurement set $(2,25 \%)$, lifetime of 12 years, domestic boiler (2,25\%), lifetime 
of 12 years and the annual natural gas consumption $\left(857 \mathrm{~m}^{3}\right.$ per "Conditional Dwelling" -0.12 $\left.€ / \mathrm{m}^{3}\right)$.

The efficiency of the NG boiler is the best during winter when space heating is needed. During summer, when only hot water is required the boiler is often operated at a very low load and the average efficiency is reduced. For examination in this paper, on-line database SEDBUK ${ }^{4}$ (Seasonal Efficiency of Domestic Boilers in United Kingdom) [32] is very useful (Fig. 6 and 7). District heating is often less efficient with respect to modern heating technologies using natural gas. Condensing boilers guarantee higher efficiencies with respect to "traditional'” district heating.

An investment in a new heating plant or the increasing domestic gas boiler's price is included in the calculation, with the introduction of such costs or investments on both G and DH sides simultaneously, caused the equal impact in all of the six "examination segments" (does not change slope of borderline in Fig. $5^{5}$ ).

In the equations above, the common costs for both systems are not shown. Different investments in these two opposite systems can be compared for the purpose of a model (Fig 8).

All the previous investments are considered for the present conditions in Serbian energy sector. Of course, this model is applicable for conditions and particular cases all over the world, but

4 available from www.sedbuk.com

${ }^{5}$ or in case study in Fig 11 
diagrams (figures in this paper) are generated for prices ratio in Serbia. Detail calculation for one case of 96 is shown in table 4 .

Values of initial costs (shown in Table 3) for DH subtracted by initial costs of $\mathrm{G}$ are shown in table 5 .

Generally, each project task has a time component. Every particular element of the two systems shown here has a lifetime, and it has a price on the market (expressed in $€$ ). If one of the elements has reached the end of its lifetime (e.g. 26 years), it has to be replaced. Thus, in a project, during the first and the next several years, costs for provision, maintenance and replacement of elements exist (e.g., some elements must be replaced after 14 years and some after 25 years). A sum of costs calculated for each year (t) for gas distribution system is labeled here as G, and for district heating system as DH. "Present Value of Costs" is one of the most useful criterions for project analyses for a whole lifetime of every particular system element. In that way, discount flows reduced on "Present Value of Costs" can be evaluated. "Present Value of Costs" is, by default, cumulative cost for all the elements of the system in present and in future expanded for discount rate. "Future Value of Costs" has to be reduced to present value and to be added to real present costs. Thus, the generated value is called "Present Value of Costs". For the reduction of "Future Value of Costs", an appropriate "Discount Rate" (dr) has to be adopted. In the case of possible risks for the safety of investments, higher value of "Discount Rate" is being calculated. "Discount Rate" could be equalized with "Interest" on the market or for realized credit. 
In our case, an economical evaluation is realized during the comparison of two "Present Values of Costs", for gas distribution system (G) and for district heating system (DH) [33]. "Net Present Value of Costs" (NPV) (eq. 3) is the result of subtraction of the "Present Value of Costs" calculated for district heating system (DH) and the "Present Value of Costs" calculated for gas distribution system $(\mathrm{G})$.

$\mathrm{NPV}=\sum_{\mathrm{t}=1}^{\mathrm{n}} \frac{\mathrm{DH}-\mathrm{G}}{\left(1+\mathrm{D}_{\mathrm{r}}\right)^{\mathrm{t}}}$

The value of "Discount Rate" or capital cost rate in this case is rated and adopted as dr=10\%. The value of discount rate has great impact on the optimal choice of quantitative conclusions (Fig. 5). The changes of calculated values for $\mathrm{dr}=5 \%$ and $\mathrm{dr}=7 \%$ are shown in Table 6 . Annual gas consumption calculated for one "Conditional Dwelling" is $857 \mathrm{~m}^{3}$ for heating only, and this amount is $10 \%$ higher for district heating system. Besides, a statistical approach based on nonlinear regression principles can be made to natural gas consumption estimation of individual residential and small commercial customers [34]. The annual costs of electrical energy for running the pumps for district heating system are estimated to $250 \mathrm{kWh}$ per "Conditional Dwelling".

Analyses are done for all the 96 cases (six "Conditional Urban Area" multiplied by eight "Heat Loads" and by two conditions of insulation - bad or good insulation) for the period of $t=26$ years. In table 6 , case with a bad insulation is shown. 
The values in certain cases in table 6 vary more or less from zero. For example, for "Conditional Urban Area" with 16 buildings and with "Heat Loads" $50 \mathrm{MW} / \mathrm{km}^{2}$, the calculated "Net Present Value of Costs" (NPV) is only -5 per "Conditional Dwelling” for a period of 26 years. Therefore, the realization of gas distribution system for that "Conditional Dwelling" is only $5 €$ for 26 years in advantage versus district heating system. This case and the other similar cases are in the "gray zone" (Fig. 9). In the "gray zone", both systems are payable, especially for a period of 26 years.

If a considered value for a certain housing block exceeds the recommended limiting value, more or less, the decision to recommend a particular centralized heating system is more reasonable. Changing the structure and the price ratio (i.e. the state political decision to subsidize the gas price in a system or to issue a price, which would disturb the current price ratio of gas used for district heating system and individual consumers), the conception and manner of a construction of certain system and its elements may cause these parameters to vary. Currently, plasticpolyethylene conduits (cheep) are used for distribution to individual consumers while steel conduits (expensive) had been used before. It led to the considerable cuts in network construction prices, while maintaining the same level of safety and endurance.

For the same "Heat Loads", when there are many smaller family houses located on a "Conditional Urban Area" e.g. N=32, sometimes only with one "Conditional Dwelling", gas distribution system is more reasonable. On the contrary, when there is a smaller number of skyscrapers located on "Conditional Urban Area" e.g. $\mathrm{N}=4$, it is more reasonable to use district heating system (Fig. 9). 
By means of techno - economic analysis for a certain area, it is possible to determine the advantages of one system over the other (district heating over gas). However, considering the situation on the ground, it may turn out that the system is inaccessible in that part of the city (heating plant does not have enough capacity or, in the first stage, the areas closest to the plant could have a priority in system installation). In that case, if the installation costs of the other available system are not too high, it is rational to install that type of heating system (thus saving the consumption costs of electric energy and reducing the amount of pollution if the object is coal).

If, after the analysis, it turns out that one system has more significant economic advantages than the others, but it is unavailable, some form of hybrid system should be considered. For instance, if the installation of district heating system has a lot of economic advantages but it is not available, it is possible to build a local boiler room which would be gas operated. This hybrid solution would demand additional economic and ecologic analyses [35] and estimations of which good features of district heating system would be kept and which would be discarded.

\section{Case study; Application under real conditions}

The characteristics of the "Real Urban Area": number of buildings, disposition and size of buildings, construction type, etc. are the factors of influence. The adoption of a type of centralized heating system can be done according to the conclusion established by the model shown. That is possible only if both systems are available near the settlement. 
Today, social help habitants have a discount for district heating price of up to 50\%. For the gas consumers who use gas distribution systems directly, such discounts are not available. Besides, the payment for the DH is per $\mathrm{m}^{2}$ of heated surface area (proportional to the size of the house), and in the G system payment is per $\mathrm{m}^{3}$ of used gas, in Serbia. In the DH bills are fixed, and any sort of economizing in that way is discouraged.

In that case (Belgrade's settlement Karaburma is taken here into consideration), a type of the chosen system depends on urban characteristic of the settlement only. Because of that, the demonstrative settlements are parceled (divided) into eight "Real Urban Areas" with similar buildings on each particular parcel; (Fig. 10). That way, the determined "Real Urban Area" can be associated with the "Conditional Urban Area". The characteristic points for each of the eight parcels (intersection of number of buildings and heat load of parcel) can be plotted into the characteristic model diagram; (Fig. 10). The types of insulation of buildings in the settlement are mixed; old buildings have bad and new buildings have good insulation. Both old and new buildings have heterogeneous spatial disposal.

Two boundary cases have been treated, because of heterogeneity of insulation quality of buildings [27, 28, 36-38]; (Fig. 11):

-Maximal "Heat Load", all buildings have bad insulation $\left(142 \mathrm{~W} / \mathrm{m}^{2}\right)$, -Minimal "Heat Load", all buildings have good insulation $\left(95 \mathrm{~W} / \mathrm{m}^{2}\right)$, 
The value of fuel consumption depends on heating insulation of the building. Energy consumption in the residential sector can be determined according to various methods shown in an available literature [39]. Therefore, the "Heat Load" depends on heating insulation of the building. The number of buildings on each particular parcel is constant. "Gray zone" is the zone where decision on the type of the system depends, in a great deal, on the type of insulation of the building; (Fig. 9. and 10). In the "Gray zone", the costs for both systems (gas distribution system and district heating system) are very similar. Characteristic points for each of eight particular also depend on the quality of insulation. Small change in slope of borderline for good insulation $\left(\mathrm{K}_{1}=\operatorname{tg} \theta_{1}\right)$ and for bad insulation $\left(\mathrm{K}_{2}=\operatorname{tg} \theta_{2}\right)$ in Fig 11 is generated only because of differentiation in structure of diameters of conduits in pipeline (Fig 12).

"Real Urban Area" No 8 includes types of small buildings or family houses which can contain only one "Conditional Dwelling". Only for that "Real Urban Area" the gas distribution system has very payable advantages versus district heating system. "Real Urban Area" No 3 includes school, kindergarten, local office, shops. These kinds of buildings can contain twenty or more "Conditional Dwellings". Only for that "Real Urban Area" the district heating system has great advantages. All the other zones are in the "gray zone". In the "gray zone", one system is more payable in comparison with the other, no more than $200 €$ per "Conditional Dwellings". This amount cannot be crucial for decision. Some illustrations of investigation of price changes (natural gas price, or domestic boilers price) are shown in figure 13.

If large areas are covered by agricultural terrain, by excluding it, the above-mentioned parameters obtain unrealistic values. 
Note that pipeline is one of the most important parameters of the analyses shown in this paper. Every particular type of the "examination segment" has a different length of a pipeline route. The length of a pipeline route is fixed by choosing of one six "examination segments". This selection has to be done to present density of built up areas. Further, for detailed examination, when certain type of "examination segment" is chosen, the length of the route is determined, at the same time. Now, the next factor to be varied is the heat load. The heat load is directly correlated with the size of buildings, i.e. diameters can vary for the fixed length of a pipeline and its structure. Larger diameters of conduits in pipeline structure are correlated to larger buildings. So, the length of a pipeline route depends on the density of built up areas, and structure of the pipe diameters in a pipeline depends on the size of buildings. Therefore, in city conditions, the diameters of pipes are more sensitive (have a greater impact) in some cases, apropos to the length of a pipeline for decision between heating systems. In the conditions of densely populated urban areas, when one type of the "examination segment" is considered, the decision for implementation of certain heating system has to be done according to the above mentioned criterions. The lengths of pipelines and the structures of diameters of conduits are the main factors for establishing these criterions. Accordingly, in villages, the distances between houses are larger, so the length of the dwelling's pipeline has greater impact then the pipeline diameters. The analysis of the distribution of district heat in sparse areas by C. Reidhav and S. Werner [40, 41] shows that such distribution can be profitable for Swedish district heating companies, if wisely implemented. Sparse district heating is a label for district-heating systems located in the areas of low heat densities. However, a profitable sparse district heating presupposes a favorable combination of certain factors. The boundaries of two such factors have been identified for 
Swedish conditions; linear heat density and annual use of district heat/house. An annual use of district heat higher than $50 \mathrm{GJ} /$ house and a linear heat density greater than $2 \mathrm{GJ} / \mathrm{m}$ are required for profitability. In Sweden, the general competitiveness of sparse district heating is facilitated by the high consumption taxes for fuel oil, natural gas, and electricity. Hence, it should be more difficult to introduce sparse district heating in other countries with low energy taxes. Such areas are unfavorable, since revenues from heat sold are low compared with the investment costs for the local distribution network. This situation results in high distribution costs. Distribution heatlosses are also higher at low heat-densities.

All the previous values of limiting parameters are calculated for the present gas prices for heating plants, for households, for domestic gas boilers' price, the costs of pipes, labor, etc. Regarding the variation of all parameters, readers can consult electronic annex (Microsoft Excel file). Valuable information for the energetic situation in the city of Belgrade is shown in the paper of M. Jovanović, N. Afgan, P. Radovanović and, V. Stevanović [42] (Belgrade's settlement Karaburma is shown in Fig. 10).

A city is considered to be sustainable if it establishes the balance between economic and sociocultural development, on one side, and the progress in environmental protection with active participation of its citizens, on the other side. When using one of the power resources (in this case natural gas) in various systems, the difference in the amount of pollution is very small. Big differences cannot occur in the overall effect on the city level, but in certain areas they can. While heating plant is a concentrated pollutant which disperses harmful combustion products evenly on a wide area depending on the wind, gas lined consumption disperses locally (consumer 
pollutes his nearest neighborhood) [43]. Globally, the biggest gas consumer is the biggest city polluter. For including environmental impacts of different centralized energy supply systems in a model, it is necessary to estimate the annual environmental costs for both systems and include them in related equations. Compared to all of the fossil fuels, natural gas is a minor pollutant. It burns without a solid residue and has the least coefficient of $\mathrm{CO}_{2}$ emission of about $56 \mathrm{~kg} / \mathrm{GJ}$ (which is significant considering the limitations imposed by The Kyoto Protocol) [44-47] . M.S. Torekov, N. Bahnsen and B. Qvale [9] found that DH system realized 78-93 kg/MWh CO $2,0.1$ $\mathrm{kg} / \mathrm{MWh} \mathrm{NO}_{\mathrm{x}}$ and $0.06 \mathrm{~kg} / \mathrm{MWh} \mathrm{SO}_{2}$, G system with individual furnace realize $205 \mathrm{~kg} / \mathrm{MWh}$ $\mathrm{CO}_{2}, 0.07 \mathrm{~kg} / \mathrm{MWh} \mathrm{NO} \mathrm{x}_{\mathrm{x}}$ and $0.001 \mathrm{~kg} / \mathrm{MWh} \mathrm{SO}_{2}$, and electrical heating system $559 \mathrm{~kg} / \mathrm{MWh}$ $\mathrm{CO}_{2}, 88 \mathrm{~kg} / \mathrm{MWh} \mathrm{NO}$ and $44 \mathrm{~kg} / \mathrm{MWh} \mathrm{SO}_{2} .1 \mathrm{MWh}$ of delivered energy is $61 \%$ cheaper in natural gas in comparison with electrical energy [46]. The comparison of environmental impacts of two residential heating systems in Canada is shown in paper of L. Yang, Zmeureanu R., and Rivard H. [48].

The key advantage of installing gas or district heating system is not in their mutual differences, but in the substitution of by the far more expensive (in terms of energy and ecology [49]) and the highest quality form of energy - the electric energy, whose usage for heating is by far less rational; (Fig. 14). The introduction of competition to electricity generation and commercialization has been the main focus of many restructuring experiences around the world. The open accesses to the transmission network and a fair regulated tariff have been the keystones for the development of the electricity market [50]. Parallel to the electricity industry, the natural gas business has great interaction with the electricity market in terms of fuel consumption and energy conversion. Given that the transmission and distribution monopolistic activities are very 
similar to the natural gas transportation through pipelines, economic regulation related to the natural gas network should be coherent with the transmission counterpart [51]. Electricity and natural gas use for residential space heating in USA is shown in paper by D. Bodansky [52]. Today, discussions about district heating systems are not rare in scientific literature [53-63].

\section{Conclusions}

The latest increase in gas prices turned all eyes once again to the space heating problem in Europe. However, economic concern is not the only factor pushing the authorities to rethink about the suitability of the currently existing sources. Cities are the biggest consumers of the country's energy production. The increase in annual consumption of total primary energy is $3 \%$ and its largest part is used for lighting, cooking, heating, cooling, and transport of freights and passengers. The importance of reducing the energy consumption level, by changing the forms of consumption and making improvements in technology and lifestyle, should be noted. Sustainable forms of energy production, distribution and usage represent the goals of a sustainable development. A city is considered to be sustainable if it establishes the balance between economic and socio-cultural development, on one side and the progress in environmental protection with active participation of citizens. On the other side, the economics of the $\mathrm{G}$ and the DH systems very much depend on the specific circumstances $[64,65]$. If installed in an area with only scattered buildings, the length of the pipes which are necessary to supply households will be higher, relative to the number of buildings. Installation costs will be shared by fewer consumers. The DH system is the capital intensive; in particular due to the distribution system of insulated pipes. The G system is another form of energy which is being distributed for domestic heating 
purposes. The dimensions of pipes are small compared to the $\mathrm{DH}$ pipes and no insulation is needed, thus the distribution system is less capital intensive.

District heating is often less efficient with respect to modern heating technologies using natural gas [66-68]. Condensing boilers guarantee higher efficiencies with respect to the "traditional" district heating. In this study, a noncondensing boiler with average efficiency has been chosen from following database: "Seasonal Efficiency of Domestic Boilers in United Kingdom" [32]. The efficiency of domestic boiler and heating plant has equalized by efficiency in this model. The typical efficiencies of plants fueled by natural gas are reported in paper of R. Lazzarin and M. Noro [10].

Figure 5 is essential for the full understanding of the model presented here. All dwellings in the option of gas distribution system are equipped with one type of an average boiler. The linear price increase moves the borderline in the model diagram in advantage of the district heating (Fig. 10. and Fig. 11.). The same conclusion is made for the investments in new capacities in heating plant, but it moves borderline in direction of the gas distribution system. On the contrary, changes in value of discount rate have a great impact (Fig 5.). Changes in the price of domestic boilers or investment in new capacities in heating plant has the equal impact in all of the six "examination segments", changes of discount rate does not.

The conducted analyses confirm literature and empirical information: 
- District heating system is a better option in areas with small built up density, but with skyscrapers.

-Gas system is a better option in areas with high density of individual houses (in this case gas distribution system is significantly in advance).

These two boundary cases are illustrative. But in the case with small density of built up areas with individual houses, the G system is a cheaper option (but not necessary according to some Swedish studies [40, 41]). With high density of built up areas with skyscrapers, the G system is also a cheaper solution. But, safety regulation is a limiting factor for the implementation of gas system directly in such a high building. Anyway, in this case the G system has a slight advantage, and by the increasing price of domestic gas boilers, the DH system became the cheaper option (Fig 8. and Table 5).

In more details, if a certain number of objects $\mathrm{N}$ exist in a "Conditional Urban Area", it can be concluded that (Fig. 8.):

1. $\mathrm{N}=4$, district heating system has an advantage over gas if an average building has over 29 "Conditional Dwellings" (i.e. if the overall heating surface is over $1740 \mathrm{~m}^{2}$ or if the length of pipeline route is below $8 \mathrm{~m}$ )

2. $\mathrm{N}=8$, district heating system has an advantage over gas if an average building has over 22 "Conditional Dwellings" (i.e. if the overall heating surface is over $1320 \mathrm{~m}^{2}$ or if the length pipeline route is below $7,6 \mathrm{~m})$ 
3. $\mathrm{N}=16$, district heating system has an advantage over gas if an average building has over 18 "Conditional Dwellings" (i.e. if the overall heating surface is over $1080 \mathrm{~m}^{2}$ or if the length of pipeline route is below $7 \mathrm{~m}$ )

4. $\mathrm{N}=32$, district heating system has an advantage over gas if an average building has over 15 “Conditional Dwellings" (i.e. if the overall heating surface is over $900 \mathrm{~m}^{2}$ or if the length of pipeline route is below $6,4 \mathrm{~m})$

5. $\mathrm{N}=64$, district heating system has an advantage over gas or if an average building has over 12 “Conditional Dwellings" (i.e. if the overall heating surface is over $720 \mathrm{~m}^{2}$ or if the length of pipeline route is below $5,8 \mathrm{~m}$ )

6. $\mathrm{N}=128$, gas system is practically always advantageous (for a high density of small individual house equal as for high density of skyscrapers). Note that case with 128 skyscrapers on $0.05 \mathrm{~km}^{2}$ rarely appears in practice. The gas distribution system is advantageous because all 128 buildings must be equipped with expensive heat exchangers. That is highly unpractical and expensive for individual houses. For skyscrapers, gas system, theoretically, has a slight advantage, but with an increased price of domestic gas boilers, district heating system can be applied in larger buildings. Besides, the implementation of the gas system in skyscrapers is forbidden according to safety regulations.

\section{Acknowledgment}

This paper is a part of the research done within the project of Ministry of Science NP EE 34406A, Serbia, Belgrade and the authors would like to thank for financial support. 


\section{Appendix}

The algorithm for initial decision for selection of a natural gas heating system in settlements is shown in figure 15:

\section{References}

[1]. Brkić D. Natural gas as heating fuel (Природни гас као гориво за грејање). Beograd: Andrejevic Foundation (Задужбина Андрејевић), 2006. (in Serbian)

[2] Dzenajaviciene EF., Kveselis V., McNaught C., Tamonis M. Economic analysis of the renovation of small-scale district heating systems - 4 Lithuanian case studies. Energy Policy 2007; 35 (4): 2569-2578.

[3]. Gustavsson L., Karlsson A. Heating detached houses in urban areas. Energy 2003; 28 (8): $851-875$.

[4] Riva A., D'Angelosante S., Trebeschi C. Natural gas and the environmental results of life cycle assessment. Energy 2006; 31 (1): 138-148.

[5]. Douthitt RA. An economic analysis of the demand for residential space heating fuel in Canada. Energy 1989; 14 (4): 187-197.

[6] Papadopoulos AM., Oxizidis S., Papandritsas G. Energy, economic and environmental performance of heating systems in Greek buildings. Energy and Buildings 2008; 40 (3): 224230.

[7] Dinca C., Badea A., Rousseaux P., Apostol T. A multi-criteria approach to evaluate the natural gas energy systems. Energy Policy 2007; 35 (11): 5754-5765. 
[8] Gustafsson SI., Karlsson BG. Natural gas in optimized bivalent heating systems. Energy 1990; 15 (11): 993-999.

[9]. Torekov M S., Bahnsen N., Qvale B. The relative competitive positions of the alternative means for domestic heating. Energy 2007; 32 (5): 627-633.

[10]. Lazzarin R., Noro M. Local or district heating by natural gas: which is better from energetic, environmental and economic point of views?. Applied Thermal Engineering 2006; 26 (2-3): 244-250.

[11]. Grohnheit PE., Mortensen BOG. Competition in the market for space heating. district heating as the infrastructure for competition among fuels and technologies. Energy Policy 2003; 31 (9): 817-826.

[12]. Roth U., Häubi F., Albrecht J. Interaction between urban infrastructure and district heating system (Wechselwirkungen zwischen des Siedlungsstruktur und Wärmeversorgungssystemen). Bonn: Bundesminister für Raumordnung, Bauwesen und Städtebau, 1980. (in German)

[13]. AGFW-Arbeitsgemeinschaft Fernwärme. Pluralistische Wärmeversorgung - Zeithorizont 2005 (Vorstudie). See also: http://www.agfw.de/86.0.html (in German)

[14]. AGFW-Arbeitsgemeinschaft Fernwärme. Pluralistische Wärmeversorgung - Zeithorizont 2020. Hauptstudie See also: http://www.agfw.de/86.0.html (in German)

[15]. Ter Brugge R. Spatial structure in relation to energy production and consumption. Journal of Economic and Social Geography-Tijdschrift voor Economische en Sociale Geografie 1984; 75 (3): 214-222.

[16]. Bojić M., Despotović M. Influence of duration of thermal comfort provision on heating behavior buildings. Energy Conversion and Management 2007; 48 (8): 2416-2423. 
[17] Holz F., von Hirschhausen C., Kemfert C. A strategic model of European gas supply (GASMOD). Energy Economics 2008; 30 (3): 766-788.

[18] Afgan NH., Carvalho MG., Pilavachi PA., Martins N. Evaluation of natural gas supply options for south east and central Europe. Part 1: Indicator definitions and single indicator analysis. Energy Conversion and Management 2007; 48 (9): 2517-2524.

[19] Lund Sagen E., Tsygankova M., Russian natural gas exports-Will Russian gas price reforms improve the European security of supply?. Energy Policy 2008; 36 (2): 867-880. [20] Remme U., Blesl M., Fahl U. Future European gas supply in the resource triangle of the Former Soviet Union, the Middle East and Northern Africa. Energy Policy 2008; 36 (5): $1622-$ 1641.

[21] Lise W., Hobbs W. Future evolution of the liberalised European gas market: Simulation results with a dynamic model. Energy 2008; 33 (7): 989-1004.

[22] Herbert JH., Berg J. Soviet natural gas exports and the European energy balance. Energy 1990; 15 (10): 833-840.

[23] Kabirian A., Reza Hemmati M. A strategic planning model for natural gas transmission networks. Energy Policy 2007; 35 (11): 5656-5670.

[24]. Santamouris M., Kapsis K., Korres D., Livada I., Pavlou C., Assimakopoulos M.N. On the relation between the energy and social characteristics of the residential sector. Energy and Buildings 2007; 39 (8): 893-905.

[25]. Stanislaw S. The measurement of demand for natural gas. Energy 1985; 10 (2): 165-180.

[26]. Hartshorn JE. Introduction: Natural gas development begins at home. Energy 1985; 10 (2): $111-118$. 
[27]. Mihalakakou G., Santamouris M., Tsagrassoulis A. On the energy consumption in residential buildings. Energy and Buildings, 2002; 34 (7): 727-736.

[28]. Olesen BW., Parsons KC. Introduction to thermal comfort standards and to the proposed new version of EN ISO 7730. Energy and Buildings 2002; 34 (6): 537-548.

[29]. Huei-Chu L., Tsai-Feng C. Space-heating and water-heating energy demands of the aged in the US. Energy Economics 2002; 24 (3): 267-284.

[30]. Corfield G., Hunt BE., Ott RJ., Binder GP., Vandaveer F. E. Distribution Design for Increased Demand. In: Segeler CG, editor. Gas Engineers Handbook. New York: Industrial Press. p. 9/63-9/83.

[31]. Recknagel H., Sprenger E., Honmann W. Heating (Греjaњe). In: Višnjić M., editor. Heating and Air Condition (Грејање и климатизација). Beograd: Gradjevinska knjiga. p. 293835. (in Serbian)

[32]. SEDBUK-Seasonal Efficiency of Domestic Boilers in United Kingdom. See also: http://www.sedbuk.com

[33]. Papadopoulos AM., Theodosiou T., Karatzas K. Feasibility of energy saving renovation measures in urban buildings: the impact of energy prices and the acceptable pay back time criterion. Energy and Buildings 2002; 34 (5): 455-466.

[34]. Vondraček J., Pelikan E., Konar O., Čermakova J., Eben K., Maly M., Brabec M. A statistical model for the estimation of natural gas consumption. Applied Energy 2008; 85 (5): $362-370$.

[35]. Braniš M., Domasova M., Rezačova P. Particulate air pollution in a small settlement: the effect of local heating. Applied Geochemistry 2007; 22 (6): 1255-1264. 
[36]. Gustafsson SI., Bojić M. Optimal heating-system retrofits in residential buildings. Energy 1997; 22 (9): 867-874.

[37]. Torchio MF., Genon G., Poggio A., Poggio M. Merging of energy and environmental analyses for district heating systems. Energy 2008; doi:10.1016/j.energy.2008.01.012

[38]. Ossebaard ME., van Wijk AJM., van Wees MT. Heat supply in the Netherlands: a systems analysis of costs, exergy efficiency, $\mathrm{CO}_{2}$ and $\mathrm{NO}_{x}$ emissions. Energy 1997; 22 (11): 1087-1098. [39]. Aydinalp-Koksal M., Ismet Ugursal V. Comparison of neural network, conditional demand analysis, and engineering approaches for modeling end-use energy consumption in the residential sector. Applied Energy 2008; 85 (4): 271-296.

[40]. Reidhav C., Werner S. Profitability of sparse district heating. Applied Energy 2008; 85 (9): $867-877$.

[41]. Forsaeus Nilsson S., Reidhav C., Lygnerud K. Werner S. Sparse district-heating in Sweden. Applied Energy 2008; 85 (7): 555-564.

[42]. Jovanović M., Afgan N., Radovanović P.,Stevanović V. Sustainable development of the Belgrade energy system. Energy 2008; doi:10.1016/j.energy.2008.01.013

[43]. Strachan N., Farrell A. Emissions from distributed vs. centralized generation: The importance of system performance. Energy Policy 2006; 34 (17): 2677-2689.

[44]. Haberl H., Adensam H., Geissler S. Optimal climate protection strategies for space heating; the case of Austria. Energy Policy 1998; 26 (15): 1125-1135.

[45]. Cowie AL., Kirschbaumb MUF., Ward M. Options for including all lands in a future greenhouse gas accounting framework. Environmental Science \& Policy 2007; 10 (4): 306-321. [46]. Karlssona A., Gustavsson L. External costs and taxes in heat supply systems. Energy Policy 2003; 31 (14): 1541-1560. 
[47]. Holmgren K., Amiri S. Internalising external costs of electricity and heat production in a municipal energy system. Energy Policy 2007; 35 (10): 5242-5253.

[48] Yang L., Zmeureanu R., Rivard H. Comparison of environmental impacts of two residential heating systems. Building and Environment 2008; 43 (6): 1072-1081.

[49] Ford A. Simulation scenarios for rapid reduction in carbon dioxide emissions in the western electricity system. Energy Policy 2008; 36 (1): 443-455.

[50] Jednak S, Kragulj D, Bulajić M, Pittman R. Electricity reform in Serbia. Utilities Policy 2008; doi:10.1016/j.jup.2008.02.002

[51] Morais MS., Marangon JW. Lima Combined natural gas and electricity network pricing. Electric Power Systems Research 2007; 77 (5-6): 712-719.

[52]. Bodansky D. Electricity and natural gas use for residential space heating: U.S. experience, 1976-1980. Energy 1984; 9 (4): 303-313.

[53]. Lunda H., Hvelplunda F., Kassb I., Dukalskisb E., Blumberga D. District heating and market economy in Latvia. Energy 1999; 24 (7): 549-559.

[54]. de Almeida AT., Lopes AC., Carvalho A., Mariano J., Jahn A., Broege M. Examining the potential of natural gas demand-side measures to benefit customers, the distribution utility, and the environment: two case studies from Europe. Energy 2004; 29 (7): 979-1000.

[55]. Knutsson D., Sahlin J., Werner S., Ekvall T., Ahlgren EO. HEATSPOT—a simulation tool for national district heating analyses. Energy 2006; 31 (2-3): 278-293.

[56]. Dotzauer E. Experiences in mid-term planning of district heating systems. Energy 2003; 28 (15): 1545-1555.

[57]. Sundberg G., Karlsson BG. Interaction effects in optimising a municipal energy system. Energy 2000; 25 (9): 877-891. 
[58]. Gustavsson L. District heating systems and energy conservation-part I. Energy 1994; 19 (1): 81-91.

[59]. Gustavsson L. District heating systems and energy conservation-part II. Energy 1994; 19 (1): 93-102.

[60]. Benonysson A., Bohm B., Ravn HF. Operational optimization in a district heating system. Energy Conversion and Management 1995; 36 (5): 297-314.

[61]. Gebremedhin A., Moshfegh B. Modelling and optimization of district heating and industrial energy system - an approach to a locally deregulated heat market. International Journal of Energy Research 2004; 28 (5): 411-422.

[62]. Barelli L., Bidini G., Pinchi EM. Implementation of a cogenerative district heating: Optimization of a simulation model for the thermal power demand. Energy and Buildings 2006; 38 (12): 1434-1442.

[63]. Larsen HV., Paisson H., Bohm B., Ravn H.F. Aggregated dynamic simulation model of district heating networks, Energy Conversion and Management 2001; 43 (8): 995-1019. [64]. Bouvy C., L.Klaus. Multicriterial optimisation of communal energy supply concepts. Energy Conversion and Management 2007; 48 (11): 2827-2835.

[65]. Söderman J., Pettersson F. Structural and operational optimisation of distributed energy systems. Applied Thermal Engineering 2006; 26 (13): 1400-1408.

[66]. Rosa L., Tosato R. Experimental evaluation of seasonal efficiency of condensing boilers. Energy and Buildings 1990; 14 (3): 237-241.

[67]. Lazzarin RM., Schibuola L. Performance analysis of heating plants equipped with condensing boilers. Journal of Heat Recovery Systems 1986; 6 (4): 269-276. 
[68]. Agrell J., Bogetoft P. Economic and environmental efficiency of district heating plants.

Energy Policy 2005; 33 (10): 1351-1362. 
Figure 1. "Real Urban Area" associates with several types of "Basic segments" according to the spatial disposition of buildings

Figure 2. Examples of different "Heat Loads" for the same "Basic segments" (two cases)

Figure 3. Standard length of networks for all the six types of "Examination segments" $\left(0,5 \mathrm{~km}^{2}\right)$

Figure 4. "Conditional Urban Areas" - two examples

Figure 5. Effects of price and discount rate changes, example of factors with linear influence and nonlinear influence (costs for one average dwelling)

Figure 6. Brand new domestic boilers in the UK market sorted according to efficiency class (SEDBUK)

Figure 7. Diagram for selection of appropriate domestic boiler for the examination condition Figure 8. Comparisons of investments in district heating and gas distribution system Figure 9. Identification of some characteristic cases in model diagram Figure 10. Diagram for adoption of optimal system for observed settlement Figure 11. Displacement of borders and characteristic points calculated for different quality of building insulation

Figure 12. Length of conduits sort by diameters for DH pipeline for good and poor insulated buildings in the Karaburma settlement - case study

Figure 13. Price changing sensitivity, sample for few factors of influence

Figure 14. Consumption of electrical energy in the observed settlement

Figure 15. Algorithm for centralized energy supply system selection fueled by natural gas 
Table 1: Identification of all of the 96 considered case (number of average dwelling per building)

Table 2: Structure of pipe diameters for one of the cases (example)

Table 3: Investments in both systems per dwelling; G and DH [€]

Table 4: Costs for gas distribution system and district heating system (example)

Table 5: Initial costs ${ }^{\mathrm{a}}$ - $€$ per "Conditional Dwelling"

Table 6: "Net Present Value of Costs" (NPV) - $€$ per "Conditional Dwelling" 
1 Deleted from old version

2 Added in new version

Systematic Approach to Natural Gas Usage for Domestic Heating in Urban Areas

${ }^{\mathrm{a}}$ Ministry of Science and Technological Development, Đušina 7, 11000 Beograd, Serbia,

${ }^{b}$ Faculty of Mining and Geology, University of Belgrade, Đušina 7, 11000 Beograd, Serbia

Received: 22 February 2008; received in revised form:

Abstract: Establishing of proper criteria for economical and energy efficient operation of district heating i.e. natural gas supply system for fulfilling low temperature heat demands in domestic

11 use, is necessary condition for optimal and mutual persuasive operation of these systems. The main goal of this paper is to establish general model to achieve coordinated development of

13 centralized energy supply systems, based on defined and accepted criteria. An analysis of

14 structure for centralized systems for energy supply has been done with accent on their pipelines.

15 Investment and exploitation costs are evaluated considering specified area of town as a function

16 of systems' technical characteristics. Model for evaluation of economy for different selutions is

17 established, backed up by computer spreadsheet. This model for different heat loads and number

18 of objects on conditional urban area (as parameters of real energy and urban situation) with

19 defined prices and costs, suggests one of systems as optimal for the area. General model for

20 harmonization and optimal development of district heating and natural gas supply systems

21 represents analytical appreach in considering development of centralized energy supply systems

22 in towns. The goal function of this model besides component that considers costs, involves

\footnotetext{
* Corresponding author. Tel./fax: +381113243457, e-mail: dejanrgf@tesla.rcub.bg.ac.yu, (D. Brkić)
} 
23 energetic, techno economic, søcial, ecological and safety constraints.Natural gas can be used for

24 satisfying population needs for heating, either directly by bringing the gas to the dwellings

25 through the gas distribution system and combusting it in the domestic boiler (gas distribution

26 system-G), or indirectly by combusting the natural gas in the heating plant and distributing the

27 heat energy to the dwellings through the district heating system (district heating system-DH).

28 The selection of a certain type of heating system is made according to the disposition of

29 buildings in the area, their number, size, insulation quality, etc. Based on these characteristics,

30 calculations of investments and exploitation costs have been made for both heating systems and a

31 comparison has been made for all of the 96 presented cases. Almost each type of real settlement

32 can be represented by one of the types of the conditional urban area which are introduced in the

33 paper. The main goal of this paper is to establish a general model to achieve coordinated

34 development of centralized energy supply systems fueled by natural gas, based on defined and

35 accepted criteria. A structure analysis of centralized systems for energy supply has been done

36 with accent on their pipelines.

37 Keywords: Natural Gas, Settlement, Gas Distribution, District Heating, Urbanism

38

39 Nomenclature

$40 \mathrm{y}$ - number of "Conditional Dwellings" per building [-]

$41 \mathrm{~N}$ - number of buildings per "Conditional Urban Area" [-]

$42 \mathrm{x}$ - Peak load densities or "Heat Load" $\left[\mathrm{MW} / \mathrm{km}^{2}\right]$

$43 \mathrm{DH}-$ costs of district heating system [€]

$44 \mathrm{G}$ - costs of local gas heating system (domestic boiler in each dwelling) [€] 
45 DHN - costs of district heating network, i.e. costs of building/civil works, costs of materials

46 (insulated pipes, pumps, accessories, etc.) and telemetry systems, etc [€]

$47 \mathrm{HE}$ - costs of heat exchanger stations located in buildings [€]

$48 \mathrm{HP}$-investment in new heating plant [€]

49 DHOC - annual costs of maintenance calculated as percentage of investment, in-network, heat

50 exchanger station, annual natural gas consumption and annual electricity consumption for pumps

51 drive $[€]$

52 MPRS - costs includes costs of main pressure reduction stations [€]

53 PRS - costs of pressure reduction stations [€]

54 DN - costs of natural gas distribution network [€]

55 DS - costs of domestic measurement sets [€]

56 B - costs of domestic boilers [€]

57 GOC - annual costs of maintenance calculated as percentage of investment; in gas distribution

58 network, in pressure reduction station, in measurement set, domestic boiler and annual natural

59 gas consumption [€]

60 dr - "Discount Rate" [\%]

61 NPV - "Net Present Value of Costs" [€]

$62 \mathrm{t}$ - Time [years]

63

\section{1. Introduction}

65

66 If a gas based system in a settlement is planned, the decision can be done among two conflicted

67 options: 
1. Indirect system; natural gas is being combusted in a heating plant and household heat supply is

69 provided by a District Heating System (DH),

70 2. Direct system; dwellings are being heated by natural gas brought through a gas distribution

71 system and then combusted in domestic gas boilers in each dwelling, individually (G).

73 The initial decision on choosing one of two systems is based on the number and size of buildings

74 in a settlement, the size of the settlement itself and the heating insulation of buildings [1]. In

75 boundary cases, if it is possible to achieve both options it is also possible to introduce a sort of

76 hybrid system which is not considered in this paper. The economic analysis of the renovation of

77 small-scale district heating systems in Lithuania is available [2]. District heating systems using

78 cogeneration, as well as the local fuel-based and electric heating systems for detached houses,

79 are analyzed by L. Gustavsson and A. Karlsson [3]. Their analysis includes the whole energy

80 system, from the natural resource to the end user, with respect to the primary energy use,

81 emission and cost. They found that natural gas based systems are less expensive than the

82 corresponding wood-fuel based systems, except the matter of ecology. In the future, green

83 energy sources or fossil energy sources such as oil and natural gas will be more used in industrial

84 processes in order to decrease the ratio of greenhouse gases released from the coal-based local

85 and industrial processes [4].

86

87 The goal of the model introduced in this paper is to determine the connections among urban and

88 energy characteristics of settlements in cities and to be benefit from more rational usage of

89 natural gas as non-renewable fossil fuel. Energy demands for heating are shown for the Canadian

90 case [5], from the economical point of view. The introduction of natural gas in the Greek energy 
91 market have broadened the options in the field of space heating [6]. The paper by C. Dinca, A.

92 Badea, P. Rousseaux, and T. Apostol [7] aims to select the optimal energetic scenario applied to

93 a consumer with 100000 inhabitants from the residential-tertiary sector in Romania (series of

94 seven scenarios based on natural gas have been analyzed). The natural gas in optimized bivalent

95 heating systems is shown in the paper of SI. Gustafsson and BG. Karlsson [8]. The study of MS.

96 Torekov, N. Bahnsen, and B. Qvale [9] is in correlation with this paper and strives to clarify to

97 what extent the improved insulation of new buildings affects the economically rational choice of

98 heating supply. District heating should be advocated only for areas with a strong heat demand,

99 primarily for areas with apartment buildings [9]. R. Lazzarin and M. Noro [10] have done

100 analyses of local or district natural gas heating from energetic, environmental and economic

101 points of view. The legal and policy aspects of the utilization of different energy supply systems

102 in households sector can also be found in the available literature [11]. Some German studies with

103 subject relevant for development of district heating systems in urban environment are also useful

104 and highly evaluated, but this literature is available only in German language [12-14], with

105 related papers presented in scientific journals [15]. The main achievement of these German

106 researches is the establishing of interaction between heating systems, settlement structure and

107 urban planning at the local level. The study analyses options for heat supply in up to 10 types of

108 built up areas [12] - from densely populated urban areas to villages. A new German study 20

109 years later_refers to this work [13], with projection to 2020 [14].

110

111 The present practice in many cities, for heating systems selection and utilization of existing

112 eapacities in systems for centralized energy supply, includes separate consideration of every

113 single case or very often selection without clear criterions. Proposed Considering the selection of 
114 heating systems and the utilization of the existing capacities in the systems for centralized energy

115 supply, the present practice in many cities is that every single case must be considered separately

116 and, very often, the selection is done without clear criterions. The proposed model could be

117 useful to urban planners, municipal officials, public utility companies, etc., as a first step in

118 system selection (see Electronic Annex in the online version of this article).

120 In urban areas, the most suitable option for satisfying the heating demands is by using a

121 eentralized system. The most suitable option for satisfying heating demands in urban areas is by

122 using a centralized system. The centralised energy supply from heating plants has many

123 advantages: saves primary energy (due to the modern construction of boilers in heating plants as

124 well as the utilisation of modern energetic and ecological ways of combustion, the primar energy

125 sources are better used during the transformation of primar energy into heat energy), the

126 distribution of hot water consumption (the centralised hot water distribution is the way to avoid

127 the transformation of primary energy, mostly from heat to electric energy, and then again, from

128 electric to heat energy), the possible utilisation of low quality fuel, the possible utilisation of

129 some alternative kind of fuel, the centralised storage for fuel, less expenses for the standard

130 discontinuous transportation of fuel (saving motor vehicles' fuel), due to the centralised and

131 highly controled heating, there is less danger from fire. There is also a well organised,

132 professional fire protection. There are also some negative aspects of the heating systems from

133 heating plants: high investments during the initial phase of building of heating sources and

134 pipeline structure, possible quitting with heat energy supply caused by the damage in heating

135 plant or distribution network, in some cases, heating expenses are measured by squaring, not by

136 consumption. The advantages of the systems for the individual consumption of gas in households 
137 by using the gas distribution network are the following: the gas consumption is being measured

138 separately for each appartment and the paying of costs depends on consumption (which is not

139 always the case when DH systems are being used), gas saving for hot water supply and cooking

140 (these demands are being satisfied directly by the transformation of chemical energy of natural

141 gas into heat energy, that is how the gas used for transformations of primary energy into electric

142 energy is saved), there is no need for storehouses in households, less costs for the standard fuel

143 distribution (the fuel is saved for motor vehicles), relatively small investments in the construction

144 of distibution network in relation to thermal network, less possibility for quitting of supply. The

145 disadvantages of the centralised natural gas supply systems are: an increased fire danger,

146 explosions, or possibility of suffocation caused by damaged instalations for different reasons, the

147 combustion is taking place in the appartment, the possible lack of gas or an interrupted

148 distribution pipeline, etc.

149

150 If a gas based system in a settlement is planned, decision can be done among two conflicted

151 eptions:

152 1. Indirect system; natural gas is being combusted in a heating plant and households heat supply

153 is provided by a District Heating System (DH),

$154 \quad 2$. Direct system; dwellings are being heated by natural gas brought through a gas distribution

155 system and then combusted in domestic gas boilers in each dwelling individually $(G)$.

157 Life comfort [16] is the same in both options; every individual dwelling has the same network of

158 conduits and radiators. Main The main intention of this model approach is to find a way how to

159 deliver distribute heat energy in each dwelling using the existing capacities (not to make strategy 
160 for a city planning, but to exploit most possible rationally existing capacities). Primarily The

161 primary goal of this paper is not to investigate whole district heating or gas distributive

162 infrastructure, but to compare investments in both systems with their specific details (pipelines

163 with included costs of domestic boilers for the $\mathrm{G}$ system or costs of heat exchanger for the $\mathrm{DH}$

164 system, investment in new capacities in heating plant, etc.). Main The main subject of the

165 examination is in the "Conditional Urban Areas". Comparisons The comparison of investments

166 in pipelines for both systems are is the most important parameter in of this analysis. The most

167 detailed analyses of the heating in one town must take into consideration other types of fuel for

168 heating plant, alternatives for heating in the cases of the lack of natural gas, etc. In the most

169 detailed heating analyses in one town, the other types of fuel for heating plants, the alternatives

170 for heating in the cases of the lack of natural gas, etc. must also be taken into consideration.

171

172 Model The model which is presented here is developed as a tool for solving some of the

173 misunderstandings in the strategy of urbanism correlated to natural gas heating in Serbian towns.

174 This project has been supported by the Ministry of Science of Serbia. All the values in this paper

175 refer to conditions in Serbia, but readers also have an access to the relevant file (see Electronic

176 Annex 1 in the online version of this article), and can change all the values (green tones in excel

177 file can be changed). According to that possibility, this model can be applied for conditions

178 anywhere in the world.

179

180 Stratey The strategy for heating of dwellings in urban areas of Serbia, since-frem the

181 communist period, had been made to favor district heating systems in towns. Consumer The

182 consumer area of Belgrade is being supplied with thermal energy by district heating system 
183 consisting of 15 heating plants which use gas $\left(83 \%=265 \cdot 10^{6} \mathrm{~m}^{3} /\right.$ year [1]) and crude oil as basic

184 fuel. Statistical data show that $38 \%$ of the buildings are connected to the district heating system,

185 is, which represents 240000 flats and 7500 business offices are heated in that way. In the

186 scope of the Belgrade environmental protection program, construction of thermal network and

187 gas distribution network in downtown area takes an impertant place-The construction projects of

188 thermal network and gas distribution network in downtown areas take an important place in the

189 scope of the Belgrade environmental protection program, so approximately 800 individual solid

190 fuel boilers have been shut down so far. Most of these plants nowadays are fueled by natural gas,

191 but in the past they were fueled by liquid fuels or some smaller and obsolete by coat. Allof these

192 mini plants have to be closed, and heating for relevant dwellings, according to new strategy, will

193 be provided by some sort of natural gas heating. Nowadays, most of these plants are being fueled

194 by natural gas, but in the past they were fueled by liquid fuels or by coal (in some smaller and

195 obsolete plants). All of these mini plants have to be closed. According to the new strategy, the

196 heat supply for relevant dwellings will be provided by some sort of natural gas heating.

197 Government strateg is the government has the strategy to connect almost all dwelling

198 dwellings to some form of natural gas heating system. Geat The goal is not to use solid fuel

199 heating, and especially not electrical electric energy. They should be used only in some rare

200 cases. There are 42 city heating plants in Serbia with heat energy capacity of 5.5GW. However,

201 Serbia does not have sufficient energy production or funds for their procurement. The main

202 characteristics of Serbia's heating plants are low operating readiness due to insufficient

203 maintenance and outdated equipment, financial exhaustion and an inability to perform urgent

204 intervention on sources and grids. Heating is poor and there is a need for additional capacity,

205 mostly fueled by natural gas. Serbia doesn't have enough gas production reserves from its own 
206 fields or to satisfy the demands (the annual peak of the production was $600 \cdot 10^{6} \mathrm{~m}^{3}$ and now it's 207 several times lower $\left.\left(285 \cdot 10^{6} \mathrm{~m}^{3}\right)[1]\right)$. Note, that The imported gas from import is available for

208 Serbia since 1979. from one direction (from north, through Hungary). Alse, Serbia Serbia also

209 has the EU perspective [2,3 17, 18], and government the Government's strategy is to be-make

210 Serbia a transient country for the export of Russian gas to the western countries of EU countries

211 (from the second direction, through Bulgaria). Due to the European obligation to reduce

212 greenhouse gas emissions in the framework of the Kyoto Protocol, the trend towards the use of

213 natural gas is expected to continue in the future. The increased consumption is faced with and

214 comparably low indigenous gas resources within Europe,so that the dependen

215 gas imports from abroad will rise in the future are expected to increase the Europe's dependency

216 on gas imports from abroad in the future. In addition to the existing supply sources from Russia

217 [4 19] and Algeria, gas resources from the Middle East and the Caspian and the Central Asian

218 regions may be could be the possible supply options to cover Europe's gas demand in the future.

219 Today, natural gas heating in Serbia has a great perspective [5-8-20-23].

220

221 For every type of settlement a hypothetical equivalent within a model was made. A hypothetical

222 equivalent within a model has been made for every type of settlement. For each (of limited

223 number) of hypothetical settlements investments were caleulated and comparison was made. The

224 investment costs were calculated and the comparison has been made for each (of a limited

225 number) of hypothetical settlements. The system with the least smallest investments (including

226 exploitation and the maintenance in the next 25 years), depending on the city planning

227 parameters, is more cost effective and it is adopted. This creates a direct link between the city

228 planning parameters and the choice of one of the systems. 
230 The initial decision on choosing one of two systems is based on the number and the size of

231 buildings in a settlement, it's size and heating insulation of the buildings [1]. In boundary cases,

232 if it is possible to achieve both options it is also possible to introduce a sort of hybrid system, not

233 considered in this paper. Economic analysis of the renovation of small-scale district heating

234 systems in Lithuania is available [9]. District heating systems using cogeneration, as well as local

235 fuel based and electric heating systems for detached houses, are analyzed by L. Gustavsson and

236 A. Karlsson [10]. Their analysis includes the whole energy system, from the natural resource to

237 the end user, with respect to primary energy use, emission and cost. They found that systems

238 based on natural gas are less expensive than the corresponding wood fuel based systems, except

239 the matter of ecology. In the futmre, green energy sources or fossil energy sources such as oil and

240 natural gas will be more greatly used in industrial processes in order to decrease the ratio of

241 greenhouse gases released from coal based local and industrial processes [11].

243 Goal of model introduced in this paper is to determine the connections among unban andenergy

244 eharacteristics of settlements in cities, and to be of benefit for more rational usage of natural gas

245 as non-renewable fossil fuel. Energy demands for heating are shown for Canadian case [12] from

246 the economical point of view. The introduction of natural gas in the Greek energy market

247 broadened the options in the field of space heating [13]. Paper by C. Dinca, A. Badea, P.

248 Rousseaux, and T. Apostol[14] aims to select the optimal energetic scenario applied to at

249 eonstmer with 100000 inhabitants from the residential tertiary sector in Romania (series of

250 seven scenarios based on natural gas has been analyzed). Natural gas in optimized bivalent

251 heating systems is shown in paper of SI. Gustafsson and BG. Karlsson [15]. Study of MS. 
Torekov, N. Bahnsen, and B. Qvale [16] is in correlation with this paper and strives to clarify to

253 what extent the improved insulation of new buildings affects the economically rational choice of

254 heating supply. District heating should be advocated only for areas with a high concentration of

255 heat demand, primarily areas with apartment buildings [16]. R. Lazzarin and M. Nore-[17] have

256 done analyses of local or district heating by natural gas from energetic, environmental and

257 econømic point of views. Legal and policy aspects of different energy supply systems utilization

258 in households sector can also be found in available literature [18].

259

\section{Concept-The concept of conditional urban areas}

262 The model upon which the decision on choosing one of two systems is made (DH vs. G), is

263 based on the introduction of hypothetical urban settlements. By introducing this practice,

264 performing it is not necessary to perform the entire calculation for both systems is avoided and

265 after which the choice on of a heating system in a the settlement is made. Application The

266 application of this model makes easier the job for energy planners and city planners. People with

267 higher living standard; often do not take economic parameters into consideration ecenemic

268 parameters when deciding between gas or district heating system. The decision is based on a

269 personal affinity (and often, prejudice) [19 24].

270

271 Parts The parts of a city with residential and other buildings within real settlements are called

272 „Real Urban Area“. They can be divided into several zones based on the same or similar urban

273 characteristics. Zones The zones divided like this, for the model purpese purposes, need to have

274 an area of $0.05 \mathrm{~km}^{2}$ - "Basic segment" (Fig. 1.). Further on, real urban parameters of a real 
275 settlement can be copied onto the selected "Basic segment" (Fig. 2.). "Basic segment" with

276 rectangular size with dimension approximately $160 \mathrm{~m} \cdot 315 \mathrm{~m}=0.05 \mathrm{~km}^{2}$ is adopted for this

277 purpose [1]. Based on the spatial disposition within the model, there are 6 different versions of

278 "Basic segments": 4, 8, 16, 32, 64 and 128 buildings per "Basic segments": (Fig. 1).

279 "Examination segment" (Fig. 3.) eөnsist consists of ten "Basic segment-segments" with an added

280 pipeline (gas and district heating). Only one type of "Basic segment" can exist inte in one

281 "Examination segment". Real zone formed like this can be joined with one of the 96

282 „Conditional urban Urban Areas“(Fig. 4. and Table 1.). Each particular "Conditional urban

283 Urban Area" consists of ten "Basic segments" (all the ten belong to one of the

284 six types shown in fig 1.), buildings (all the buildings is are the same in one regarded segment)

285 and, pipeline (district heating pipeline or gas distribution pipeline) - Table 2. Every real situation

286 in town has to be joined to one of the best fitted „Conditional urban AreaUrban Areas”. Toeach

287 one of these basic types of "Examination segment" a A different heat load (peak load density)

288 can be given to each one of these basic types of "Examination segment", which is based on the

289 size of buildings.

$29020 \mathrm{MW} / \mathrm{km}^{2}, 30 \mathrm{MW} / \mathrm{km}^{2}, 40 \mathrm{MW} / \mathrm{km}^{2}, 50 \mathrm{MW} / \mathrm{km}^{2}, 75 \mathrm{MW} / \mathrm{km}^{2}, 100 \mathrm{MW} / \mathrm{km}^{2}$ or 125

$291 \mathrm{MW} / \mathrm{km}^{2}$ (Fig. 2). These values are chosen for the analysis in order to include a wide range of

292 possible real urban situations.

293

294 Every settlement, found in reality, corresponds to one of the 96 hypothetical settlements included

295 in the model (Table 1). They are called "Conditional Urban Area" (six "Basic segment" multiply

296 by eight "Heat Loads" multiply by two type types of insulation) [1]. According to a variety of

297 possible settlements (in density, size and layout of buildings) a model which has the ability to 
298 represent their different characteristics is formed. With six types of "Basic segment segments"

299 (Fig. 1) all the possible densities of built up areas in settlements can be described. In each

particular uban area, buildings with different sizes be found; Different sizes of buildings can

301 be found in each particular urban area from small houses to skyscrapers, i.e. with eight types of

302 buildings graduated by size all situations can be described (eight different "Heat Loads"). Each

303 of the 96 proposed hypothetical settlements can be joined with different city planning parameters

304 such as: the number of buildings reduced to the unit value of surface, the size of buildings, the

305 number of dwellings within the buildings, the number of floors within buildings, the spatial

306 disposition of buildings within the settlement, the quality of heat insulation of dwellings etc 20

307 22 25-27]. If within the settlement there are several types of buildings or density of built up

308 areas, If there are several types of buildings or density of built up areas within the settlement,

309 settlements need to be divided into several „Conditional Urban Areas“. Every single type of

310 building can be very good or poor insulated (older buildings versus newer buildings) [ 2328$]$.

311 Numbers of "Conditional Dwellings" per building are shown in Table 1.

313 For every „Conditional Urban Area“, it is possible to calculate the entire investment eest of costs

314 for the implementation of gas distribution and district heating system systems (Table 3).

315 Investments are calculated The investment's calculations are based on the detailed estimate of

316 distribution network for both systems with all of the equipment included, as well as the labor

317 expenses and the spare parts for replacement in the first 25 years. Thus, the investments for all

318 the 96 cases can be calculated (one of these cases is shown in Table $z 4$ ). After that, the values of

319 gas distribution costs are being subtracted from the investment eest costs of the district heating 
320 system (Table 3 5) and then they are being discounted (Table 4 6). For cases with positive values

321 the option of gas distribution is more favorable than the district heating system (negative values).

322

323 Dispesition The disposition of networks for all cases is shown in figure 3 ("Examination

324 segment"). Đisposition means length of pipeline The disposition designates the pipeline length,

325 but not structure of diameters of conduits in eompesition of pipeline the pipeline composition.

326 Determination The determination of structure of diameters of conduits in composition of pipeline

327 the pipeline composition can be done only after the "Conditional Urban Area" is formed. A

328 structure of pipes diameters depends ef on building size. The "Examination segment" has ten

329 times bigger area surface than the "Basic segment" because of the network sensitivity

330 exploration. Note that in fig. 3 ("Examination segment") exist pipeline network pipeline network

331 exists, while in Fig. 1 or in Fig. 2 den'tit doesn't (“Basic segment”).

332

333 So, the similarity between "Conditional Urban Area" and "Real Urban Area" can be determined

334 by two different independent quantities [1].

335

336 1) Number of buildings in an urban area (the number of buildings on $0.05 \mathrm{~km}^{2}-5$ hectares);

337 (Fig. 1),

338 2) Heat A heat demand [24 29] of an urban area ("Heat Load" or peak load densities of all

339 buildings heated in a zone divided by the size of an area), MW/km²; (Fig. 2),

341 Term The term "building" is used here alse-for family houses also, as well as for the and similar

342 smaller constructions with the same meaning as e.g. skyscrapers. In all analyses, "Conditional 
343 Residential Unit" [1], i.e. "Conditional Dwelling" [1] with net heating surface area of $60 \mathrm{~m}^{2}$ is

344 observed. "Conditional Dwelling" has, for the purpose of the model approach, a heat demand of

$345142 \mathrm{~W} / \mathrm{m}^{2}$ (heat peak load for lower insulated dwelling) in case of tor a low (bad) insulation,

346 and in case of better (good) insulation it has a heat demand of $95 \mathrm{~W} / \mathrm{m}^{2}$ (heat peak load for better

347 insulated dwelling). Each combination of a defined number of buildings and peak load density

348 corresponds to a different number of average dwellings in the building (Table 1). Average An

349 average dwelling $\left(60 \mathrm{~m}^{2}\right)$ is practically "Conditional Dwelling".

350

351 Cencept The concept of the "Examination segment" is regarded only for the purpose of

352 exploration on realistic values of diameters in structure of pipeline the pipeline structure, but

353 values of $\mathrm{N}$-number of buildings presented in this paper are nominally per "Basic segment".

354 "Heat load" is expressed in MW/ $\mathrm{km}^{2}$ (not in MW/0.05 km ${ }^{2}$ or in MW/0.5 km²) and accordingly

355 it is nominally equal for for both "Examination segment" as for and "Basic segment".

357 3. Model The model of rational natural gas usage based on city planning parameters

359 Based on the introduced "Conditional Urban Area“, a techno-economical model of rational

360 natural gas usage was has been made. For each of the 96 cases investment investment, a

361 calculation was has been made in both of the proposed heating systems (Gas Distribution [25 30]

362 vs. District Heating [z6 31]) including the exploitation in the next 25 years (investments). For

363 each case, a comparison of costs has been made so that the heating system with the least

364 smallest cost has an advantage in the implementation. Number. The number of dwelling 
365 dwellings per buildings, i.e. the identification of all here shown 96 cases the 96 cases shown here

366 is shown in Table 1.

368 In the model, both types of heating Both of the heating types in the model have special costs

369 since both of them have special elements; e.g. the district heating system is built with made of

370 steel conduits, pumps and heat exchangers, on the contrary, the gas distribution system is built

371 with made of cheaper polyethylene conduits and has stations for measuring and regulation with

372 internal gas equipment (each dwelling has domestic gas boiler etc). Investment The investment

373 in new capacities in for heating plant are is included in the model in a directly i.e. by

374 increasing the price of natural gas for district heating, or can be added by including the new cost

375 indirectly. Investments The investments in a new heating plant fuel fueled by natural gas are:

$37680000 € / \mathrm{MW}$ (for heat plant capacity <50MW), 65000 €/MW (for heat plant capacity 50-100

377 MW) and 52000 €/MW (for heat plant capacity 100-200 MW) [1]. That means additional eest

378 costs of 450-680 € per "Conditional dwelling”. That It implies that this kind of additional eost

379 costs is not essential for this kind of analyses (Fig 5.). Changes The changes in the slope of

380 borderline in the model diagram ${ }^{1}$ are caused by changes in discount rate the discount rate

381 changes (Fig 5.) or by differentiation in the structure of diameters of conduits in the pipeline ${ }^{2}$.

382 Same conclusion can be made with variation in price price variations of domestic boiler (see

383 Table 35 and Fig 5). L. Gustavsson and A. Karlsson [10-3] estimated DH investment costs and

384 DH maintenance costs the DH investment and maintenance costs. Increasing of price of domestic

385 gas boiler simultaneously with introducing of investments in heating plant in the same amount

386 are to be annulled An increasing price of domestic gas boilers simultaneously with the

${ }^{1}$ See also Fig 11.

2 See also Fig 12 in case study 
388 detailed analyses consult electronic annex 1).

390 Relative A relative amount of investments (per "Conditional Dwelling" included annual costs) in

391 district heating - DH and in local gas heating system - G (each "Conditional Dwelling" is

392 equipped with domestic boiler fueled by natural gas) can be calculated after following eqs. (1 393 and 2).

$395 \mathrm{DH}=\frac{\mathrm{DHN}+\mathrm{HE}+\mathrm{HP}+\mathrm{DHOC}}{\mathrm{y}}$

396 Where there are: DH - costs of District Heating System [€], DHN - costs of District Heating

397 Network, i.e. costs of building/civil works, costs of materials (insulated pipes, pumps,

398 accessories, etc.) and telemetry systems, etc [€], HE - costs of Heat Exchanger stations located in

399 buildings [€], HP -investment in new heating plant [€], DHOC - annual costs of maintenance

400 calculated as a percentage of investment, in network, heat exchanger station, annual natural gas

401 consumption and annual electricity consumption for pumps drive [€] and y - number of

402 "Conditional Dwellings" per building [-].

403

404 Annual costs of maintenance The annual maintenance costs calculated as a percentage of

405 investment (eq. 1), in network (2,5\%); lifetime of 25 years, heat exchanger station (1,5\%);

406 lifetime 12 years, annual natural gas consumption - 10\% more than in the system with domestic

407 boiler in each "Conditional Dwelling") $\left(942,7 \mathrm{~m}^{3}\right.$ per "Conditional Dwelling" - $\left.0.12 € / \mathrm{m}^{3}\right)$ and

408 the annual electricity consumption for pumps drive $\left(250 \mathrm{kWh}-0,035 € / \mathrm{kWh}^{2}\right)$. Assumption of

409 The estimated heat losses in the district-heating network is are $10 \%$. 
$411 \mathrm{G}=\frac{\mathrm{MPRS}+\mathrm{PRS}+\mathrm{DN}+\mathrm{DS}+\mathrm{B}+\mathrm{GOC}}{\mathrm{y}}$

412 Where there are: G - costs of Local Gas Heating System (domestic boiler in each dwelling) [€],

413 MPRS - costs include costs of Main Pressure Reduction Stations [€], PRS - costs Pressure

414 Reduction Stations [€], DN - costs of natural gas Distribution Network [€], DS - costs of

415 Domestic measurement sets [€], B - costs of domestic boilers [€],GOC - annual costs of

416 maintenance calculated as a percentage of investment; in gas distribution network, in pressure

417 reduction station, in measurement set, domestic boiler and annual natural gas consumption [€]

418 and and y - number of "Conditional Dwellings" per building [-].

419

420 Annual costs of maintenance The annual maintenance costs calculated as a percentage of

421 investment (eq. 2); in gas distribution network (2,25\%); lifetime of 25 years, in pressure

422 reduction station $(2,25 \%)$; lifetime of 25 years, in measurement set (2,25\%), lifetime of 12 years,

423 domestic boiler (2,25\%), lifetime of 12 years and the annual natural gas consumption $\left(857 \mathrm{~m}^{3}\right.$

424 per "Conditional Dwelling" - $\left.0.12 € / \mathrm{m}^{3}\right)$.

425

426 The efficiency of the NG boiler is the best during the winter when space heating is needed. In

427 During summer, when only hot water is required the boiler is often operated at a very low load

428 and the average efficiency is reduced. For examination in this paper, on-line database SEDBUK ${ }^{3}$

429 (Seasonal Efficiency of Domestic Boilers in United Kingdom) [32] is very useful (Fig. 6 and 7).

430 District heating is often less efficient with respect to modern heating technologies using natural

${ }^{3}$ available from www.sedbuk.com 
431 gas. Condensing boilers guarantee higher efficiencies with respect to "traditional" district

432 heating.

433

434 Investment An investment in a new heating plant or the increasing ef price of domestic gas beiler 435 boiler's price is included in the calculation, with the introduction of such costs or investments on 436 both $\mathrm{G}$ and $\mathrm{DH}$ sides simultaneously, caused the equal impact in all of the six "examination 437 segments" (does not change slope of borderline in Fig. $5^{4}$ ).

438

439 In the equations above, the common costs for both systems are not shown.

440 Different investments in these two opposite systems can be compared for the purpose of a model 441 (Fig 6 8).

442

443 All the previous investments are considered for the present conditions in Serbian energy sector.

444 Of course, this model is applicable for conditions and particular cases all over the world, but 445 diagrams (figures in this paper) are generated for prices ratio in Serbia. Detail calculation for one 446 case of 96 is shown in table $z 4$.

447

448 Values of initial costs (shown in Table 3) for DH subtracted by initial costs of G are shown in 449 table 35.

450

451 Generally, each project task has a time component. Every particular element of the two systems

452 shown here has a lifetime, and it has a price on the market (expressed in $€$ ). If one of the

\footnotetext{
${ }^{4}$ or in case study in Fig 11
} 
453 elements has reached the end of its lifetime (e.g. 26 years), it has to be replaced. Thus, in a 454 project, during the first and the next several years, costs for provision, maintenance and 455 replacement of elements exist (e.g., some elements must be replaced after 14 years and some 456 after 25 years). A sum of costs calculated for each year (t) for gas distribution system is labeled 457 here as G, and for district heating system as DH. "Present Value of Costs" is one of the most 458 useful criterions for project analyses for a whole lifetime of every particular system element. In 459 that way, discount flows reduced on "Present Value of Costs" can be evaluated. "Present Value 460 of Costs" is, by default, cumulative cost for all the elements of the system in present and in 461 future expanded for discount rate. "Future Value of Costs" has to be reduced to present value and 462 to be added to real present costs. Thus, the generated value is called "Present Value of Costs". 463 For the reduction of "Future Value of Costs", an appropriate "Discount Rate" (dr) has to be 464 adopted. Higher value of "Discount Rate" is calculated when risks for the safety of investments 465 exist In the case of possible risks for the safety of investments, higher value of "Discount Rate"

466 is being calculated. "Discount Rate" could be equalized with "Interest" on the market or for 467 realized credit.

468

469 In our case, an economical evaluation is realized during the comparison of two "Present Values 470 of Costs", for gas distribution system (G) and for district heating system (DH) [27 33] . "Net 471 Present Value of Costs" (NPV) (eq. 3) is the result of subtraction of the "Present Value of Costs" 472 calculated for district heating system (DH) and the "Present Value of Costs" calculated for gas 473 distribution system $(\mathrm{G})$.

474

$475 \quad \mathrm{NPV}=\sum_{\mathrm{t}=1}^{\mathrm{n}} \frac{\mathrm{DH}-\mathrm{G}}{\left(1+\mathrm{D}_{\mathrm{r}}\right)^{\mathrm{t}}}$ 
477 Value The value of "Discount Rate" or capital cost rate in this case is rated and adopted as

$478 \mathrm{dr}=10 \%$. The value of discount rate has great impact on the optimal choice of quantitative

479 conclusions (Fig. 5). Changes The changes of calculated values for $\mathrm{dr}=5 \%$ and $\mathrm{dr}=7 \%$ are shown

480 in Table 4 6. Annual An annual gas consumption calculated for one "Conditional Dwelling" is

$481857 \mathrm{~m}^{3}$ for heating only, and for district heating system, this amount is $10 \%$ higher and this

482 amount is $10 \%$ higher for district heating system. Also, Besides, a statistical approach based on

483 nonlinear regression principles can be made to natural gas consumption estimation of individual

484 residential and small commercial customers [28 34]. Annuat The annual costs of electrical

485 energy for running the pumps for district heating system are estimated to $250 \mathrm{kWh}$ per

486 "Conditional Dwelling".

487

488 Analyses are done for all the 96 cases (six "Conditional Urban Area" multiplied by eight "Heat

489 Loads" and by two conditions of insulation - bad or good insulation) for the period of t=26

490 years. In table 4 , case with a bad insulation is shown.

491

492 The values in certain cases in table 46 vary more or less from zero. For example, for

493 "Conditional Urban Area" with 16 buildings and with "Heat Loads" $50 \mathrm{MW} / \mathrm{km}^{2}$, the calculated

494 "Net Present Value of Costs" (NPV) is only -5 per "Conditional Dwelling" for a period of 26

495 years. Therefore, in this case, the realization of gas distribution system for that "Conditional

496 Dwelling" is only $5 €$ for 26 years in advantage versus district heating system. This case and the

497 other similar cases are in the "gray zone" (Fig. 7 9). In the "gray zone", both systems are

498 payable, especially for a period of 26 years. 
500 If a considered value for a certain housing block exceeds, more or less, the recommended

501 limiting value the recommended limiting value, more or less, the decision to recommend a

502 particular centralized heating system is more reasonable. Changing the structure and the price

503 ratio (i.e. the state political decision to subsidize the price of gas gas price in a system or to issue

504 a price, which would disturb the current price ratio of gas used for district heating system and

505 individual consumers), the conception and manner of a construction of certain system and its

506 elements, may cause these parameters to vary. Currently, plastic-polyethylene conduits (cheep)

507 are used for distribution to individual consumers while steel conduits (expensive) had been used

508 before. It led to the considerable cuts in network construction prices, while maintaining the same

509 level of safety and endurance.

510

511 For the same "Heat Loads", when there are many smaller family houses located on a

512 “Conditional Urban Area" e.g. N=32, sometimes only with one "Conditional Dwelling”, gas

513 distribution system is more reasonable. On the contrary, when there is a smaller number of

514 skyscrapers located on "Conditional Urban Area" e.g. $\mathrm{N}=4$, it is more reasonable to use district

515 heating system (Fig. 7 9).

516

517 By means of techno - economic analysis for a certain area, it is possible to determine the

518 advantages of one system over the other (district heating over gas). However, considering the

519 situation on the ground, it may turn out that the system is inaccessible in that part of the city

520 (heating plant does not have enough capacity or, in the first stage, the areas closest to the plant

521 could have a priority in system installation). In that case, if the installation costs of the other 
522 available system are not too high, it is rational to install that type of heating system (thus saving

523 the consumption costs of electric energy and reducing the amount of pollution if the object is 524 coal).

525

526 If, after the analysis, it turns out that one system has more significant economic advantages than

527 the others-de, but it is unavailable, some form of hybrid system should be considered. For

528 instance, if the installation of district heating system has a lot of economic advantages but it is

529 not available, it is possible to build a local boiler room which would be gas operated. This hybrid

530 solution would demand additional economic and ecologic analyses [29 35] and estimations of

531 which good features of district heating system would be kept and which would be discarded.

532

533 4. Case study; Application under real conditions

534

535 Characteristies The characteristics of the "Real Urban Area": number of buildings, disposition

536 and size of buildings, construction type, etc. are the factors of influence. Adeption The adoption

537 of a type of centralized heating system can be done according to the conclusion established by

538 the model shown. That is possible only if both systems are available near the settlement.

540 Today, social help habitants have a discount for district heating price of up to $50 \%$. For

541 consumers of gas the gas consumers who use gas distribution systems directly, such discounts

542 are not available. Alse, in Serbia, Besides, the payment for the DH is per $\mathrm{m}^{2}$ of heated surface

543 area (proportional to the size of the house), and in the G system payment is per $\mathrm{m}^{3}$ of used gas, in

544 Serbia. In the DH bills are fixed, and any sort of economizing in that way is discouraged. 
546 In that case (Belgrade's settlement Karaburma is taken here into consideration), a type of the

547 chosen system depends enly on urbancharacteristic of the sementem on urban characteric of

548 the settlement only. Because of that, the demonstrative settlements are parceled (divided) into

549 eight "Real Urban Areas" with similar buildings on each particular parcel; (Fig. \& 10). That way,

550 the determined "Real Urban Area" can be associated with the "Conditional Urban Area".

551 Characteristic The characteristic points for each of the eight parcels (intersection of number of

552 buildings and heat load of parcel) can be plotted into the characteristic model diagram; (Fig. \&

553 10). The types of insulation of buildings in the settlement are mixed; old buildings have bad

554 and new buildings have good insulation. Both old and new buildings have heterogeneous spatial

555 disposal.

556

557 Two border boundary cases have been treated, because of heterogeneity of insulation quality of

558 buildings [22, 23, 30-32 27, 28, 36-38]; (Fig. 9 11):

560 -Maximal "Heat Load", all buildings have bad insulation (142 W/m²),

561 -Minimal "Heat Load", all buildings have good insulation $\left(95 \mathrm{~W} / \mathrm{m}^{2}\right)$,

563 The value of fuel consumption depends on heating insulation of the building. Energy

564 consumption in the residential sector can be determined according to various methods shown in

565 an available literature [33 39]. Therefore, the "Heat Load" depends on heating insulation of the

566 building. The number of buildings on each particular parcel is constant. "Gray zone" is the zone

567 where decision on the type of the system depends in great deal depends, in a great deal, on the 
568 type of insulation of the building; (Fig. 79. and 8 10). In the "Gray zone", the costs for both

569 systems (gas distribution system and district heating system) are very similar. Characteristic

570 points for each of eight particular also depend on the quality of insulation. Small change in slope

571 of borderline for good insulation $\left(K_{1}=\operatorname{tg} \theta_{1}\right)$ and for bad insulation $\left(K_{2}=\operatorname{tg} \theta_{2}\right)$ in Fig 911 is

572 generated only because of differentiation in structure of diameters of conduits in pipeline (Fig 10

573 12).

574

575 "Real Urban Area" No 8 includes types of small buildings or family houses which can contain 576 only one "Conditional Dwelling". Only for that "Real Urban Area" the gas distribution system

577 has very payable advantages versus district heating system. "Real Urban Area" No 3 includes

578 school, kindergarten, local office, shops. These kinds of buildings can contain twenty or more

579 "Conditional Dwellings". Only for that "Real Urban Area" the district heating system has great

580 advantages. All the other zones are in the "gray zone". In a the "gray zone", one system is more

581 payable in comparison with the other, no more than $200 €$ per "Conditional Dwellings". This

582 amount cannot be crucial for decision. Some illustrations of investigation of price changes

583 (natural gas price, or domestic boilers price) are shown in figure 1113.

584

585 If large areas are covered by agricultural terrain, by excluding it, the above-mentioned

586 parameters obtain unrealistic values.

587

588 Note that pipeline is one of the most important parameters of the analyses shown in this paper.

589 Every particular type of the "examination segment" has a different length of a pipeline route. The

590 length of a pipeline route is fixed by choosing of one six "examination segments". This selection 
591 has to be done to present density of built up areas. Further, for detailed examination, when

592 certain type of "examination segment" is chosen, the length of the route is determined, at the

593 same time. Now, the next factor to be varied is the heat load. The heat load is directly correlated

594 with the size of buildings, i.e. diameters can vary for the fixed length of a pipeline and it's

595 structure. Larger diameters of conduits in pipeline structure are correlated to larger buildings. So,

596 the length of a pipeline route depends on the density of built up areas, and structure of the pipe

597 diameters in a pipeline depends on the size of buildings. Therefore, in city conditions, the

598 diameters of pipes are more sensitive (have a greater impact) in some cases, apropos to the

599 length of a pipeline for decision between heating systems. In the conditions of densely populated

600 urban areas, when one type of the "examination segment" is considered, the decision for

601 implementation of certain heating system has to be done according to the above mentioned

602 criterions. The lengths of pipelines and the structures of diameters of conduits are the main

603 factors for establishing these criterions. Accordingly, in villages, the distances between houses

604 are larger, so the lenth of the dwelling's pipeline has greater impact then the pipeline diameters.

605 The analysis of the distribution of district heat in sparse areas by C. Reidhav and S. Werner [40,

606 41] shows that such distribution can be profitable for Swedish district heating companies, if

607 wisely implemented. Sparse district heating is a label for district-heating systems located in the

608 areas of low heat densities. However, a profitable sparse district heating presupposes a favorable

609 combination of certain factors. The boundaries of two such factors have been identified for

610 Swedish conditions; linear heat density and annual use of district heat/house. An annual use of

611 district heat higher than $50 \mathrm{GJ} /$ house and a linear heat density greater than $2 \mathrm{GJ} / \mathrm{m}$ are required

612 for profitability. In Sweden, the general competitiveness of sparse district heating is facilitated

613 by the high consumption taxes for fuel oil, natural gas, and electricity. Hence, it should be more 
614 difficult to introduce sparse district heating in other countries with low energy taxes. Such areas

615 are unfavorable, since revenues from heat sold are low compared with the investment costs for

616 the local distribution network. This situation results in high distribution costs. Distribution heat-

617 losses are also higher at low heat-densities.

618

619 All the previous values of limiting parameters are calculated for the present gas prices for

620 heating plants, for households, for domestic gas boilers' price, the costs of pipes, labor, etc.

621 Regarding the variation of all parameters, readers can consult electronic annex (Microsoft Excel

622 file). Valuable information for the energetic situation in the city of Belgrade is shown in the

623 paper of M. Jovanović, N. Afgan, P. Radovanović and, V. Stevanović [42] (Belgrade's

624 settlement Karaburma is shown in Fig. 10).

625

626 A city is considered to be sustainable if it establishes the balance between economic and socio-

627 cultural development, on one side, and the progress in environmental protection with active

628 participation of its citizens, on the other side. Using When using one of the power reseurce

629 resources (in this case natural gas) in various systems, the difference in the amount of pollution

630 is very little small. Big differences cannot occur in the overall effect on the city level, but in

631 certain areas they can. While heating plant is a concentrated pollutant which disperses harmful

632 combustion products evenly on a wide area depending on the wind, gas lined consumption

633 disperses locally (consumer pollutes his nearest neighborhood) [43]. Globally, the biggest gas

634 consumer is the biggest city polluter. For including environmental impacts of different

635 centralized energy supply systems in a model, it is necessary to estimate the annual

636 environmental costs for both systems and to include them in related equations. Compared to all 
637 of the fossil fuels, natural gas is a minor pollutant. It burns without a solid residue and has the

638 least coefficient of $\mathrm{CO}_{2}$ emission of about $56 \mathrm{~kg} / \mathrm{GJ}$ (which is significant considering the

639 limitations imposed by The Kyoto Protocol) [34 37 44-47] . M.S. Torekov, N. Bahnsen and B.

640 Qvale [16-9] found that DH system realized 78-93 kg/MWh $\mathrm{CO}_{2}, 0.1 \mathrm{~kg} / \mathrm{MWh} \mathrm{NO}$ and 0.06

$641 \mathrm{~kg} / \mathrm{MWh} \mathrm{SO}_{2}, \mathrm{G}$ system with individual furnace realize $205 \mathrm{~kg} / \mathrm{MWh} \mathrm{CO}, 0.07 \mathrm{~kg} / \mathrm{MWh} \mathrm{NO}_{\mathrm{x}}$

642 and $0.001 \mathrm{~kg} / \mathrm{MWh} \mathrm{SO}$, and electrical heating system $559 \mathrm{~kg} / \mathrm{MWh} \mathrm{CO}_{2}, 88 \mathrm{~kg} / \mathrm{MWh} \mathrm{NO}_{\mathrm{x}}$ and

$64344 \mathrm{~kg} / \mathrm{MWh} \mathrm{SO} 2.1 \mathrm{MWh}$ of delivered energy is $61 \%$ cheaper in natural gas in comparison with

644 electrical energy [36 46]. Comparison The comparison of environmental impacts of two

645 residential heating systems in Canada is shown in paper of L. Yang, Zmeureanu R., and Rivard

646 H. [38 48].

647

648 The key advantage of installing gas or district heating system is not in their mutual differences, 649 but in the substitution of by the far more expensive (in terms of energy and ecology [39 49]) and 650 the highest quality form of energy - the electric energy, whose usage for heating is by far less 651 rational; (Fig. 12 14). The introduction of competition to electricity generation and

652 commercialization has been the main focus of many restructuring experiences around the world.

653 The open accesses to the transmission network and a fair regulated tariff have been the keystones

654 for the development of the electricity market [50]. Parallel to the electricity industry, the natural

655 gas business has great interaction with the electricity market in terms of fuel consumption and 656 energy conversion. Given that the transmission and distribution monopolistic activities are very

657 similar to the natural gas transportation through pipelines, economic regulation related to the 658 natural gas network should be coherent with the transmission counterpart [40 51]. Electricity and 
natural gas use for residential space heating in USA is shown in paper by D. Bodansky [44 52].

\section{5. Conclusions}

664 The latest increase in gas prices turned all eyes once again to the space heating problem in

665 Europe. However, economic concern is not the only factor pushing the authorities to rethink

666 about the suitability of the currently existing sources. Cities are the biggest consumers of the

667 country's energy production. The increase in annual consumption of total primary energy is $3 \%$

668 and its largest part is used for lighting, cooking, heating, cooling, and transport of freights and

669 passengers. It should be noted how important it is to reduce the energy consumption level, by

670 changing the forms of consumption and making improvements in technology and lifestyle The

671 importance of reducing the energy consumption level, by changing the forms of consumption

672 and making improvements in technology and lifestyle, should be noted. Sustainable forms of

673 energy production, distribution and usage represent the goals of a sustainable development.

674 A city is considered to be sustainable if it establishes the balance between economic and socio-

675 cultural development, on one side and the progress in environmental protection with active

676 participation of citizens. On the other side, the economics of G and DH very much depends

677 depend on the specific circumstances $[64,65]$. If installed in an area with only scattered

678 buildings, the length of the pipes which are necessary to supply households will be higher,

679 relative to the number of buildings. Installation costs will be shared by fewer consumers. The

$680 \mathrm{DH}$ system is the capital intensive; in particular due to the distribution system of insulated pipes.

681 The $\mathrm{G}$ system is another form of energy which is being distributed for domestic heating 
682 purposes. The dimensions of the pipes are small compared to the DH pipes and no insulation is

683 needed, thus the distribution system is less capital intensive.

685 District heating is often less efficient with respect to modern heating technologies using natural 686 gas [66-68]. Condensing boilers guarantee higher efficiencies with respect to the "traditional"

687 district heating. In this study, a noncondensing boiler with average efficiency was has been 688 chosen from following database: "Seasonal Efficiency of Domestic Boilers in United Kingdom" 689 [42 32]. Efficiency The efficiency of domestic boiler and efficiency of heating plant on that way 690 has equalized by efficiency in this model. Typieal The typical efficiencies of plants fueled by 691 natural gas are reported in paper of R. Lazzarin and M. Noro [17-10].

693 Figure 5 is essential forfully the full understanding of the model presented here. All dwellings in 694 the option of gas distribution system are equipped with one type of an average boiler. Inereasing 695 the prize linearly The linear price increase moves the borderline in the model diagram in 696 advantage of the district heating (Fig. 8 10. and Fig. 9 11.). The same conclusion is made for the 697 investments in new capacities in heating plant, but that it moves borderline in direction of the gas 698 distribution system. On the contrary, changes in value of discount rate have a great impact (Fig 699 5.). Changes in the price of domestic boiler boilers or investments investment in new capacities

700 in heating plant has the equal impact in all of the six "examination segments", changes of

701 discount rate does not.

702

703 The conducted analyses confirm literature and empirical information: 
705 - District heating system is a better option in areas with small built up density, but with

706 skyscrapers.

707 -Gas system is a better option in areas with high density of individual houses (in this case gas

708 distribution system is significantly in advance).

709

710 These two boundary cases are illustrative. But in the case with small density of built up areas

711 with individual houses, the G system is a cheaper option (but not necessary according to some

712 Swedish studies [43,44 40, 41]). On the contrary, with With high density of built up areas with

713 skyscrapers, the G system is also a cheaper solution. But, safety regulation is a limiting factor for

714 the implementation of gas system directly in a building so high-such a high building. Anyway, in

715 this case the $\mathrm{G}$ system has a slight advantage, and by the increasing the price of domestic gas

716 boiler boilers, the DH system became the cheaper option (Fig 6 8. and Table 3 5).

717

718 In more detail details, if a certain number of objects N exist in a "Conditional Urban Area", it

719 can be concluded that (Fig. 6-8.):

720

721 1. $\mathrm{N}=4$, district heating system has an advantage over gas if an average building has over 29

722 "Conditional Dwellings" (i.e. if the overall heating surface is over $1740 \mathrm{~m}^{2}$ or if the length of 723 pipeline route is below $8 \mathrm{~m}$ )

724 2. $\mathrm{N}=8$, district heating system has an advantage over gas if an average building has over 22

725 "Conditional Dwellings" (i.e. if the overall heating surface is over $1320 \mathrm{~m}^{2}$ or if the length

726 pipeline route is below 7,6m) 
727 3. $\mathrm{N}=16$, district heating system has an advantage over gas if an average building has over 18

728 "Conditional Dwellings" (i.e. if the overall heating surface is over $1080 \mathrm{~m}^{2}$ or if the length of

729 pipeline route is below $7 \mathrm{~m}$ )

$7304 . \mathrm{N}=32$, district heating system has an advantage over gas if an average building has over 15

731 "Conditional Dwellings" (i.e. if the overall heating surface is over $900 \mathrm{~m}^{2}$ or if the length of

732 pipeline route is below $6,4 \mathrm{~m})$

$7335 . \mathrm{N}=64$, district heating system has an advantage over gas or if an average building has over 12

734 "Conditional Dwellings" (i.e. if the overall heating surface is over $720 \mathrm{~m}^{2}$ or if the length of

735 pipeline route is below $5,8 \mathrm{~m}$ )

736 6. $\mathrm{N}=128$, gas system is practically always advantageous (for a high density of small individual

737 house equal as for high density of skyscrapers). Note that case with 128 skyscrapers on $0.05 \mathrm{~km}^{2}$

738 is appeared rare rarely appears in practice. Gas The gas distribution system is advantageous

739 because all 128 buildings must be equipped with expensive heat exchanger exchangers. That is

740 highly unpractical and expensive for individual houses. For skyscrapers, gas system,

741 theoretically, has a slightly slight advantage, but with an increased prize price of domestic gas

742 beiler boilers, district heating system can be applied in larger buildings. Alse, Besides, the

743 implementation of the gas system in skyscrapers is forbidden during according to safety

744 regulations.

746 If large areas are covered by agricultural terrain, by excluding it, the above mentioned

747 parameters obtain unrealistic values. 
749 The above-mentioned limiting values for use of gas are consistent in case of an average heat-

750 insulated apartment of $60 \mathrm{~m}^{2}$. In other cases, additional corrections should be made, or different

751 input values must be entered in the model.

753 Note that, pipeline is one of the most important parameters in the analyses shown in this paper.

754 Every particular type of "examination segment" has a different length of pipeline route. Length

755 of pipeline route is fixed by chøosing of one six "examination segments". This selection has to

756 be done to present density of built up areas. Further, for detailed examination, when certain type

757 of "examination segment" is chosen, in the same time length of route is determined. Now, next

758 factor to be varied is heat load. Heat load is directly correlated with the size of buildings, i.e. for

759 fixed length of pipeline, structure of pipeline diameters can vary. Larger diameters of conduits in

760 pipeline structure are correlated to larger buildings. So, length of pipeline route depends on the

761 density of built up areas, and structure of pipe diameters in pipeline depend on the size of

762 buildings. Therefore, in city condition diameters of pipes are more sensitive in some cases (has

763 greater impact) apropos to length of pipeline for decision of heating system. In the conditions of

764 densely populated urban areas, when one type of "examination segment" is considered, decision

765 for implementation of certain heating system has to be done according to above mention

766 eriterions. Lengths of pipeline and structures of diameters of conduits are main factor for

767 establishing of these criterions. Accordingly, in villages, distances between the houses are larger,

768 sodwelling's length of pipeline has greater impact then the pipeline diameters. The analysis of

769 the distribution of district heat in sparse areas by $C$. Reidhav and S. Werner $[43,44]$ shows that

770 such distribution can be profitable for Swedish district heating companies, if wisely

771 implemented. Sparse district heating is a label for district heating systems located in areas of low 
772 heat densities. However, profitable sparse district heating presupposes a favorable combination

773 of certain factors. The boundaries of two such factors have been identified for Swedish

774 eonditions; linear heat density and annulu use of district heat/house. An annual use of distriet

775 heat higher than $50 \mathrm{GJ} / \mathrm{house}$ and a linear heat density greater than $2 \mathrm{GJ} / \mathrm{m}$ are required for

776 profitability. In Sweden, the general competitiveness of sparse district heating is facilitated by

777 the high consumption taxes for fuel oil, natural gas, and electricity. Hence, it shøuld be møre

778 difficult to introduce sparse district heating in other countries with low energy taxes. Such areas

779 are unfavorable, since revenues from heat sold are low compared with the investment cost for the

780 loealdistribution network. This situation results in high distribution costs. Distribution heat

781 losses are also higher at low heat-densities.

783 All previous values of limiting parameters is done for present prices of gas in for heating plants,

784 for households, for price of domestic gas boilers, costs of pipes, labor, etc. But for variation of all

785 parameters, readers can consult electronic annex (Microsoft Excel file).

787 Some German studies with subject relevant for development of district heating systems in urban

788 environment are also useful and highly evaluated, but this literature is available only in German

789 language [45-47], with related papers presented in scientific journals [48]. Main achievement of

790 these German researches is in establishing of interaction between heating systems, settlement

791 structure and urban planning at the local level. The study analyses options for heat supply in up

792 to types of built up areas [45] from densely populated urban areas to villages. A new

793 German study 20 years later refers to this work [46], with projection to 2020 [47]. Valuable

794 information for the energetic situation in city of Belgrade is shown in the paper of M. Jovanović, 
795 N. Afgan, P. Radovanović and, V. Stevanović [49] (Belgrade's settlement Karaburma is shown

796 in Fig. 8.).

797

798 Today, discussions about district heating systems are not rare in scientific literature [50-56].

799

\section{6. Acknowledgment}

801

802 The This paper is a part of the research done within the project of Ministry of Science NP EE 34-

803 406A, Serbia, Belgrade and the authors would like to thank for financial support.

804

805 7. Appendix

806

807 Algorithm The algorithm for initial decision for selection of a natural gas heating system in 808 settlements is shown in figure 1315 :

809

810 8. References

811

812 [1]. Brkić D. Natural gas as heating fuel (Природни гас као гориво за грејање). Beograd:

813 Andrejevic Foundation (Задужбина Андрејевић), 2006. (in Serbian)

814 [2] Holz F., von Hirschhausen C., Kemfert C. A strategic model of European gas supply

815 (GASMOD). Energy Ecenemies 2008; 30 (3): 766788. 
816 [3] Afgan NH., Carvalho MG., PilavachiPA., Martins N. Evaluation of natural gas supply

817 options for south east and central Europe. Part 1: Indicator definitions and single indicator

818 analysis. Energy Conversion and Management 2007; 48(9): 25172524.

819 [4] Lund Sagen E., Tsygankova M., Russian natural gas exports_Will Russian gas price reforms 820 improve the European security of supply?. Energy Policy 2008; 36 (2): 867880.

821 [5] Remme U., Blest M., Fahl U. Future European gas supply in the resource triangle of the

822 Former Soviet Union, the Middle East and Northern Africa. Energy Policy 2008; 36 (5): 1622

8231641.

824 [G] Lise W., Hobbs W. Future volution of the liberalised European gas market: Simulation

825 results with a dynamic model. Energy 2008; 33 (7): 989-1004.

826 [7] Herbert JH., Berg J. Soviet natural gas exports and the European energy balance. Energy

$827 \quad 1990 ; 15(10): 833-840$.

828 [8] Kabirian A., Reza Hemmati M. A strategic planning model for natural gas transmission

829 networks. Energy Policy 2007; 35 (11): 5656 5670.

830 [9] Dzenajaviciene EF., Kveselis V., MeNaughtC., Tamonis M. Economic analysis of the

831 renovation of small-seale district heating systems -4 Lithuanian case studies. Energy Policy

$832 \quad 2007 ; 35(4): 2569-2578$.

833 [10]. Gustavsson L., Karlssen A. Heating detached houses in urban areas. Energy 2003; 28 (8):

$834 \quad 851-875$.

835 [11] Riva A., D’Angelosante S., Trebeschi C. Natural gas and the envirenmental results of life

836 eycle assessment. Energy 2006; $31(1): 138148$.

837 [12]. Douthitt RA. An economic analysis of the demand for residential space heating fuel in

838 Canada. Energy 1989; 14 (4): 187197. 
[13] Papadopoulos AM., Oxizidis S., Papandritsas G. Energy, econømic and environmenta1

840 performance of heating systems in Greek buildings. Energy and Buildings 2008; 40 (3): 224

841230.

842 [14] Dinca C., Badea A., Rousseaux P., Apostol T. A multi-criteria approach to evaluate the

843 natural gas energy systems. Energy Policy 2007; 35 (11): 57545765.

844 [15] Gustafsson SI., Karlssen BG. Natural gas in optimized bivalent heating systems. Energy

845 1990; 15(11): 993-999.

846 [16]. Torekov M S., Bahnsen N., Qvale B. The relative competitive positions of the alternative

847 means for domestic heating. Energy 2007; 32 (5): 627633.

848 [17]. Lazzarin R., Noro M. Local or district heating by natural gas: which is better from

849 energetic, environmental and economic point of views?. Applied Thermal Engineering 2006; 26

$850 \quad(2-3): 244-250$.

851 [18]. Grohnheit PE., Mortensen BOG. Competition in the market for space heating. district

852 heating as the infrastructure for competition among fuels and technologies. Energy Policy 2003;

$853 \quad 31(9): 817826$.

854 [19]. Santamouris M., Kapsis K., Korres D., Livada I., Pavlou C., Assimakepoulos M.N. On the 855 relation between the energy and social characteristics of the residential sector. Energy and

856 Buildings 2007; 39 (8): 893 905.

857 [20]. Stanistaw S. The measurement of demand for natural gas. Energy 1985; 10 (2): $165 \quad 180$.

858 [21]. Hartshorn JE. Introduction: Natural gas development begins at høme. Energy 1985; 10(2):

$859 \quad 111118$.

860 [22]. Mihalakakeu G., Santamouris M., Tsagrasseulis A. On the energy consumption in

861 residential buildings. Energy and Buildings, 2002; 34 (7): 727736. 
862 [23]. Olesen BW., Parsens KC. Introduction to thermal comfort standards and to the proposed

863 new version of EN ISO 7730. Energy and Buildings 2002; 34 (6): 537548.

864 [24]. Huei Chu L., Tsai Feng C. Space heating and water heating energy demands of the aged in 865 the US. Energy Economics 2002; 24 (3): 267-284.

866 [25]. Corfield G., Hunt BE., Ott RJ., Binder GP., Vandaveer F. E. Distribution Design for

867 Increased Demand. In: Segeler CG, editør. Gas Engineers Handbøøk. New York: Industrial

868 Press.p. 9/63-9/83.

869 [26]. Recknagel H., Sprenger E., Honmann W. Heating (Греjaњe). In: Višnjić M., editør.

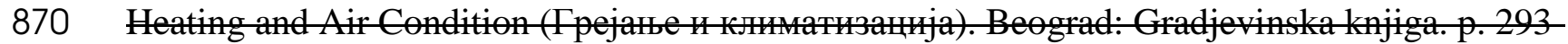

871 835. (in Serbian)

872 [27]. Papadopoulos AM., Theodosiou T., Karatzas K. Feasibility of energy saving renovation

873 measures in urban buildings: the impact of energy prices and the acceptable pay back time

874 eriterion. Energy and Buildings 2002; 34 (5): $455-466$.

875 [28] Vondraček J., Pelikan E., Konar O., Čermakova J., Eben K., Maly M., Brabec M. A

876 statistical model for the estimation of natural gas consumption. Applied Energy 2008; 85 (5):

$877 \quad 362-370$.

878 [29]. Braniš M., Domasova M., Rezačova P. Particulate air pollution in a small settlement: the 879 effect of local heating. Applied Geochemistry 2007; 22 (6): 1255 1264.

880 [30]. Gustafsson SI., Bojić M. Optimal heating system retrofits in residential buildings. Energy

$881 \quad$ 1997; $22(9): 867-874$.

882 [31]. Torehio MF., GenonG., Poggio A., Poggio M. Merging of energy andenvirenmentat

883 analyses for district heating systems. Energy 2008; doi:10.1016/j.energy.2008.01.012 
884 [32]. Ossebard ME., van Wijk AJM., van Wees MT. Heat supply in the Netherlands: a systems 885 analysis of costs, exergy efficiency, $\mathrm{CO}_{z}$ and $\mathrm{NO}_{x}$-emissions. Energy 1997; 22 (11): 10871098. 886 [33] Aydinalp-Koksal M., Ismet Ugursal V. Comparisen of neural network, conditionaldemand 887 analysis, and engineering approaches for modeling end-use energy consumption in the residentiat 888 sector. Applied Energy 2008; 85 (4): 271 296.

889 [34]. Haberl H., Adensam H., Geissler S. Optimal climate protection strategies for space heating; 890 the case of Austria. Energy Policy 1998; 26 (15): 1125-1135.

891 [35]. Cowie AL., Kirschbaumb MUF., Ward M. Options for including all lands in a future 892 greenhouse gas accounting framework. Envirenmental Science \& Policy, 2007; 10(4): 306 321. 893 [36]. Karlssona A., Gustavsson L. External costs and taxes in heat supply systems. Energy Policy $894 \quad 2003 ; 31(14): 15411560$.

895 [37]. Holmgren K., Amiri S. Internalising external costs of electricity and heat production in a 896 municipal energy system. Energy Policy 2007; 35 (10): 52425253.

897 [38] Yang L., Zmeureanu R., Rivard H. Comparison of environmental impacts of two residentiat 898 heating systems. Building and Envirenment 2008; 43 (6): 10721081.

899 [39] Ford $\Lambda$. Simulation scenarios for rapid reduction in carbon dioxide emissions in the western 900 electricity system. Energy Policy 2008; 36(1): 443-455.

901 [40] Morais MS., Marangon JW. Lima Combined natural gas and electricity network pricing. 902 Electric Power Systems Research 2007; 77 (5-6): 712719.

903 [41]. Bodansky D. Electricity and natural gas use for residential space heating: U.S. experience, $904 \quad 1976$ 1980. Energy 1984; 9 (4): 303313.

905 [42]. SEDBUK Seasonal Efficiency of Domestic Boilers. See alsø: http://www.sedbuk.com 
906 [43]. Reidhav C., Werner S. Profitability of sparse district heating. Applied Energy 2008; 85 (9):

$907 \quad 867877$.

908 [44]. Forsaeus Nilssen S., Reidhav C., Lyonerud K. Werner S. Sparse district heating in Sweden. 909 Applied Energy 2008; 85(7): 555-564.

910 [45]. Roth U., Häubi F., Albrecht J. Interaction between urban infrastructure and district heating

911 system (Wechselwirkungen zwischen des Siedlungsstruktur und Wärmeversorgungssystemen).

912 Bonn: Bundesminister für Raumordnung, Bawwesen und Städtebau, 1980. (in German)

913 [46]. AGFW Arbeitsgemeinschaft Fernwärme. Pluralistische Wärmeversorgung Zeithørizont

9142005 (Vorstulie). See also: http://ww.agfw.de/86.0.html(in German)

915 [47]. AGFW-Arbeitsgemeinschaft Fernwärme. Pluralistische Wärmeversorgung-Zeithørizont

916 2020. Hauptstudie See also: http://www.agfw.de/86.0.html (in German)

917 [48]. Ter Brugge R. Spatial structure in relation to energy production and consumption. Journal

918 of Economic and Social Geography Tijdschrift voer Economische en Sociale Geografie 1984; 75

$919(3): 214-222$.

920 [49]. Jovanović M., Afgan N., Radovanovié P.,Stevanović V. Sustainable development of the

921 Belgrade energy system. Energy 2008; doi:10.1016/j.energy.2008.01.013

922 [50]. Lunda H., Hvelplunda F., Kassb I., Dukalskisb E., Blumberga D. District heating and

923 market economy in Latvia. Energy 1999; 24 (7): 549-559.

924 [51]. de Almeida AT., Lopes AC., Carvalho A., Mariano J., Jahn A., Broege M. Examining the

925 potential of natural gas demand-side measures to benefit customers, the distribution utility, and

926 the envirenment: two case studies from Europe. Energy 2004; 29 (7): $979 \quad 1000$.

927 [52]. Knutsson D., Sahlin J., Werner S., Ekvall T., Ahlgren EO. HEATSPOT a simulation toø1

928 for national district heating analyses. Energy 2006; 31 (2 3): 278293. 
929 [53]. Dotzauer E. Experiences in mid-term planning of district heating systems. Energy 2003; 28

930 (15): $1545-1555$.

931 [54]. Sundberg G., Karlssen BG. Interaction effects in optimising a municipalenergy system.

932 Energy 2000;25(9):877-891.

933 [55]. Gustavsson L. District heating systems and energy conservation part I. Energy 1994; 19

934 (1): 81-91.

935 [56]. Gustavsson L. District heating systems and energy conservation part II. Energy 1994; 19

$936(1): 93-102$.

937 [2] Dzenajaviciene EF., Kveselis V., McNaught C., Tamonis M. Economic analysis of the

938 renovation of small-scale district heating systems - 4 Lithuanian case studies. Energy Policy

$939 \quad 2007 ; 35$ (4): 2569-2578.

940 [3]. Gustavsson L., Karlsson A. Heating detached houses in urban areas. Energy 2003; 28 (8):

$941 \quad 851-875$.

942 [4] Riva A., D’Angelosante S., Trebeschi C. Natural gas and the environmental results of life

943 cycle assessment. Energy 2006; 31 (1): 138-148.

944 [5]. Douthitt RA. An economic analysis of the demand for residential space heating fuel in

945 Canada. Energy 1989; 14 (4): 187-197.

946 [6] Papadopoulos AM., Oxizidis S., Papandritsas G. Energy, economic and environmental

947 performance of heating systems in Greek buildings. Energy and Buildings 2008; 40 (3): 224

948230.

949 [7] Dinca C., Badea A., Rousseaux P., Apostol T. A multi-criteria approach to evaluate the

950 natural gas energy systems. Energy Policy 2007; 35 (11): 5754-5765. 
951 [8] Gustafsson SI., Karlsson BG. Natural gas in optimized bivalent heating systems. Energy

952 1990; 15 (11): 993-999.

953 [9]. Torekov M S., Bahnsen N., Qvale B. The relative competitive positions of the alternative

954 means for domestic heating. Energy 2007; 32 (5): 627-633.

955 [10]. Lazzarin R., Noro M. Local or district heating by natural gas: which is better from

956 energetic, environmental and economic point of views?. Applied Thermal Engineering 2006; 26

957 (2-3): 244-250.

958 [11]. Grohnheit PE., Mortensen BOG. Competition in the market for space heating. district

959 heating as the infrastructure for competition among fuels and technologies. Energy Policy 2003;

$96031(9): 817-826$.

961 [12]. Roth U., Häubi F., Albrecht J. Interaction between urban infrastructure and district heating

962 system (Wechselwirkungen zwischen des Siedlungsstruktur und Wärmeversorgungssystemen).

963 Bonn: Bundesminister für Raumordnung, Bauwesen und Städtebau, 1980. (in German)

964 [13]. AGFW-Arbeitsgemeinschaft Fernwärme. Pluralistische Wärmeversorgung - Zeithorizont

9652005 (Vorstudie). See also: http://www.agfw.de/86.0.html (in German)

966 [14]. AGFW-Arbeitsgemeinschaft Fernwärme. Pluralistische Wärmeversorgung - Zeithorizont

967 2020. Hauptstudie See also: http://www.agfw.de/86.0.html (in German)

968 [15]. Ter Brugge R. Spatial structure in relation to energy production and consumption. Journal

969 of Economic and Social Geography-Tijdschrift voor Economische en Sociale Geografie 1984; 75

970 (3): 214-222.

971 [16]. Bojić M., Despotović M. Influence of duration of thermal comfort provision on heating

972 behavior buildings. Energy Conversion and Management 2007; 48 (8): 2416-2423. 
973 [17] Holz F., von Hirschhausen C., Kemfert C. A strategic model of European gas supply

974 (GASMOD). Energy Economics 2008; 30 (3): 766-788.

975 [18] Afgan NH., Carvalho MG., Pilavachi PA., Martins N. Evaluation of natural gas supply

976 options for south east and central Europe. Part 1: Indicator definitions and single indicator

977 analysis. Energy Conversion and Management 2007; 48 (9): 2517-2524.

978 [19] Lund Sagen E., Tsygankova M., Russian natural gas exports-Will Russian gas price

979 reforms improve the European security of supply?. Energy Policy 2008; 36 (2): 867-880.

980 [20] Remme U., Blesl M., Fahl U. Future European gas supply in the resource triangle of the

981 Former Soviet Union, the Middle East and Northern Africa. Energy Policy 2008; 36 (5): 1622

9821641.

983 [21] Lise W., Hobbs W. Future evolution of the liberalised European gas market: Simulation

984 results with a dynamic model. Energy 2008; 33 (7): 989-1004.

985 [22] Herbert JH., Berg J. Soviet natural gas exports and the European energy balance. Energy

986 1990; 15 (10): 833-840.

987 [23] Kabirian A., Reza Hemmati M. A strategic planning model for natural gas transmission

988 networks. Energy Policy 2007; 35 (11): 5656-5670.

989 [24]. Santamouris M., Kapsis K., Korres D., Livada I., Pavlou C., Assimakopoulos M.N. On the

990 relation between the energy and social characteristics of the residential sector. Energy and

991 Buildings 2007; 39 (8): 893-905.

992 [25]. Stanislaw S. The measurement of demand for natural gas. Energy 1985; 10 (2): 165-180.

993 [26]. Hartshorn JE. Introduction: Natural gas development begins at home. Energy 1985; 10 (2):

$994 \quad 111-118$. 
995 [27]. Mihalakakou G., Santamouris M., Tsagrassoulis A. On the energy consumption in

996 residential buildings. Energy and Buildings, 2002; 34 (7): 727-736.

997 [28]. Olesen BW., Parsons KC. Introduction to thermal comfort standards and to the proposed

998 new version of EN ISO 7730. Energy and Buildings 2002; 34 (6): 537-548.

999 [29]. Huei-Chu L., Tsai-Feng C. Space-heating and water-heating energy demands of the aged in

1000 the US. Energy Economics 2002; 24 (3): 267-284.

1001 [30]. Corfield G., Hunt BE., Ott RJ., Binder GP., Vandaveer F. E. Distribution Design for

1002 Increased Demand. In: Segeler CG, editor. Gas Engineers Handbook. New York: Industrial

1003 Press. p. 9/63-9/83.

1004 [31]. Recknagel H., Sprenger E., Honmann W. Heating (Гpejaњe). In: Višnjić M., editor.

1005 Heating and Air Condition (Грејање и климатизација). Beograd: Gradjevinska knjiga. p. 293-

1006 835. (in Serbian)

1007 [32]. SEDBUK-Seasonal Efficiency of Domestic Boilers in United Kingdom. See also:

1008 http://www.sedbuk.com

1009 [33]. Papadopoulos AM., Theodosiou T., Karatzas K. Feasibility of energy saving renovation

1010 measures in urban buildings: the impact of energy prices and the acceptable pay back time

1011 criterion. Energy and Buildings 2002; 34 (5): 455-466.

1012 [34]. Vondraček J., Pelikan E., Konar O., Čermakova J., Eben K., Maly M., Brabec M. A

1013 statistical model for the estimation of natural gas consumption. Applied Energy 2008; 85 (5):

$1014 \quad 362-370$.

1015 [35]. Braniš M., Domasova M., Rezačova P. Particulate air pollution in a small settlement: the

1016 effect of local heating. Applied Geochemistry 2007; 22 (6): 1255-1264. 
1017 [36]. Gustafsson SI., Bojić M. Optimal heating-system retrofits in residential buildings. Energy

1018 1997; 22 (9): 867-874.

1019 [37]. Torchio MF., Genon G., Poggio A., Poggio M. Merging of energy and environmental

1020 analyses for district heating systems. Energy 2008; doi:10.1016/j.energy.2008.01.012

1021 [38]. Ossebaard ME., van Wijk AJM., van Wees MT. Heat supply in the Netherlands: a systems

1022 analysis of costs, exergy efficiency, $\mathrm{CO}_{2}$ and $\mathrm{NO}_{\mathrm{x}}$ emissions. Energy 1997; 22 (11): 1087-1098.

1023 [39]. Aydinalp-Koksal M., Ismet Ugursal V. Comparison of neural network, conditional demand

1024 analysis, and engineering approaches for modeling end-use energy consumption in the residential

1025 sector. Applied Energy 2008; 85 (4): 271-296.

1026 [40]. Reidhav C., Werner S. Profitability of sparse district heating. Applied Energy 2008; 85 (9):

$1027 \quad 867-877$.

1028 [41]. Forsaeus Nilsson S., Reidhav C., Lygnerud K. Werner S. Sparse district-heating in Sweden.

1029 Applied Energy 2008; 85 (7): 555-564.

1030 [42]. Jovanović M., Afgan N., Radovanović P.,Stevanović V. Sustainable development of the

1031 Belgrade energy system. Energy 2008; doi:10.1016/j.energy.2008.01.013

1032 [43]. Strachan N., Farrell A. Emissions from distributed vs. centralized generation: The

1033 importance of system performance. Energy Policy 2006; 34 (17): 2677-2689.

1034 [44]. Haberl H., Adensam H., Geissler S. Optimal climate protection strategies for space heating;

1035 the case of Austria. Energy Policy 1998; 26 (15): 1125-1135.

1036 [45]. Cowie AL., Kirschbaumb MUF., Ward M. Options for including all lands in a future

1037 greenhouse gas accounting framework. Environmental Science \& Policy 2007; 10 (4): 306-321.

1038 [46]. Karlssona A., Gustavsson L. External costs and taxes in heat supply systems. Energy Policy

1039 2003; 31 (14): 1541-1560. 
1041 municipal energy system. Energy Policy 2007; 35 (10): 5242-5253.

1042 [48] Yang L., Zmeureanu R., Rivard H. Comparison of environmental impacts of two residential 1043 heating systems. Building and Environment 2008; 43 (6): 1072-1081.

1044 [49] Ford A. Simulation scenarios for rapid reduction in carbon dioxide emissions in the western 1045 electricity system. Energy Policy 2008; 36 (1): 443-455.

1046 [50] Jednak S, Kragulj D, Bulajić M, Pittman R. Electricity reform in Serbia. Utilities Policy

1047 2008; doi:10.1016/j.jup.2008.02.002

1048 [51] Morais MS., Marangon JW. Lima Combined natural gas and electricity network pricing.

1049 Electric Power Systems Research 2007; 77 (5-6): 712-719.

1050 [52]. Bodansky D. Electricity and natural gas use for residential space heating: U.S. experience,

1051 1976-1980. Energy 1984; 9 (4): 303-313.

1052 [53]. Lunda H., Hvelplunda F., Kassb I., Dukalskisb E., Blumberga D. District heating and 1053 market economy in Latvia. Energy 1999; 24 (7): 549-559.

1054 [54]. de Almeida AT., Lopes AC., Carvalho A., Mariano J., Jahn A., Broege M. Examining the 1055 potential of natural gas demand-side measures to benefit customers, the distribution utility, and 1056 the environment: two case studies from Europe. Energy 2004; 29 (7): 979-1000.

1057 [55]. Knutsson D., Sahlin J., Werner S., Ekvall T., Ahlgren EO. HEATSPOT—a simulation tool 1058 for national district heating analyses. Energy 2006; 31 (2-3): 278-293.

1059 [56]. Dotzauer E. Experiences in mid-term planning of district heating systems. Energy 2003; 28 1060 (15): 1545-1555.

1061 [57]. Sundberg G., Karlsson BG. Interaction effects in optimising a municipal energy system. 1062 Energy 2000; 25 (9): 877-891. 
1063 [58]. Gustavsson L. District heating systems and energy conservation-part I. Energy 1994; 19

1064 (1): 81-91.

1065 [59]. Gustavsson L. District heating systems and energy conservation-part II. Energy 1994; 19

1066 (1): 93-102.

1067 [60]. Benonysson A., Bohm B., Ravn HF. Operational optimization in a district heating system.

1068 Energy Conversion and Management 1995; 36 (5): 297-314.

1069 [61]. Gebremedhin A., Moshfegh B. Modelling and optimization of district heating and industrial

1070 energy system - an approach to a locally deregulated heat market. International Journal of

1071 Energy Research 2004; 28 (5): 411-422.

1072 [62]. Barelli L., Bidini G., Pinchi EM. Implementation of a cogenerative district heating:

1073 Optimization of a simulation model for the thermal power demand. Energy and Buildings 2006;

107438 (12): 1434-1442.

1075 [63]. Larsen HV., Paisson H., Bohm B., Ravn H.F. Aggregated dynamic simulation model of

1076 district heating networks, Energy Conversion and Management 2001; 43 (8): 995-1019.

1077 [64]. Bouvy C., L.Klaus. Multicriterial optimisation of communal energy supply concepts.

1078 Energy Conversion and Management 2007; 48 (11): 2827-2835.

1079 [65]. Söderman J., Pettersson F. Structural and operational optimisation of distributed energy

1080 systems. Applied Thermal Engineering 2006; 26 (13): 1400-1408.

1081

1082 [66]. Rosa L., Tosato R. Experimental evaluation of seasonal efficiency of condensing boilers.

1083 Energy and Buildings 1990; 14 (3): 237-241.

1084 [67]. Lazzarin RM., Schibuola L. Performance analysis of heating plants equipped with

1085 condensing boilers. Journal of Heat Recovery Systems 1986; 6 (4): 269-276. 
1086 [68]. Agrell J., Bogetoft P. Economic and environmental efficiency of district heating plants.

1087 Energy Policy 2005; 33 (10): 1351-1362. 
1088 Figure 1. "Real Urban Area" associates with several types of "Basic segments" according to the 1089 spatial disposition of buildings

1090 Figure 2. Examples of different "Heat Loads" for the same "Basic segments" (two cases)

1091 Figure 3. Standard length of networks for all the six types of "Examination segments" $\left(0,5 \mathrm{~km}^{2}\right)$

1092 Figure 4. "Conditional Urban Areas" - two examples

1093 Figure 5. Effects of price and discount rate changes, example of factors with linear influence and 1094 nonlinear influence (costs for one average dwelling)

1095 Figure 6. Brand new domestic boilers in the UK market sorted according to efficiency class 1096 (SEDBUK)

1097 Figure 7. Diagram for selection of appropriate domestic boiler for the examination condition

1098 Figure 6. Figure 8. Comparisons of investments in district heating and gas distribution system

1099 Figure 7. Figure 9. Identification of some characteristic cases in model diagram

1100 Figure 9. Figure 10. Diagram for adoption of optimal system for observed settlement

1101 Figure 10. Figure 11. Displacement of borders and characteristic points calculated for different 1102 quality of building insulation

1103 Figure 11. Figure 12. Length of conduits sort by diameters for DH pipeline for good and poor 1104 insulated buildings in the Karaburma settlement - case study

1105 Figure 12. Figure 13. Price changing sensitivity, sample for few factors of influence

1106 Figure 14. Consumption of electrical energy in the observed settlement

1107 Figure 15. Algorithm for centralized energy supply system selection fueled by natural gas 
1108 Table 1: Identification of all of the 96 considered case (number of average dwelling per

1109 building)

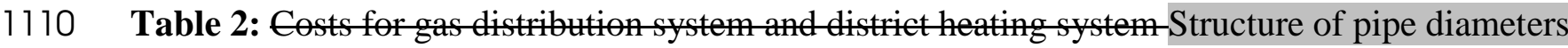

1111 for one of the cases (example)

1112 Table 3: Initial costs" — per "Conditional Dwelling" Investments in both systems per dwelling;

$1113 \mathrm{G}$ and DH [€]

1114 Table 4: "Net Present Value of Costs" (NPV)" — per "Conditional Dwelling" Costs for gas

1115 distribution system and district heating system (example)

1116 Table 5: Initial costs ${ }^{\mathrm{a}}-€$ per "Conditional Dwelling"

1117 Table 6: "Net Present Value of Costs" (NPV) ${ }^{\mathrm{a}}-€$ per "Conditional Dwelling" 


\section{${ }^{*}$ Point-to-Point Response to Reviewers}

\section{Reviewer 1:}

1. New abstract is in the paper.

2. The introduction is reorganized as requested (first literature review and after basic assumption and main objectives of our paper.

3. Explanation is added in lines 121-148; alternative option is to delete sentence 'The most suitable option for satisfying heating demands in urban areas is by using a centralized system.' to avoid further explanations

4. In our opinion text is now reorganized to explain basic assumption in better way (this request maybe we have not understood clear and we will be grateful for further explanations).

5. We hope that English expression in our paper is now improved.

6. Fig 6 and 7 with comments are added in new version of the text to improve analysis. Tables 2 and 3 have been added in new version of the text to support the analysis section. Also, Excel file is added as electronic annex to support understanding of the calculations presented in our paper.

Reviewer 2: is missing

Reviewer 3: is missing

Reviewer 4:

Meaning of variables is now incorporated in the text: line 396-402 and line 412-418 in marked text Text in conclusion is shorter, and some remarks from previous are now in section 4. Line 585-624

References are renumbered. Special thanks for the previous comments by reviewer 4 . According to his/her comment quality of our paper are significantly improved. 
Figure(s)

Click here to download high resolution image

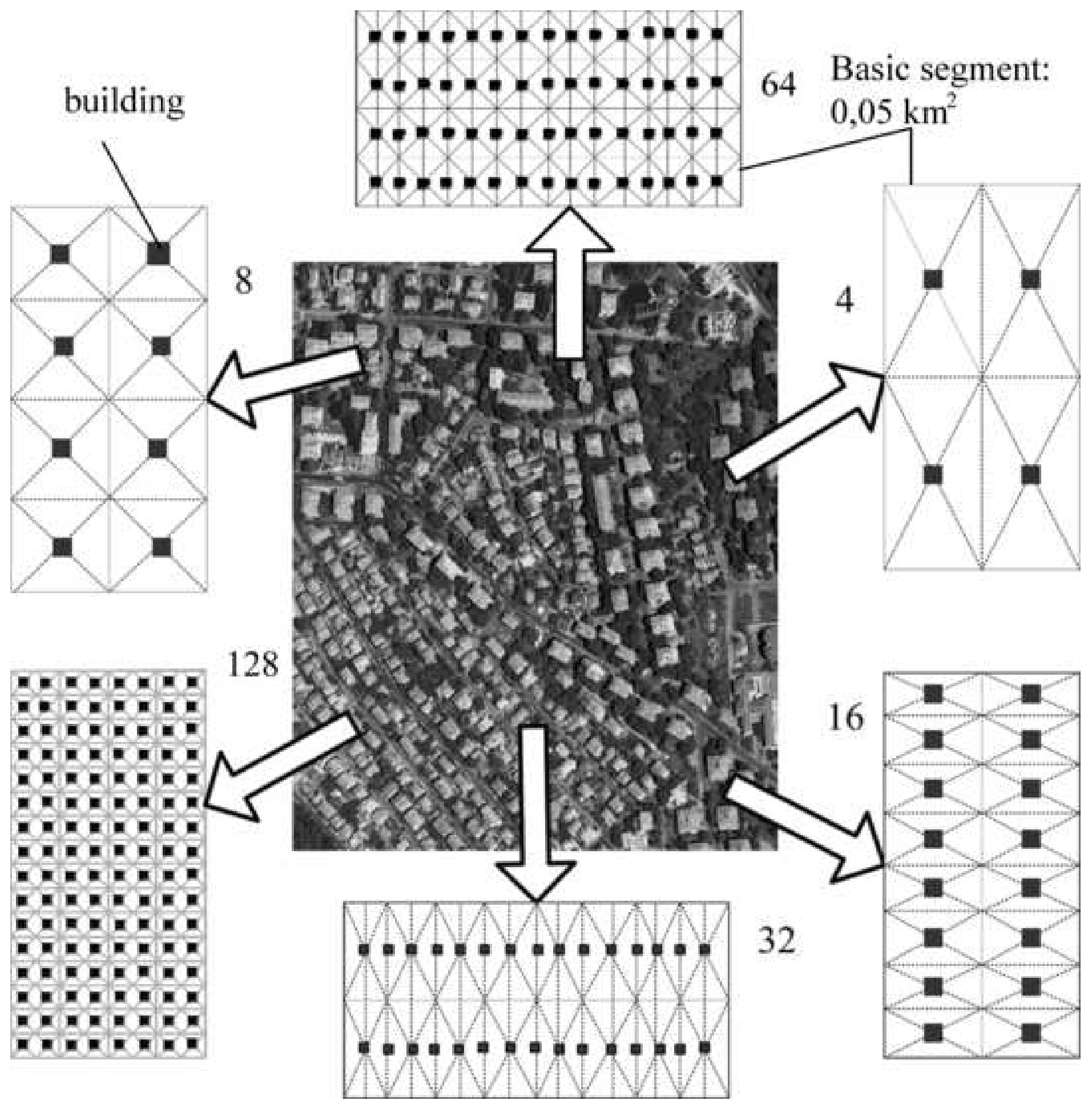


Click here to download high resolution image
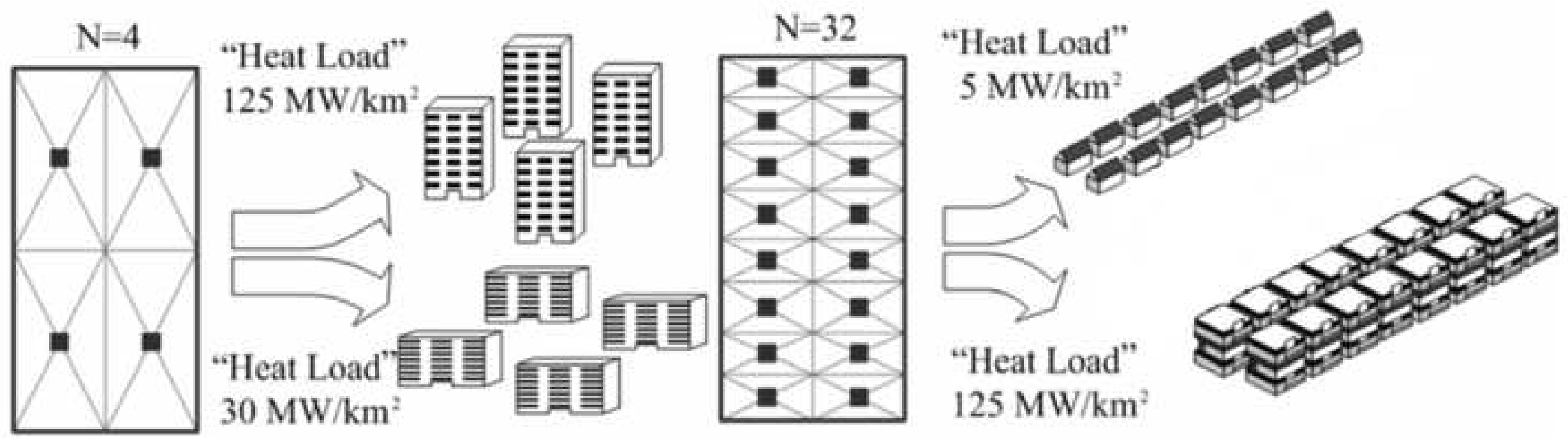

Basic segment: $0,05 \mathrm{~km}^{2}$

Basic segment: $0,05 \mathrm{~km}^{2}$ 


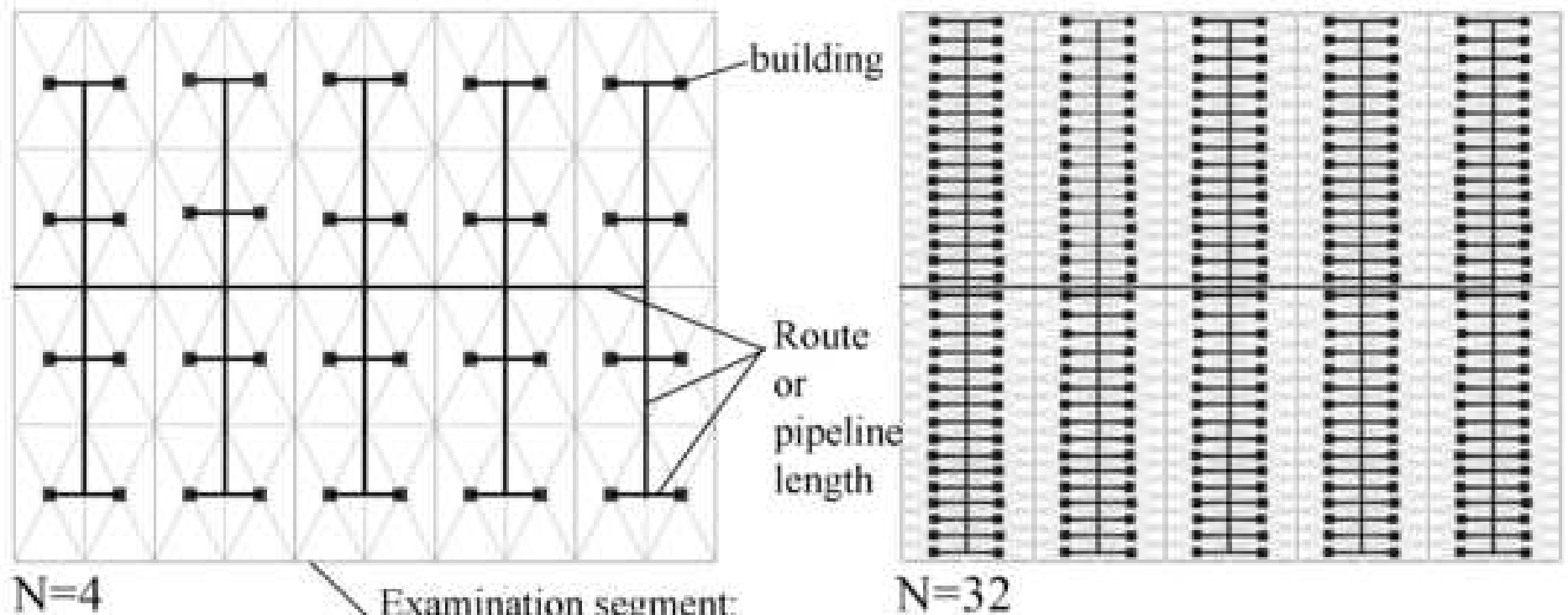

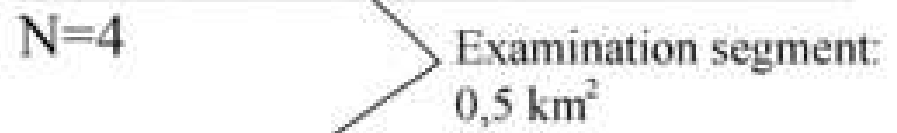

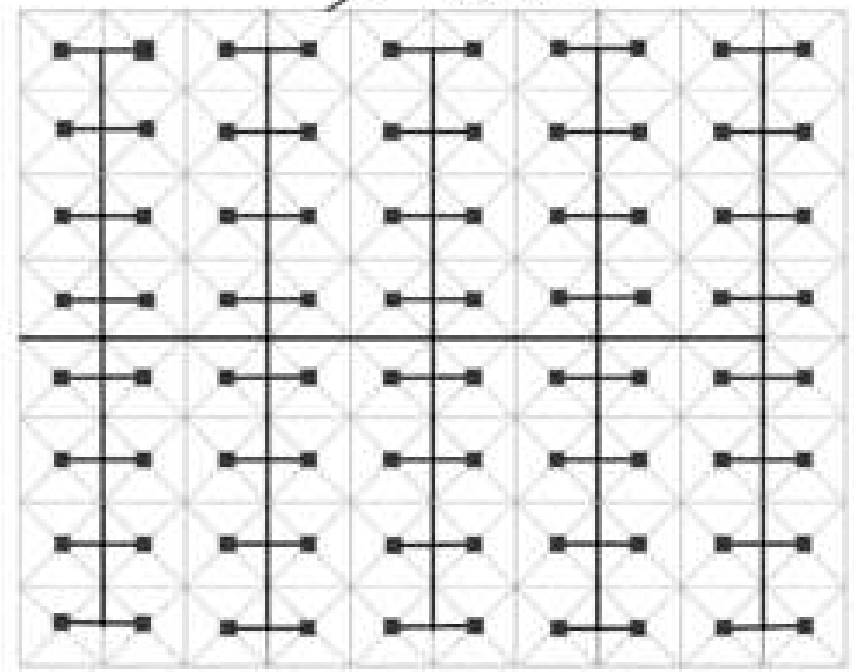

$N=8$

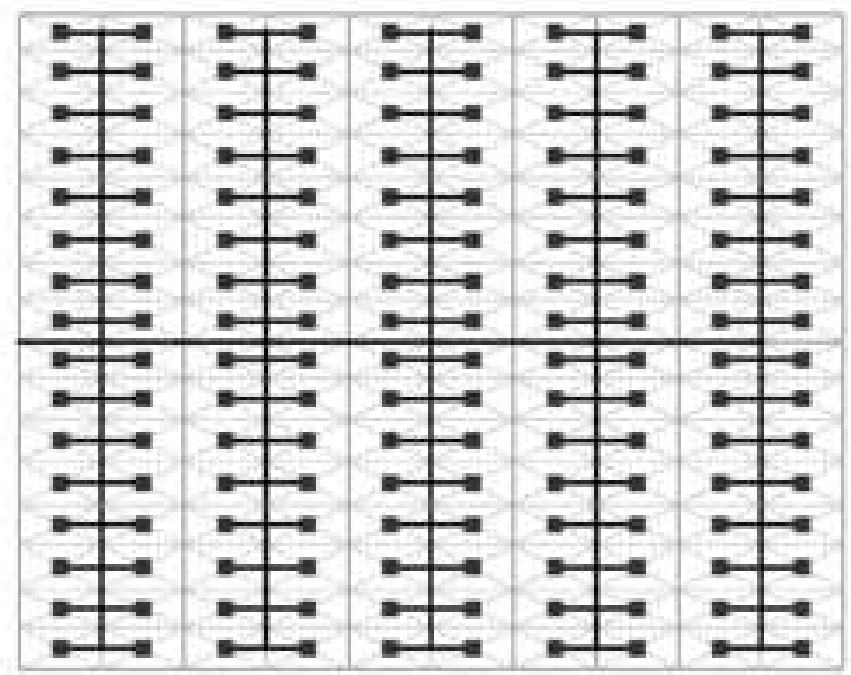

$\mathrm{N}=16$

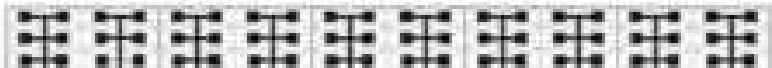

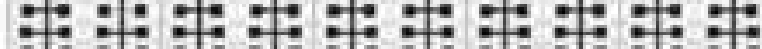

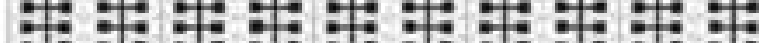
类:

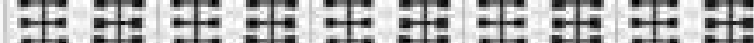

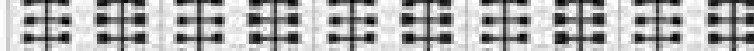

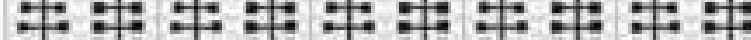

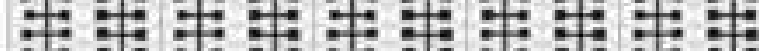

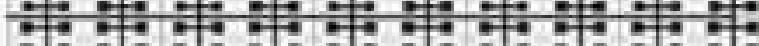
$\because \div \div \div \div \div \div$

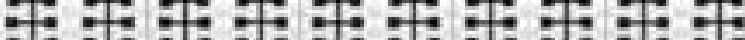

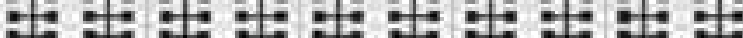

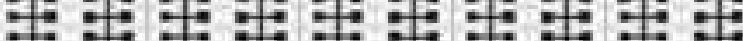

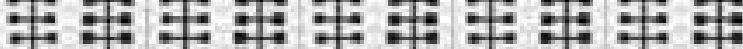

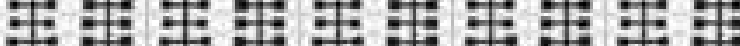

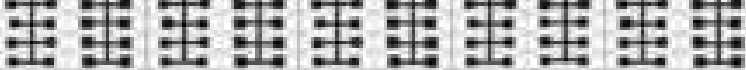
$\mathrm{N}=64$

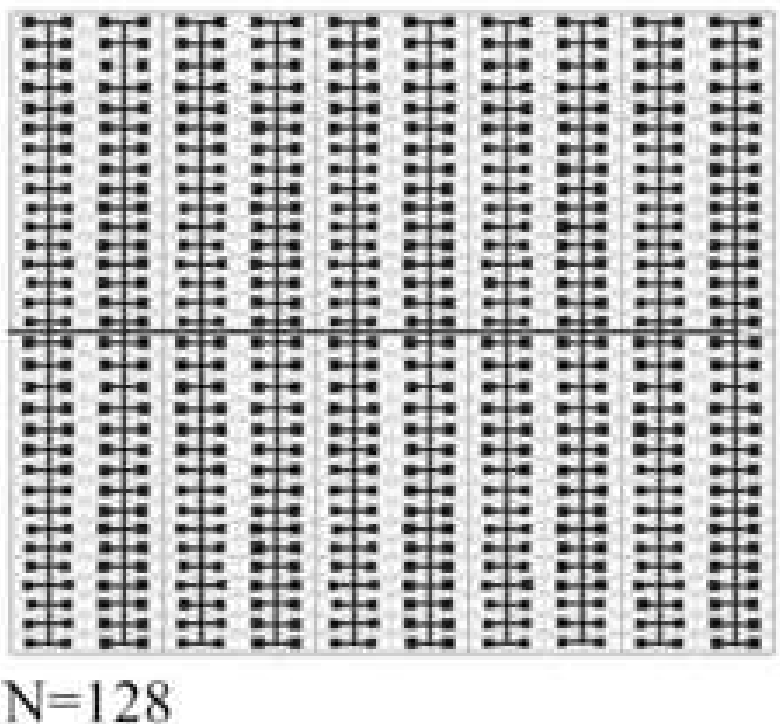




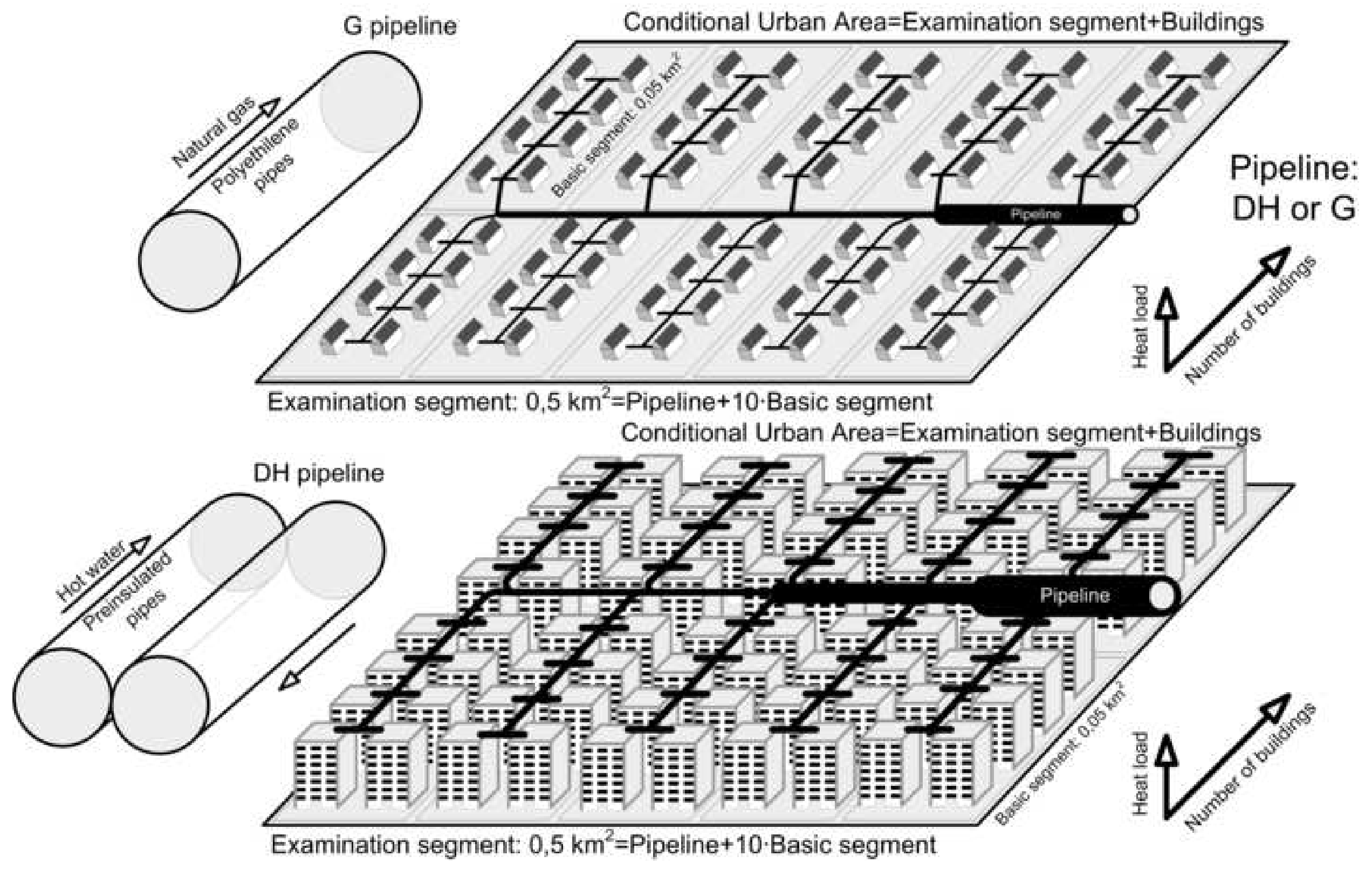



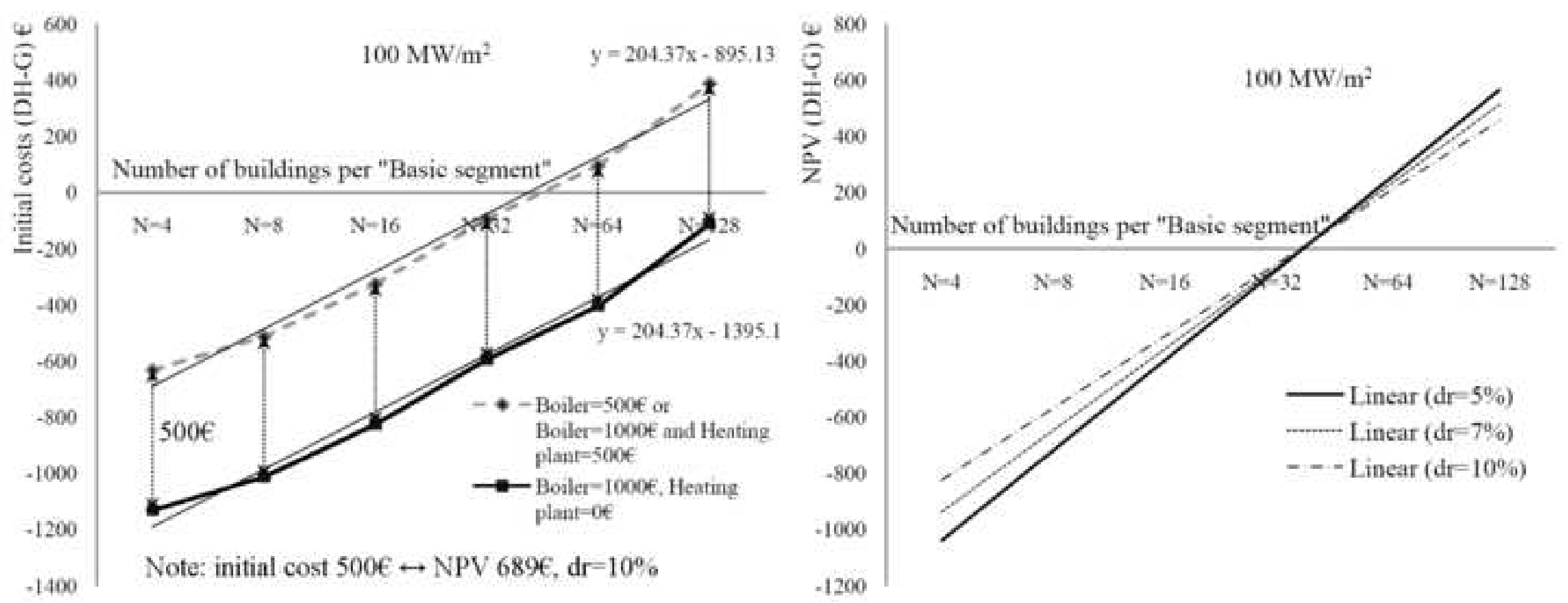


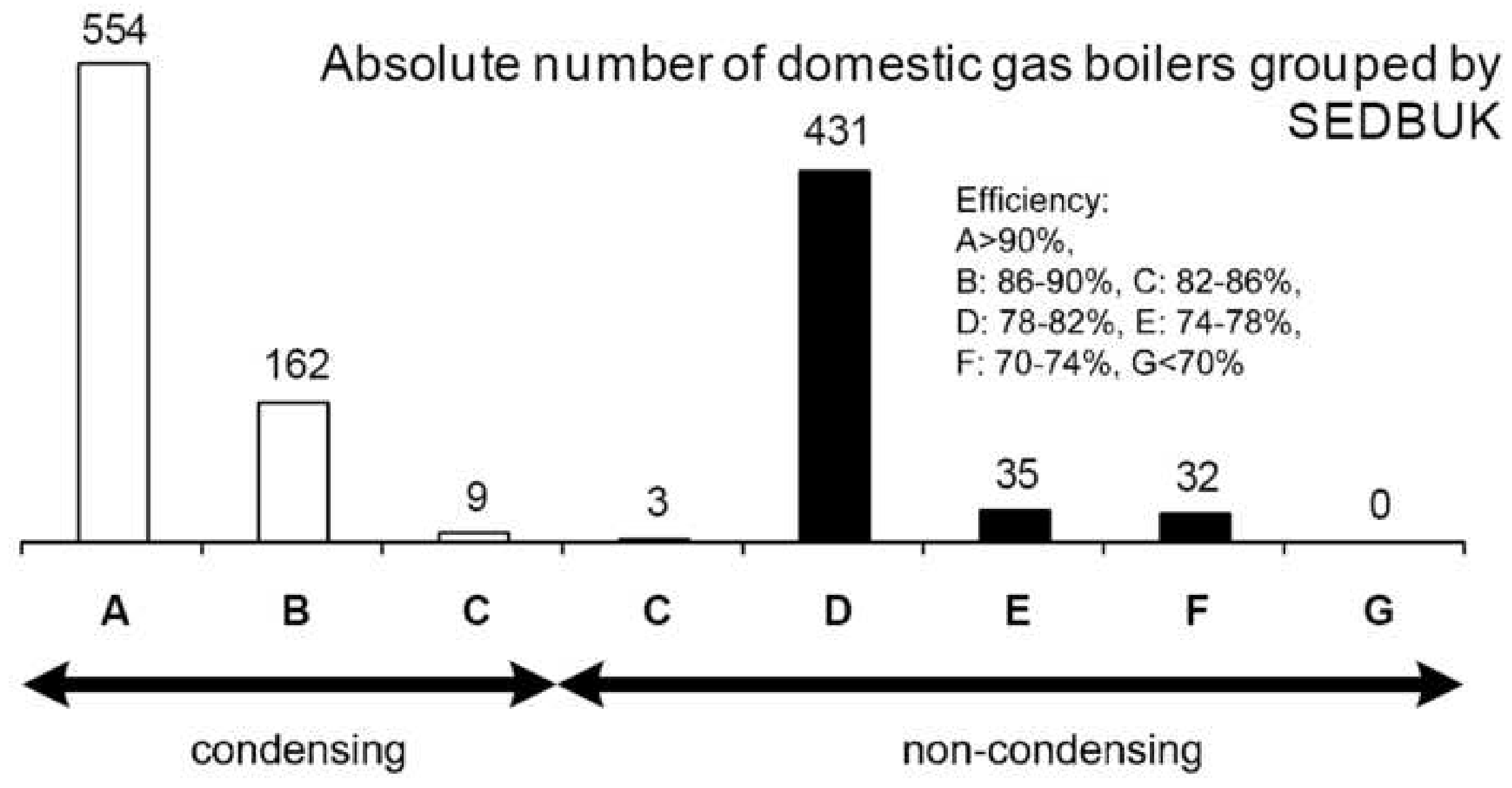


Absolute number of domestic boiler grouped by power according to SEDBUK

a-noncondensing boiler (best efficiency at $100 \%$ of nominal load)

b-condensing boiler (best efficiency at $30 \%$ of nominal load)

'-optimal power of domestic boiler for good insulated average dwelling

${ }^{2}$-optimal power of domestic boiler for bad insulated average dwelling

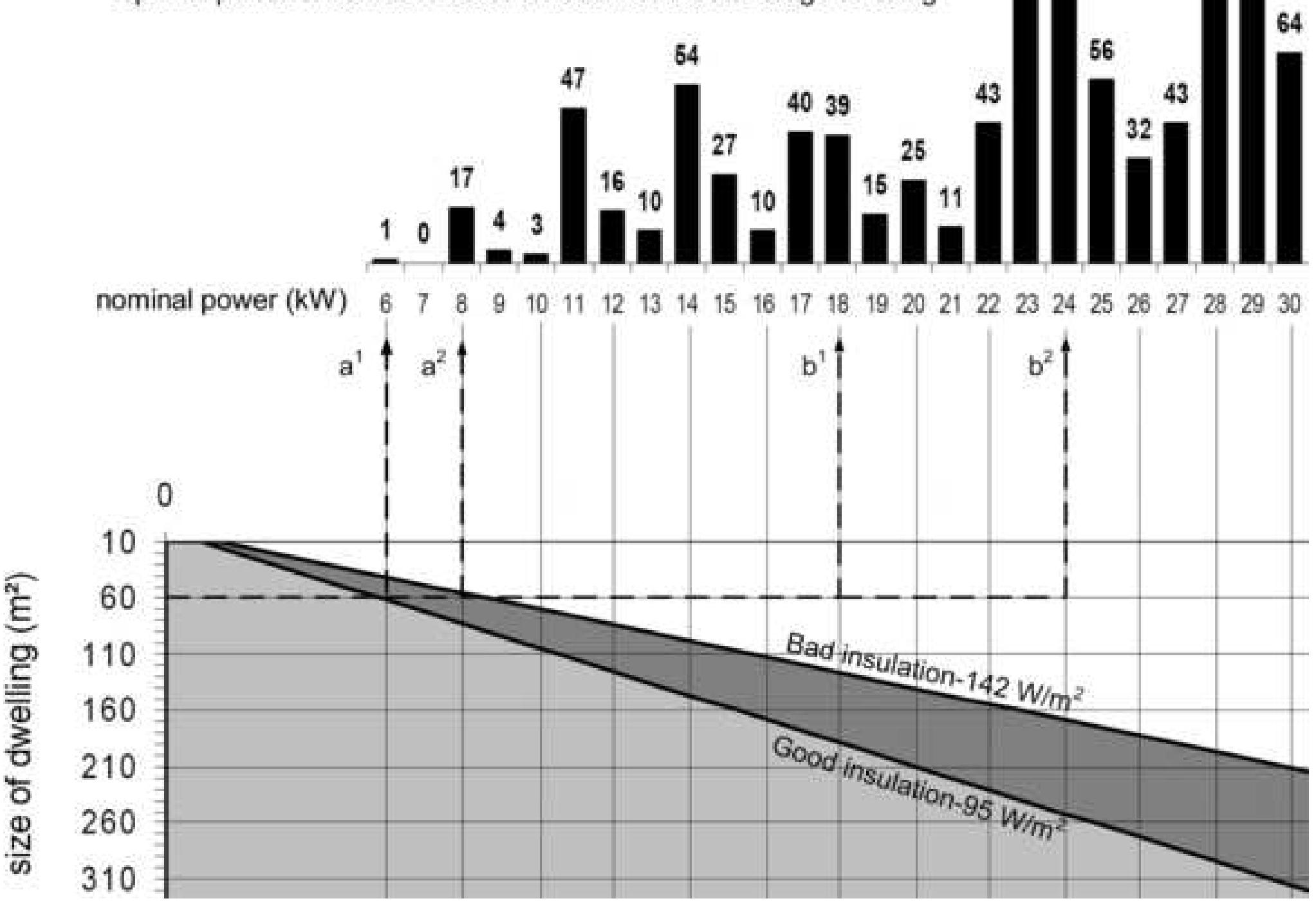




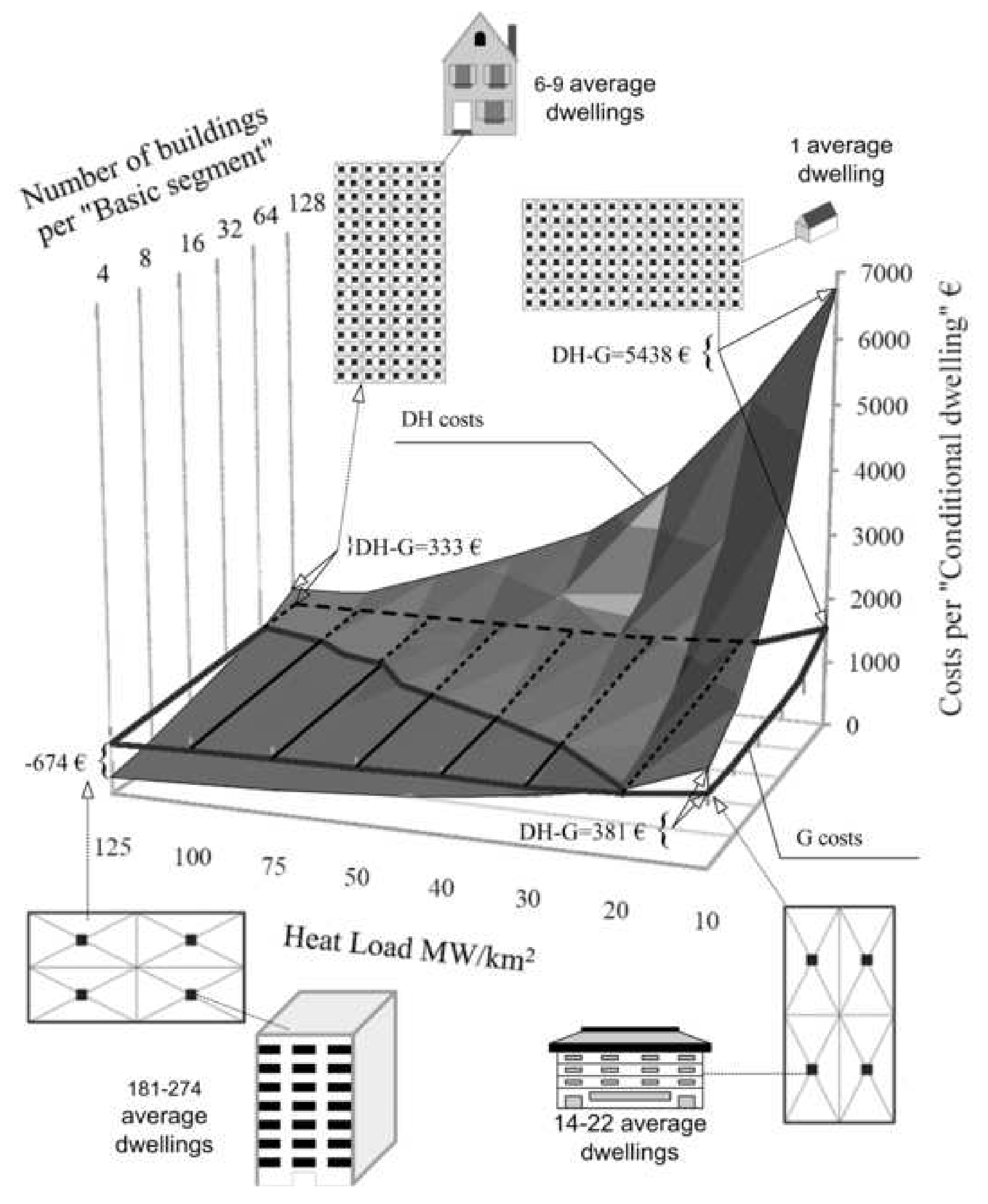

Click here to download high resolution image
1 average

(n) dwelling

\section{6-9 average \\ dwellings}

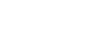

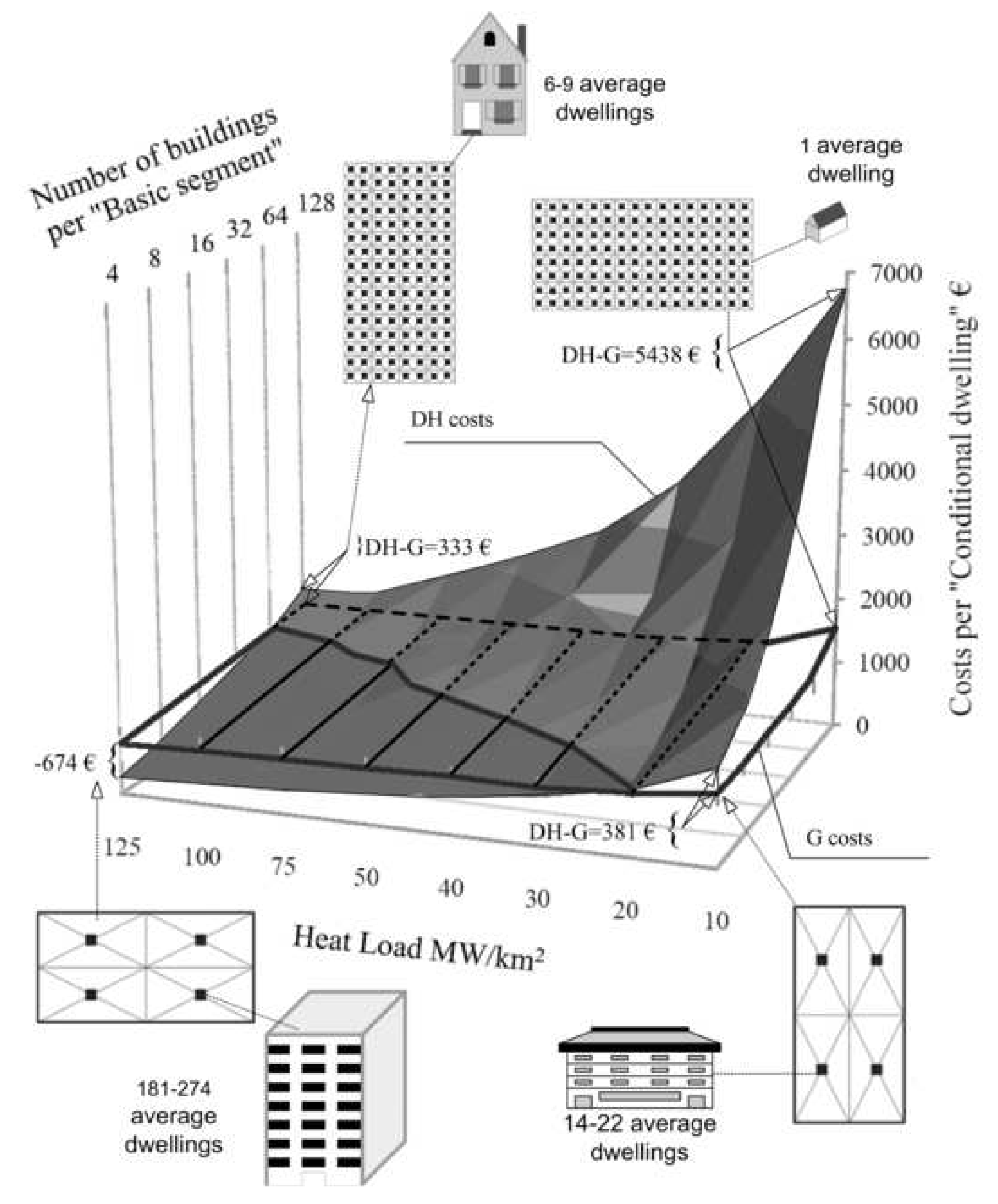

. 


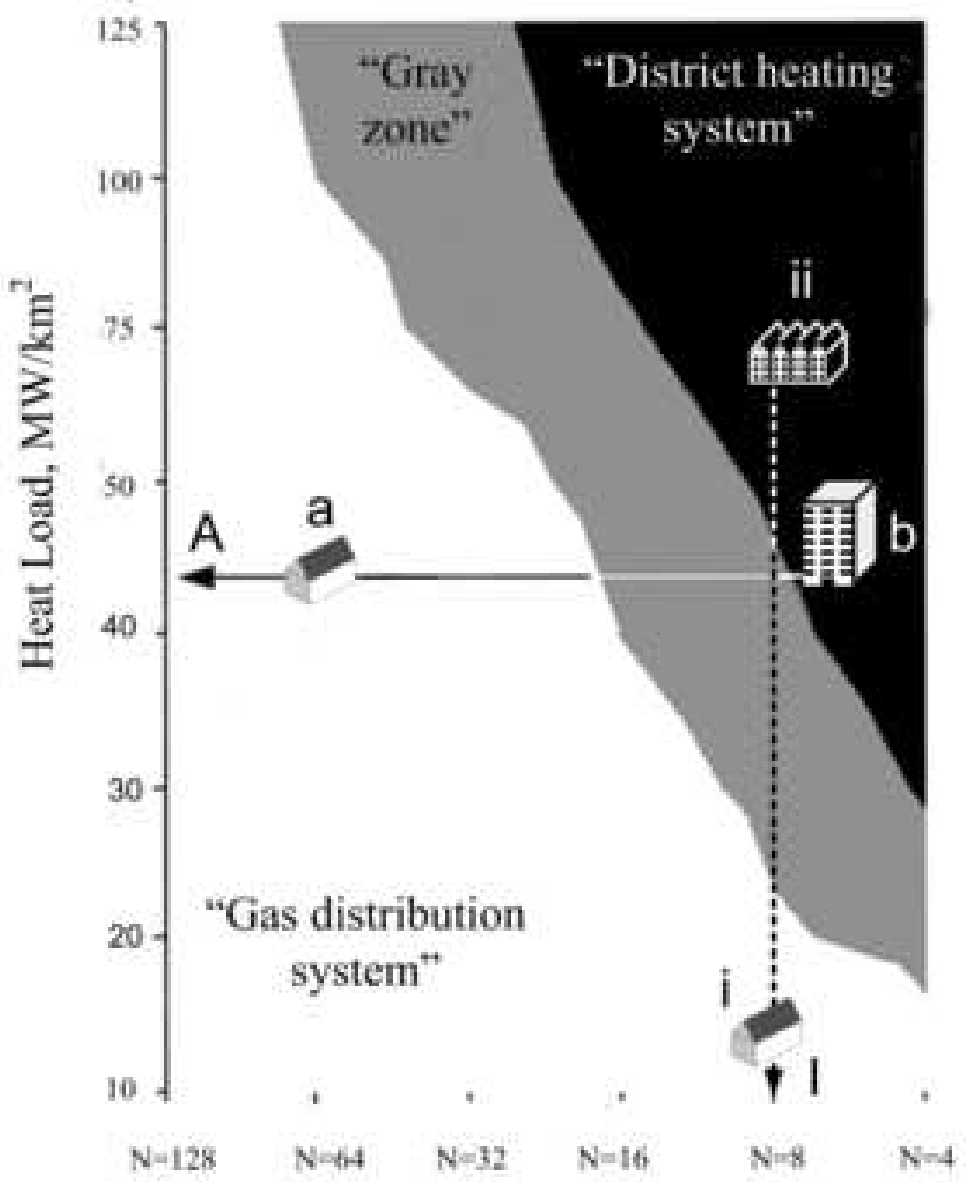

A) Same "Heat load" - Different number of building per "Basic segment"

a) gas distribution system; b) district heating system

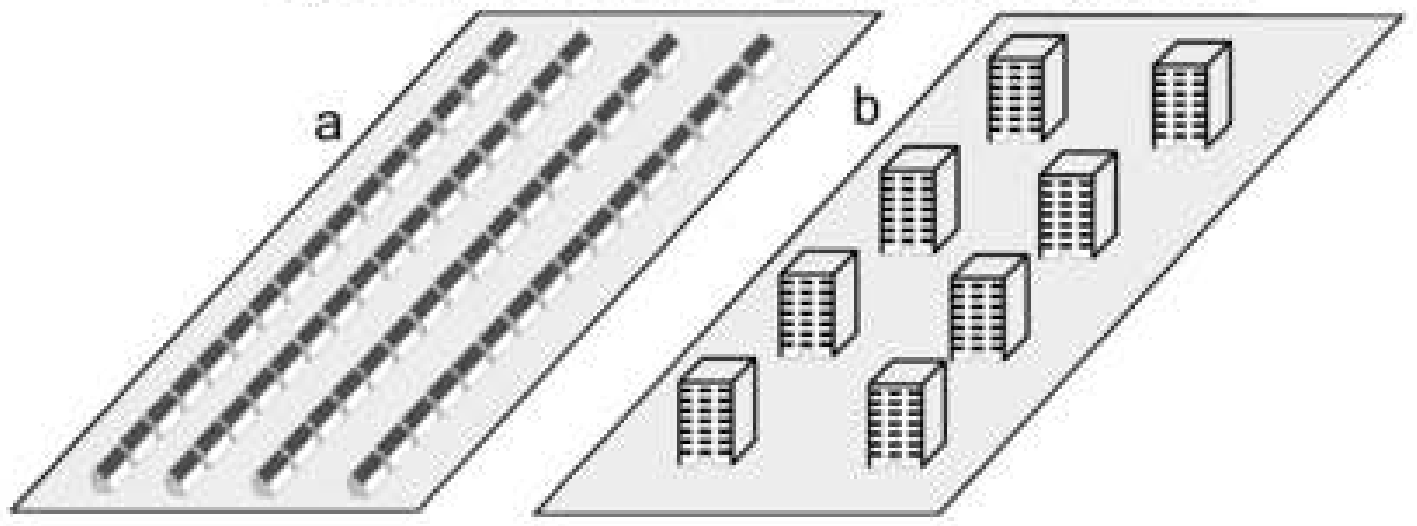

1) Different "Heat load" - same number of building per "Basic segment" i) gas distribution system; ii) district heating system

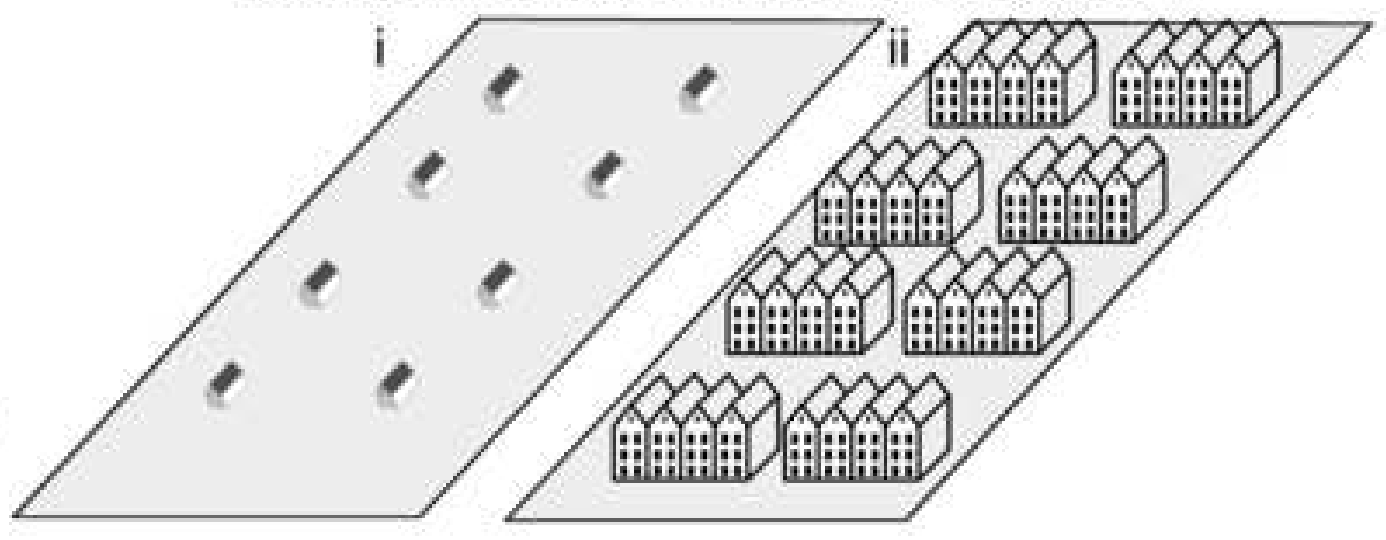

"Number of buildings" per "Basic segment" 

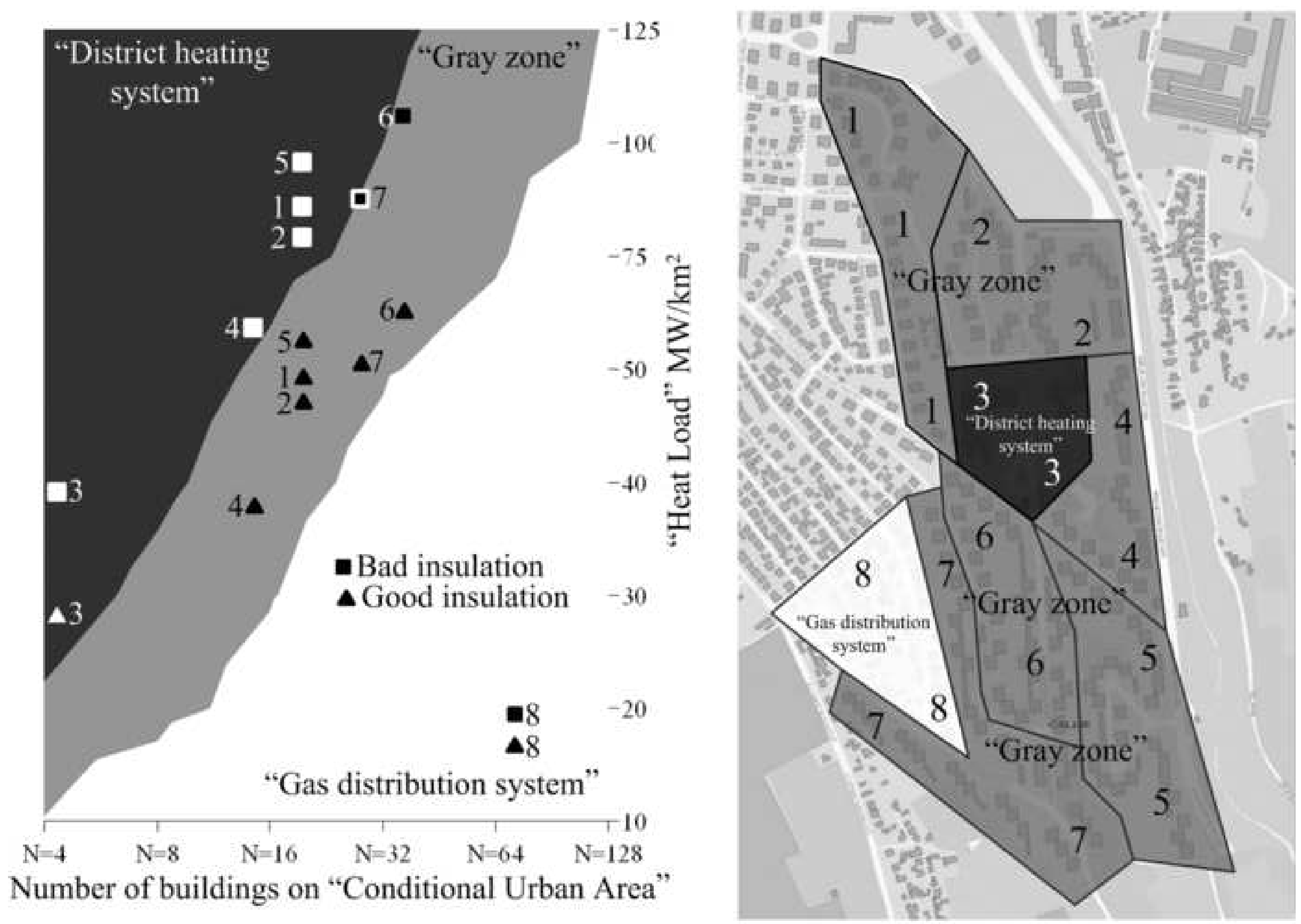

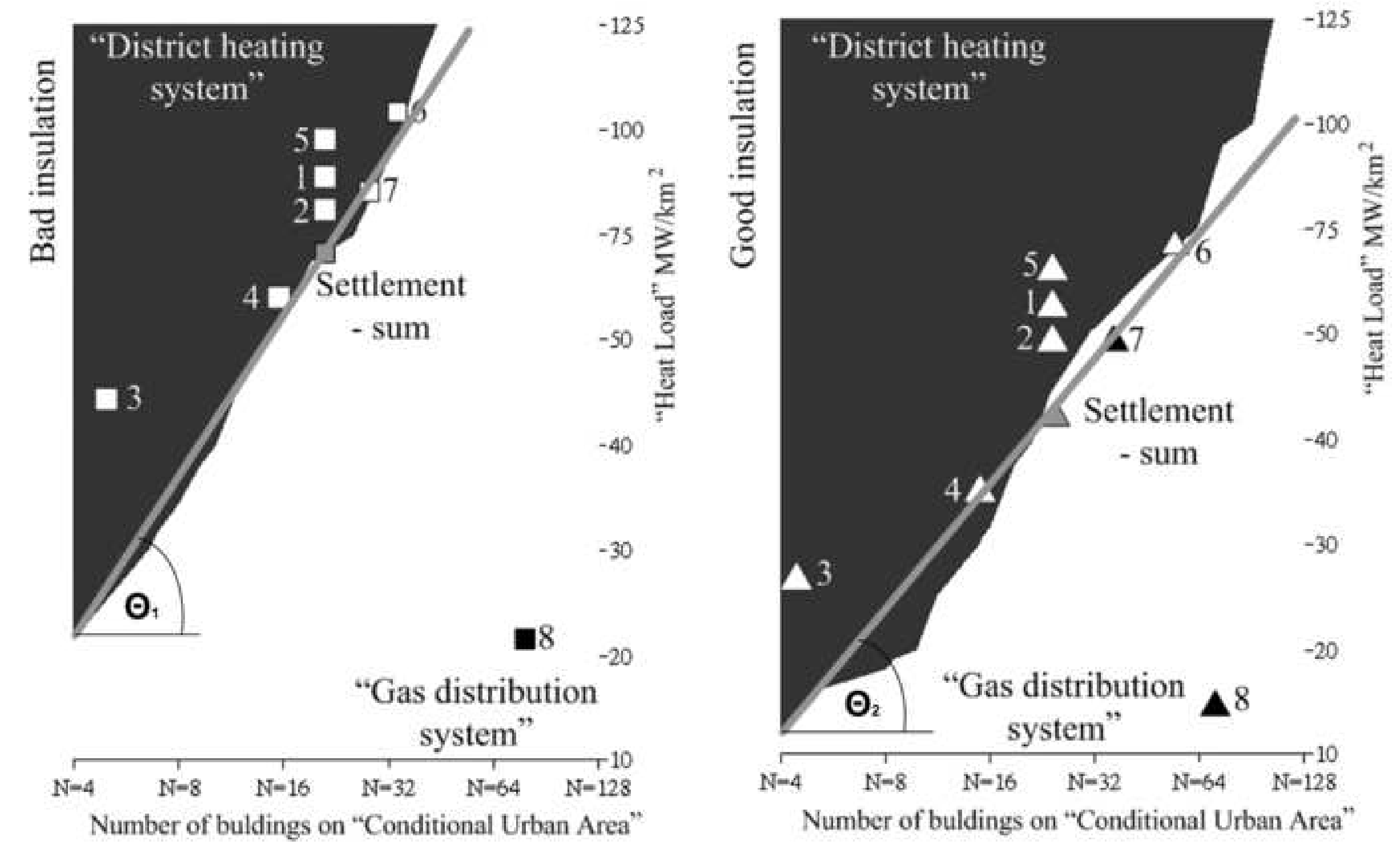


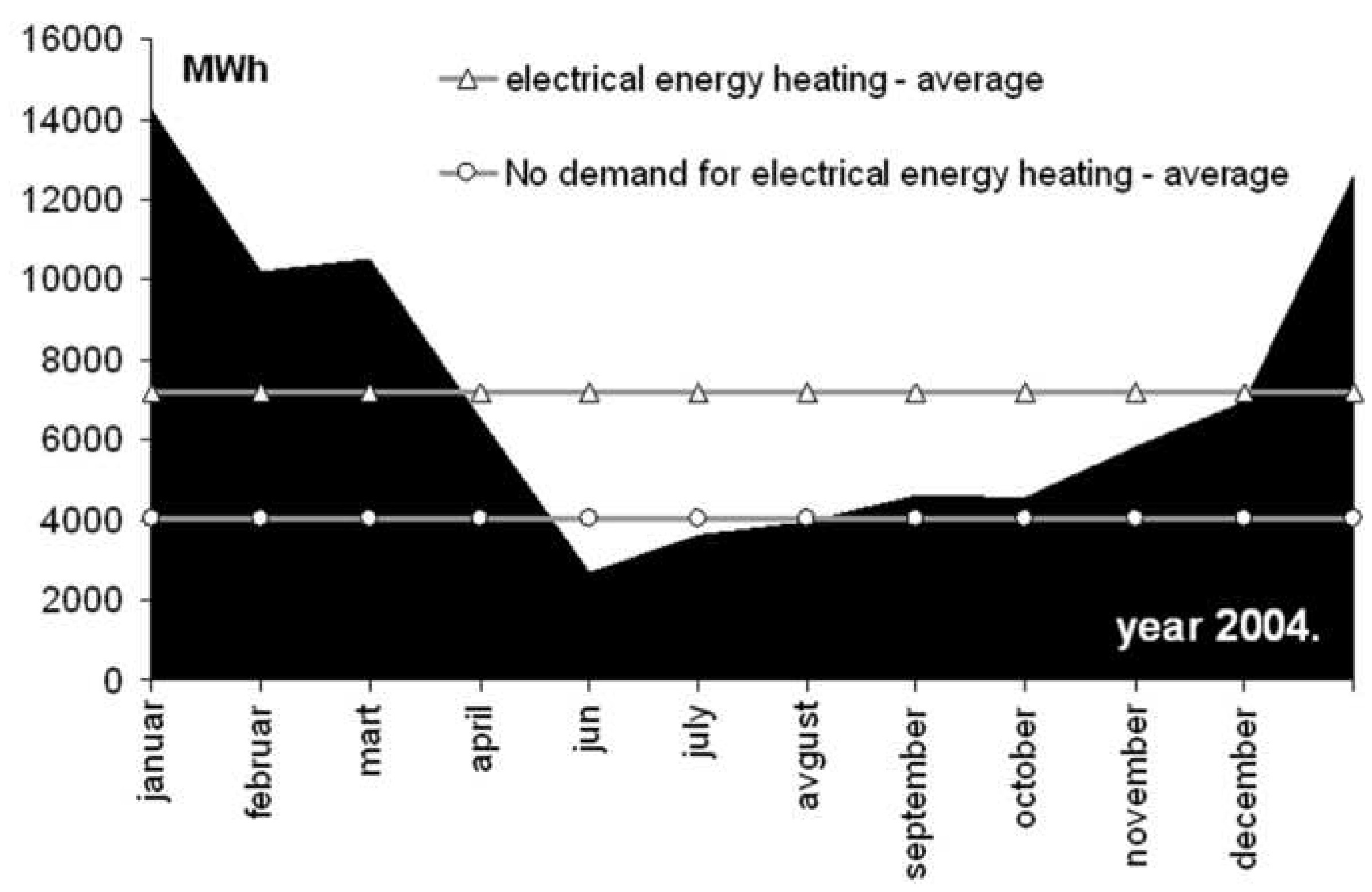


"Heat Load" MW/ $/ \mathrm{km}^{2}$

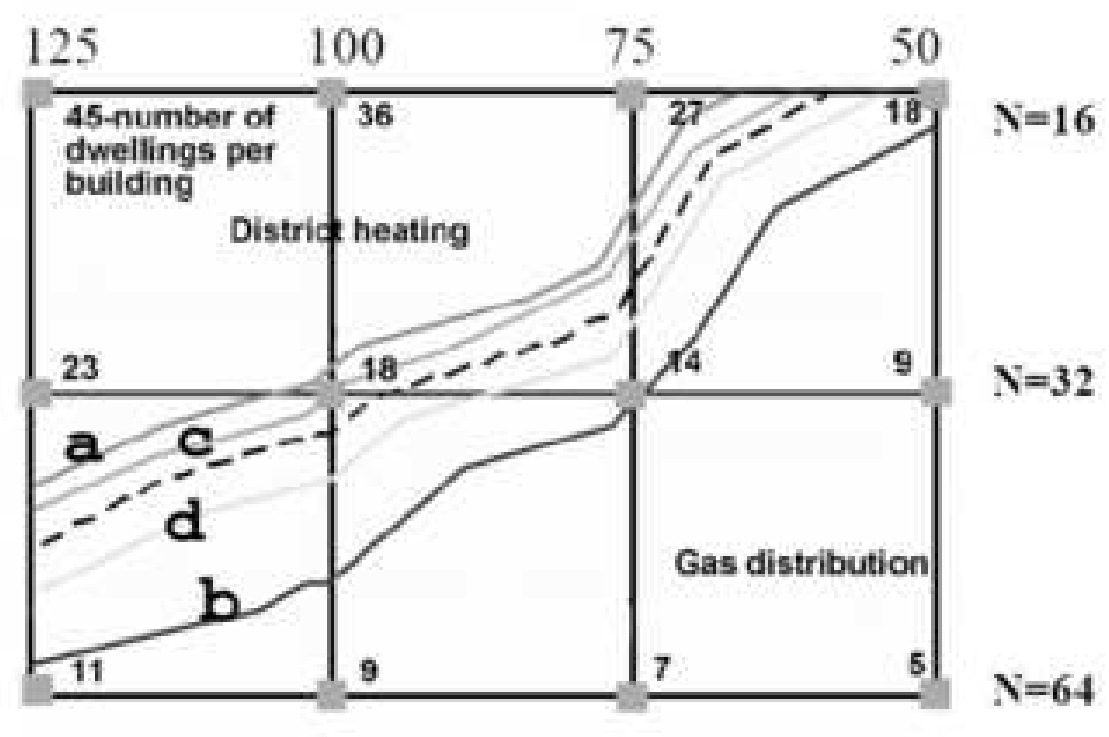

"Heat Load" MW/km²

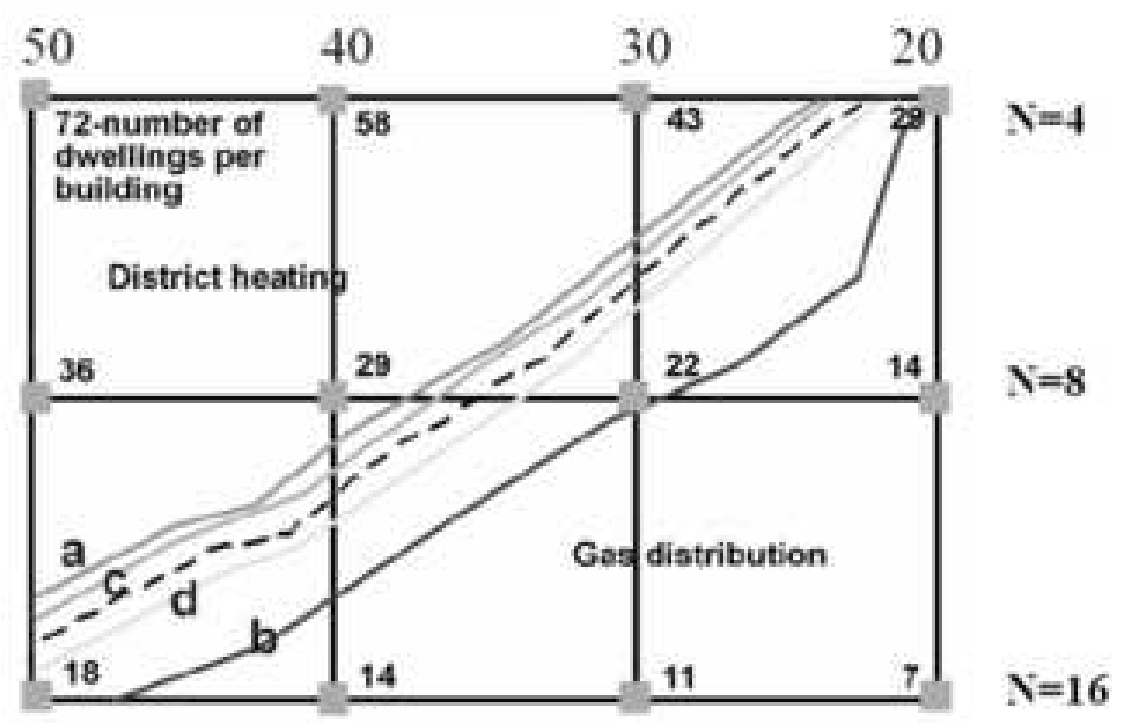

...- border between $\mathrm{DH}$ and $\mathrm{G}$ area (present condition)

a -increase of natural gas price for $50 \%$

b - increase of domestic gas appliances price for $20 \%$

$\mathrm{c}$ - bad insulation, $\mathrm{d}$ - good insulation 


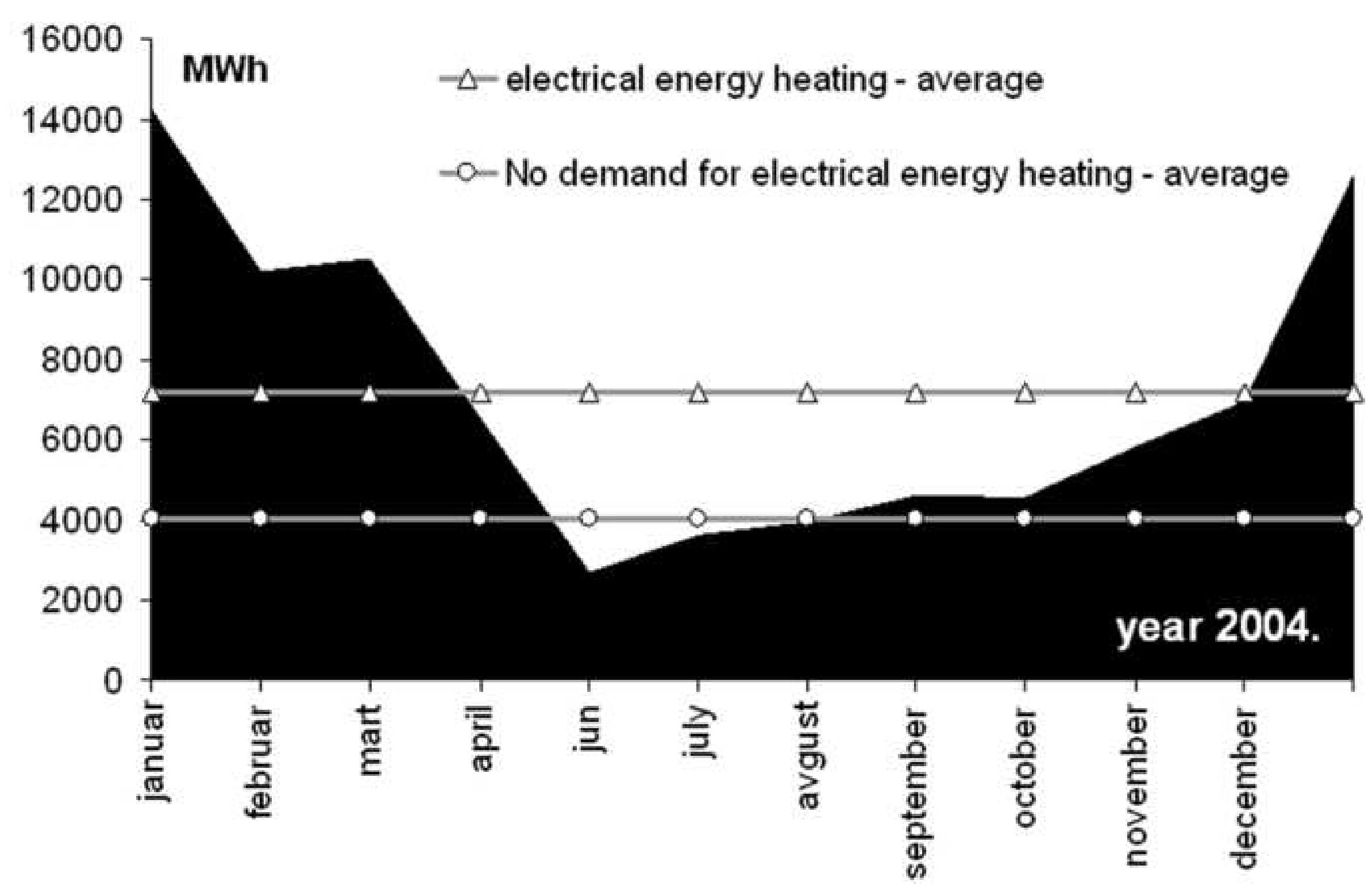


Figure(s)

Click here to download high resolution image

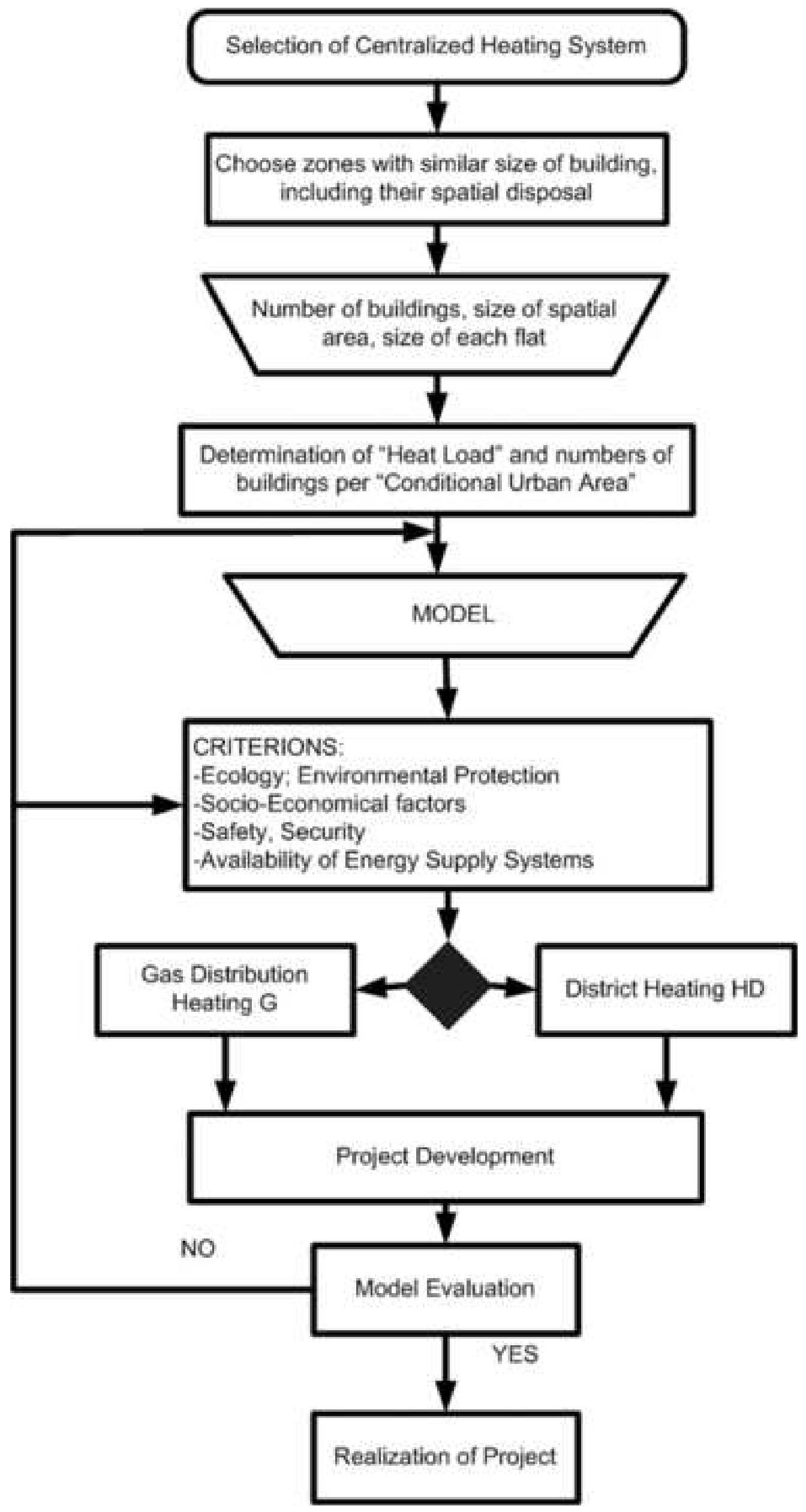


Table 1

Identification of all of 96 considered case (number of average dwelling per building)

\begin{tabular}{|c|c|c|c|c|c|c|c|c|c|}
\hline \multicolumn{10}{|c|}{ Number of buildings $-\mathrm{N}$ per basic segment } \\
\hline & \multirow[b]{2}{*}{$\mathrm{W} / \mathrm{m}^{2}$} & \multicolumn{8}{|c|}{ "Heat Loads", MW·km² } \\
\hline & & 125 & 100 & 75 & 50 & 40 & 30 & 20 & 10 \\
\hline \multirow{2}{*}{$N=4$} & $95^{\mathrm{a}}$ & $274^{\mathrm{c}}$ & 219 & 164 & 110 & 88 & 66 & 44 & 22 \\
\hline & $142^{b}$ & 181 & 145 & 109 & 72 & 58 & 43 & 29 & 14 \\
\hline \multirow{2}{*}{$\mathbf{N}=8$} & 95 & 137 & 110 & 82 & 55 & 44 & 33 & 22 & 11 \\
\hline & 142 & 90 & 72 & 54 & 36 & 29 & 22 & 14 & 7 \\
\hline \multirow{2}{*}{$N=16$} & 95 & 69 & 55 & 41 & 27 & 22 & 16 & 11 & 5 \\
\hline & 142 & 45 & 36 & 27 & 18 & 14 & 11 & 7 & 4 \\
\hline \multirow{2}{*}{$\mathbf{N}=32$} & 95 & 34 & 27 & 21 & 14 & 11 & 8 & 5 & 3 \\
\hline & 142 & 23 & 18 & 14 & 9 & 7 & 5 & 4 & 2 \\
\hline \multirow{2}{*}{$N=64$} & 95 & 17 & 14 & 10 & 7 & 5 & 4 & 3 & 1 \\
\hline & 142 & 11 & 9 & 7 & 5 & 4 & 3 & 2 & 1 \\
\hline \multirow{2}{*}{$\mathrm{N}=128$} & 95 & 9 & 7 & 5 & 3 & 3 & 2 & 1 & 1 \\
\hline & 142 & 6 & 5 & 3 & 2 & 2 & 1 & 1 & $0^{\mathrm{d}}$ \\
\hline
\end{tabular}

${ }^{\mathrm{a}}$ Good insulated dwelling, ${ }^{\mathrm{b}}$ Poor insulated dwelling

"274 good insulated dwellings per building, 4 buildings per "Basic segment"

"less than 1 average dwelling $\left(<60 \mathrm{~m}^{2}\right)$ per building; poor insulated, 128 houses per "Basic segment" 
Table 2

Structure of pipe diameters for one of the cases (example)

\begin{tabular}{|c|c|c|c|c|c|c|c|c|c|c|c|c|c|c|c|c|}
\hline \multirow[b]{3}{*}{ Pipe diameter [mm] } & \multicolumn{16}{|c|}{ "Heat Loads", MW $\mathrm{km}^{-2}$} \\
\hline & \multicolumn{2}{|c|}{125} & \multicolumn{2}{|l|}{100} & \multicolumn{2}{|l|}{75} & \multicolumn{2}{|l|}{50} & \multicolumn{2}{|l|}{40} & \multicolumn{2}{|l|}{30} & \multicolumn{2}{|l|}{20} & \multicolumn{2}{|l|}{10} \\
\hline & DH & $\mathrm{G}$ & DH & $\mathrm{G}$ & $\mathrm{DH}$ & $\mathrm{G}$ & DH & $\mathrm{G}$ & DH & $\mathrm{G}$ & DH & $\mathrm{G}$ & DH & $\mathrm{G}$ & $\mathrm{DH}$ & G \\
\hline 25 & 0 & 0 & 0 & 0 & 0 & 3200 & 0 & 3200 & 0 & 3357.5 & 0 & 3987.5 & 0 & 4302.5 & 6400 & 5798.75 \\
\hline 32 & 0 & 3200 & 0 & 3200 & 0 & 630 & 0 & 787.5 & 0 & 945 & 6400 & 787.5 & 6400 & 1496.25 & 1575 & 157.5 \\
\hline 40 & 0 & 630 & 0 & 787.5 & 6400 & 157.5 & 6400 & 787.5 & 6400 & 1260 & 1575 & 1181.25 & 1575 & 157.5 & 3150 & 160 \\
\hline 50 & 0 & 157.5 & 6400 & 630 & 0 & 787.5 & 1575 & 1181.25 & 1575 & 393.75 & 0 & 0 & 1575 & 160 & 787.5 & 160 \\
\hline $63(\mathrm{G}) ; 65(\mathrm{DH})$ & 6400 & 787.5 & 0 & 945 & 1575 & 1181.25 & 0 & 0 & 1575 & 0 & 3150 & 160 & 2362.5 & 0 & 320 & 320 \\
\hline $75(\mathrm{G}) ; 80(\mathrm{DH})$ & 1575 & 1102.5 & 1575 & - & 1575 & 0 & 3150 & 160 & 2362.5 & 160 & 787.5 & 160 & 320 & 320 & 320 & 80 \\
\hline 90 (G only) & - & 78.75 & - & 0 & - & 160 & - & 0 & - & 160 & - & 0 & - & 160 & - & 0 \\
\hline $110(\mathrm{G}) ; 100(\mathrm{DH})$ & 3150 & 160 & 3150 & 160 & 2362.5 & 0 & 787.5 & 160 & 320 & 160 & 320 & 320 & 320 & 80 & 640 & 0 \\
\hline 125 & 787.5 & 0 & 787.5 & 0 & 0 & 160 & 320 & 160 & 0 & 160 & 320 & 80 & 320 & 0 & 0 & 0 \\
\hline $140(\mathrm{G}) ; 150(\mathrm{DH})$ & 0 & 0 & 320 & 160 & 320 & 0 & 320 & 160 & 320 & 80 & 320 & 0 & 480 & 0 & 160 & 0 \\
\hline 160 (only G) & - & 160 & - & 0 & - & 160 & - & 80 & - & 0 & - & 0 & - & 0 & - & 0 \\
\hline 180 (only G) & - & 0 & - & 160 & - & 240 & - & 0 & - & 0 & - & 0 & - & 0 & - & 0 \\
\hline 200 & 320 & 160 & 320 & 160 & 640 & 0 & 640 & 0 & 800 & 0 & 480 & 0 & 0 & 0 & 0 & 0 \\
\hline 225 (only G) & - & 160 & - & 80 & - & 0 & - & 0 & & 0 & & 0 & - & 0 & - & 0 \\
\hline 250 & 320 & 80 & 320 & 0 & 320 & 0 & 160 & 0 & 0 & 0 & 0 & 0 & 0 & 0 & 0 & 0 \\
\hline 300 (only DH) & 320 & - & 320 & - & 160 & - & 0 & - & 0 & - & 0 & - & 0 & - & 0 & - \\
\hline 350 (only DH) & 320 & - & 160 & - & 0 & - & 0 & - & 0 & - & 0 & - & 0 & - & 0 & - \\
\hline 400 (only DH) & 160 & - & 0 & - & 0 & - & 0 & - & 0 & - & 0 & - & 0 & - & 0 & - \\
\hline
\end{tabular}


Table 3

Investments in both systems per dwelling; $\mathrm{G}$ and $\mathrm{DH}[€]$

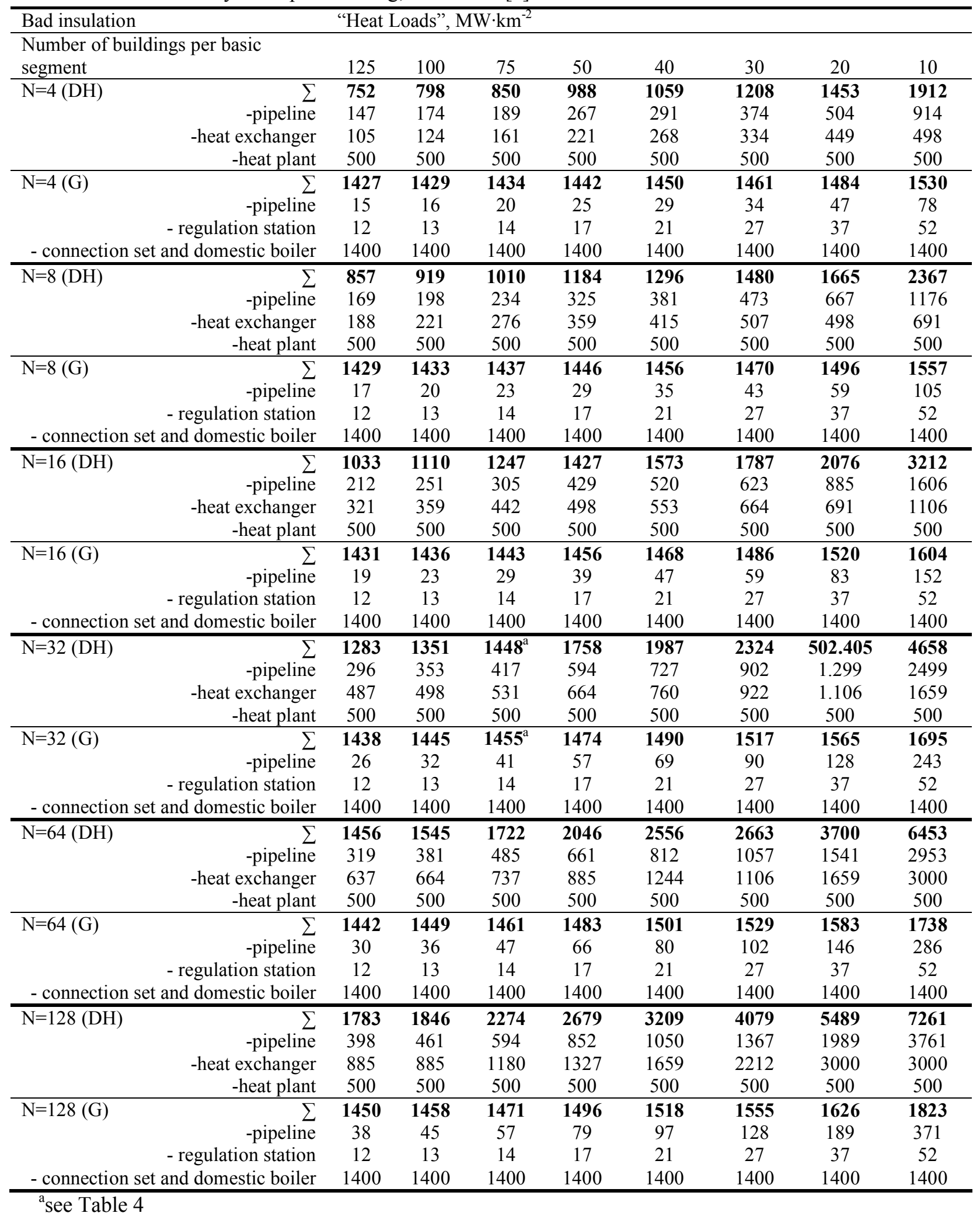


Table 4

Costs for gas distribution system and district heating system (example)

\begin{tabular}{|c|c|c|c|c|c|c|c|c|c|c|c|c|c|}
\hline \multicolumn{14}{|c|}{$\begin{array}{l}\text { per "Conditional dwelling" } \\
\mathrm{N}=32 \text { buildings per } 0,05 \mathrm{~km}^{2}, x\end{array}$} \\
\hline \multirow[b]{2}{*}{$\mathrm{a}$} & \multicolumn{6}{|c|}{ District Heating System } & \multicolumn{7}{|c|}{ Gas Distribution System } \\
\hline & $\mathrm{DH}$ & $\mathrm{b}$ & $\mathrm{c}$ & $\mathrm{d}$ & $\mathrm{e}$ & $f$ & $G$ & $\mathrm{~g}$ & $\mathrm{~h}$ & $\mathrm{i}$ & $j$ & $\mathrm{k}$ & DH-G \\
\hline 1 & 1447,5 & 916,6 & 530,8 & 0 & 0 & 0 & 1454,5 & 40,7 & 13,7 & 400 & 1000 & 0 & $-7,0$ \\
\hline 2 & 37,4 & 0 & 0 & 18,38 & 10,2 & 8,75 & 21,7 & 0 & 0 & 0 & 0 & 22 & 15,7 \\
\hline 3 & 37,4 & 0 & 0 & 18,38 & 10,2 & 8,75 & 21,7 & 0 & 0 & 0 & 0 & 22 & 15,7 \\
\hline 4 & 37,4 & 0 & 0 & 18,38 & 10,2 & 8,75 & 21,7 & 0 & 0 & 0 & 0 & 22 & 15,7 \\
\hline 5 & 37,4 & 0 & 0 & 18,38 & 10,2 & 8,75 & 21,7 & 0 & 0 & 0 & 0 & 22 & 15,7 \\
\hline 6 & 37,4 & 0 & 0 & 18,38 & 10,2 & 8,75 & 21,7 & 0 & 0 & 0 & 0 & 22 & 15,7 \\
\hline 7 & 37,4 & 0 & 0 & 18,38 & 10,2 & 8,75 & 21,7 & 0 & 0 & 0 & 0 & 22 & 15,7 \\
\hline 8 & 37,4 & 0 & 0 & 18,38 & 10,2 & 8,75 & 21,7 & 0 & 0 & 0 & 0 & 22 & 15,7 \\
\hline 9 & 37,4 & 0 & 0 & 18,38 & 10,2 & 8,75 & 21,7 & 0 & 0 & 0 & 0 & 22 & 15,7 \\
\hline 10 & 37,4 & 0 & 0 & 18,38 & 10,2 & 8,75 & 21,7 & 0 & 0 & 0 & 0 & 22 & 15,7 \\
\hline 11 & 37,4 & 0 & 0 & 18,38 & 10,2 & 8,75 & 21,7 & 0 & 0 & 0 & 0 & 22 & 15,7 \\
\hline 12 & 37,4 & 0 & 0 & 18,38 & 10,2 & 8,75 & 21,7 & 0 & 0 & 0 & 0 & 22 & 15,7 \\
\hline 13 & 37,4 & 0 & 0 & 18,38 & 10,2 & 8,75 & 21,7 & 0 & 0 & 0 & 0 & 22 & 15,7 \\
\hline 14 & 568,2 & 0 & 530,8 & 18,38 & 10,2 & 8,75 & 921,7 & 0 & 0 & 100 & 800 & 22 & $-353,5$ \\
\hline 15 & 37,4 & 0 & 0 & 18,38 & 10,2 & 8,75 & 21,7 & 0 & 0 & 0 & 0 & 22 & 15,7 \\
\hline 16 & 37,4 & 0 & 0 & 18,38 & 10,2 & 8,75 & 21,7 & 0 & 0 & 0 & 0 & 22 & 15,7 \\
\hline 17 & 37,4 & 0 & 0 & 18,38 & 10,2 & 8,75 & 21,7 & 0 & 0 & 0 & 0 & 22 & 15,7 \\
\hline 18 & 37,4 & 0 & 0 & 18,38 & 10,2 & 8,75 & 21,7 & 0 & 0 & 0 & 0 & 22 & 15,7 \\
\hline 19 & 37,4 & 0 & 0 & 18,38 & 10,2 & 8,75 & 21,7 & 0 & 0 & 0 & 0 & 22 & 15,7 \\
\hline 20 & 37,4 & 0 & 0 & 18,38 & 10,2 & 8,75 & 21,7 & 0 & 0 & 0 & 0 & 22 & 15,7 \\
\hline 21 & 37,4 & 0 & 0 & 18,38 & 10,2 & 8,75 & 21,7 & 0 & 0 & 0 & 0 & 22 & 15,7 \\
\hline 22 & 37,4 & 0 & 0 & 18,38 & 10,2 & 8,75 & 21,7 & 0 & 0 & 0 & 0 & 22 & 15,7 \\
\hline 23 & 37,4 & 0 & 0 & 18,38 & 10,2 & 8,75 & 21,7 & 0 & 0 & 0 & 0 & 22 & 15,7 \\
\hline 24 & 37,4 & 0 & 0 & 18,38 & 10,2 & 8,75 & 21,7 & 0 & 0 & 0 & 0 & 22 & 15,7 \\
\hline 25 & 37,4 & 0 & 0 & 18,38 & 10,2 & 8,75 & 21,7 & 0 & 0 & 0 & 0 & 22 & 15,7 \\
\hline \multirow[t]{2}{*}{26} & 37,4 & 0 & 0 & 18,38 & 10,2 & 8,75 & 21,7 & 0 & 0 & 0 & 0 & 22 & 15,7 \\
\hline & 2913 & 917 & 1062 & 459 & 255 & 219 & 2897 & 40,7 & 13,7 & 500 & 1800 & 544 & $16,0^{1}$ \\
\hline \multirow{2}{*}{\multicolumn{14}{|c|}{$\frac{\text { "Discount Rate" }=10,0 \%}{\text { Small differences in sum ar }}$}} \\
\hline & & & & & & & & & & & & & \\
\hline \multicolumn{14}{|c|}{ 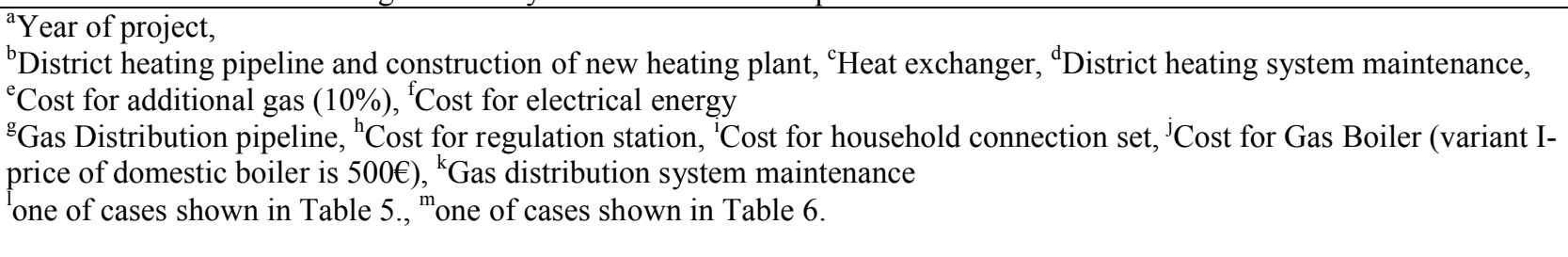 } \\
\hline
\end{tabular}


Table 5

Initial costs ${ }^{\mathrm{a}}$ - $€$ per "Conditional Dwelling"

\begin{tabular}{|c|c|c|c|c|c|c|c|c|c|}
\hline \multicolumn{10}{|c|}{ Number of buildings $-\mathrm{N}^{\mathrm{b}}$ (bad insulation) } \\
\hline & \multirow[b]{2}{*}{ c } & \multicolumn{8}{|c|}{ "Heat Loads", MW $\cdot \mathrm{km}^{-2}$} \\
\hline & & 125 & 100 & 75 & 50 & 40 & 30 & 20 & 10 \\
\hline \multirow{2}{*}{$\mathbf{N}=4$} & $\mathbf{I}$ & -674 & -631 & -583 & -454 & -390 & -253 & -30 & 381 \\
\hline & II & $-1,174$ & $-1,131$ & $-1,083$ & -954 & -890 & -753 & -530 & -119 \\
\hline \multirow{2}{*}{$\mathbf{N}=\mathbf{8}$} & $\mathbf{I}$ & -571 & -513 & -426 & -261 & -159 & 10 & 168 & 810 \\
\hline & II & $-1,071$ & $-1,013$ & -926 & -761 & -659 & -490 & -332 & 310 \\
\hline \multirow{2}{*}{$N=16$} & $\mathbf{I}$ & -398 & -325 & -195 & -28 & 106 & 301 & 556 & 1.608 \\
\hline & II & -898 & -825 & -695 & -528 & -394 & -199 & 56 & 1,108 \\
\hline \multirow{2}{*}{$\mathbf{N}=32$} & I & -156 & -94 & $-7^{\mathrm{d}}$ & 284 & 497 & 807 & 1.339 & 2.963 \\
\hline & II & -656 & -594 & -507 & -216 & -3 & 307 & 839 & 2,463 \\
\hline \multirow{2}{*}{$N=64$} & I & 14 & 96 & 262 & 563 & 1.056 & 1.134 & 2.117 & 4.714 \\
\hline & II & -486 & -404 & -238 & 63 & 556 & 634 & 1,617 & 4,214 \\
\hline \multirow{2}{*}{$\mathrm{N}=128$} & I & 333 & 388 & 1.183 & 1.183 & 1.691 & 2.524 & 3.863 & 5.438 \\
\hline & II & -167 & -112 & 303 & 683 & 1,191 & 2,024 & 3,363 & 4,938 \\
\hline \multicolumn{2}{|c|}{$\mid$ III-I $\mid$} & 500 & 500 & 500 & 500 & 500 & 500 & 500 & 500 \\
\hline & $\mathrm{e}$ & 689 & 689 & 689 & 689 & 689 & 689 & 689 & 689 \\
\hline
\end{tabular}

Negative values: gas distribution system is more expensive

Positive values: district heating system is more expensive

${ }^{\mathrm{a}} \mathrm{DH}-\mathrm{G}$ (see eq. 1 and 2 and Table 3)

bumber of buildings per $0,05 \mathrm{~km}^{2}$ ("Basic segment"; see Fig. 1 and 2), note that all examination are done on ten time larger segment ("Examination segment"; see Fig. 3) because this size of segment is more suitable for examination of pipeline costs; more representative pipe diameters are included in model

${ }^{\mathrm{c}}$ Price of domestic boiler; I-500 $€$ (value also used in Table 6, see also Fig. 6.), values for I are the same in case of increasing the prize of domestic gas boiler for $500 €$ (sum $1000 €$ for boiler), but with simultaneously adding of investments (500€ per average dwelling) in new heating plant on the other side II-1000 €; $\mathrm{dr}=10 \%$;

${ }^{\mathrm{d}}$ Example from Table 2, ${ }^{\mathrm{e}} \mathrm{NPV}$ (II)-NPV (I); $\mathrm{dr}=10 \%$ 
Table 6

"Net Present Value of Costs" (NPV) - $€$ per "Conditional Dwelling"

Number of buildings (bad insulation)

\begin{tabular}{|c|c|c|c|c|c|c|c|c|c|}
\hline \multirow[b]{2}{*}{$\mathrm{I}^{\mathrm{b}}$} & \multirow[b]{2}{*}{$\mathrm{dr}^{\mathrm{c}}$} & \multicolumn{8}{|c|}{ "Heat Loads", MW'km ${ }^{-2}$} \\
\hline & & 125 & 100 & 75 & 50 & 40 & 30 & 20 & $\mathbf{1 0}$ \\
\hline \multirow{3}{*}{$N=4$} & $5 \%$ & $-1,010$ & -946 & -870 & -679 & -576 & -371 & -34 & 529 \\
\hline & $7 \%$ & -911 & -852 & -784 & -609 & -517 & -329 & -22 & 499 \\
\hline & $10 \%$ & -802 & -749 & -689 & -532 & -451 & -283 & -9 & 467 \\
\hline \multirow{3}{*}{$\mathbf{N}=\mathbf{8}$} & $5 \%$ & -846 & -757 & -624 & -378 & -223 & 34 & 243 & 1,161 \\
\hline & $7 \%$ & -763 & -682 & -562 & -337 & -196 & 38 & 233 & 1,078 \\
\hline & $10 \%$ & -671 & -599 & -492 & -291 & -166 & 42 & 223 & 985 \\
\hline \multirow{3}{*}{$N=16$} & $5 \%$ & -573 & -462 & -262 & -23 & 174 & 472 & 822 & 2,357 \\
\hline & $7 \%$ & -516 & -416 & -234 & -15 & 166 & 437 & 761 & 2,168 \\
\hline & $10 \%$ & -454 & -364 & -203 & -5 & 157 & 398 & 695 & 1.959 \\
\hline \multirow{3}{*}{$\mathbf{N}=32$} & $5 \%$ & -197 & -111 & 16 & 446 & 762 & 1,229 & 1,999 & 4,336 \\
\hline & $7 \%$ & -176 & -97 & 20 & 413 & 701 & 1,127 & 1,834 & 3,980 \\
\hline & $10 \%$ & -152 & -80 & $25^{\mathrm{d}}$ & 377 & 635 & 1.015 & 1.652 & 3.587 \\
\hline \multirow{3}{*}{$\mathrm{N}=64$} & $5 \%$ & 79 & 196 & 441 & 891 & 1,664 & 1,722 & 3,211 & 7,103 \\
\hline & $7 \%$ & 72 & 180 & 404 & 814 & 1,514 & 1,576 & 2,931 & 6,479 \\
\hline & $10 \%$ & 65 & 163 & 363 & 730 & 1.348 & 1.415 & 2.623 & 5.791 \\
\hline \multirow{3}{*}{$\mathrm{N}=128$} & $5 \%$ & 584 & 657 & 1,305 & 1,858 & 2,642 & 3,931 & 5,971 & 8,062 \\
\hline & $7 \%$ & 528 & 596 & 1,182 & 1,689 & 2,400 & 3,569 & 5,423 & 7,374 \\
\hline & $10 \%$ & 467 & 530 & 1.048 & 1.504 & 2.135 & 3.171 & 4.820 & 6.614 \\
\hline
\end{tabular}

Negative values: gas distribution system is more expensive

Positive values: district heating system is more expensive

${ }^{\mathrm{a}}$ see eq. 3 .

${ }^{\mathrm{b}}$ Variant I-gas boiler price: $500 €$ (see Table 5)

"Value of "Discount Rate"

${ }^{\mathrm{d}}$ Example from Table 4 


\begin{tabular}{|c|c|c|c|c|c|c|c|c|c|c|c|c|c|c|}
\hline \multicolumn{6}{|l|}{$\begin{array}{l}\text { Gas distribution system vs. District heating sys } \\
\text { INPUT PARAMETERS (edit only green cells) }\end{array}$} & \multicolumn{9}{|c|}{ Main results } \\
\hline \multirow{2}{*}{$\begin{array}{l}\text { Investments per dwelling } \\
\text { Pressure Reduction Stations - G (€ per flat) }\end{array}$} & $€$ & \multicolumn{2}{|c|}{ 'ear-replacemen \% maintenance } & & & \multirow[b]{2}{*}{$\mathrm{MW} / \mathrm{km}^{2}$} & \multirow[b]{2}{*}{125} & \multirow[b]{2}{*}{100} & \multirow[b]{2}{*}{75} & \multirow[b]{2}{*}{50} & \multirow[b]{2}{*}{40} & \multirow[b]{2}{*}{30} & \multirow[b]{2}{*}{20} & \multirow[b]{2}{*}{10} \\
\hline & 12 & 25 & $2.3 \%$ & & & & & & & & & & & \\
\hline Domestic measurement sets - $\mathrm{G}$ ( $€$ per flat) & 400 & 12 & $2.3 \%$ & & & & & & & & & & & \\
\hline Domestic gas boiler - $\mathbf{G}$ ( $€$ per flat) & 1000 & 12 & $2.5 \%$ & & $\mathrm{~N} / 0.05 \mathrm{~km}^{2}$ & 4 & DH & DH & DH & DH & DH & DH & DH & G \\
\hline Heat exchanger - DH (see hidden layers for used prize) & $* *+*+*$ & 12 & $1.5 \%$ & & & 8 & DH & $\mathrm{DH}$ & $\mathrm{DH}$ & DH & DH & G & G & G \\
\hline Gas Distribution network & & 25 & $2.3 \%$ & & & 16 & DH & DH & DH & DH & G & G & G & G \\
\hline District Heating network & & 25 & $2.5 \%$ & & & 32 & $\mathrm{DH}$ & DH & G & G & G & G & G & G \\
\hline Annual gas consumption - $G$ & 857 & $\mathrm{~m}^{3} /$ year per fla & $t$ for heating in & stem & & 64 & G & G & G & G & G & G & G & G \\
\hline Annual gas consumption - DH & 1.10 & $\mathrm{DH} / \mathrm{G}$ & & & & 128 & G & G & G & G & G & G & G & G \\
\hline Investment in heating plant & 500 & €/flat & & & & & & & & & & & & \\
\hline Annual electric energy consumption & 250 & KWh/year per & lat for pumps i & system & & & & & & & & & & \\
\hline Natural gas price & 0.12 & $€ / \mathrm{m}^{3}$ (here is $\mathrm{e}$ & qual price for $\mathrm{g}$ & both syster & or Energy read & $(\mathrm{NPV})-€$ & er "Co & nditiona & al Dwelli & ing" & & & & \\
\hline Price of el. Energy & 0.035 & $\epsilon / K W h$ & & & & MW/km² & 125 & 100 & 75 & 50 & 40 & 30 & 20 & 10 \\
\hline Discount rate & $10.0 \%$ & & & & & & & & & & & & & \\
\hline *** fixed and locked for Energy readers in hidden layers & & & & & $\mathrm{N} / 0.05 \mathrm{~km}^{2}$ & 4 & -802 & $-1,335$ & -689 & -532 & -451 & -283 & -9 & 467 \\
\hline note: calculation only for poor insulated dwellings for Energy readi & & & & & & 8 & -671 & -599 & -492 & -291 & -166 & 42 & 223 & 985 \\
\hline & & & & & & 16 & -454 & -364 & -203 & -5 & 157 & 398 & 695 & 1,959 \\
\hline & Price of netv & vork conduits & & & & 32 & -152 & -80 & 25 & 381 & 635 & 1,015 & 1,652 & 3,587 \\
\hline & Gas distribu & tion pipeline & District heating & line & & 64 & 65 & 163 & 363 & 730 & 1,348 & 1,415 & 2,623 & 5,791 \\
\hline & Diameter & $€ / m$ & Diameter & $\epsilon / m$ & & 128 & 467 & 530 & 1,048 & 1,504 & 2,135 & 3,171 & 4,820 & 6,614 \\
\hline & 25 & 8.1 & 20 & 40 & & & & & & & & & & \\
\hline & 32 & 11.0 & 25 & 43 & & & & & & & & & & \\
\hline & 40 & 13.0 & 32 & 49 & & initial cos & $s-€ p$ & r "Conc & ditional & Dwellir & & & & \\
\hline & 50 & 13.6 & 40 & 52 & & MW/km² & 125 & 100 & 75 & 50 & 40 & 30 & 20 & 10 \\
\hline & 63 & 19.3 & 50 & 55.5 & & & & & & & & & & \\
\hline & 75 & 20.0 & 65 & 58.5 & $\mathrm{~N} / 0.05 \mathrm{~km}^{2}$ & 4 & -674 & $-1,131$ & -583 & -454 & -390 & -253 & -30 & 381 \\
\hline & 90 & 27.0 & 80 & 74 & & 8 & -571 & -513 & -426 & -261 & -159 & 10 & 168 & 810 \\
\hline & 110 & 30.0 & 100 & 93 & & 16 & -398 & -325 & -195 & -28 & 106 & 301 & 556 & 1,608 \\
\hline & 125 & 37.0 & 125 & 118 & & 32 & -156 & -94 & -7 & 288 & 497 & 807 & 1,339 & 2,963 \\
\hline & 140 & 39.5 & 150 & 124 & & 64 & 14 & 96 & 262 & 563 & 1,056 & 1,134 & 2,117 & 4,714 \\
\hline & 160 & 47.5 & 200 & 158 & & 128 & 333 & 388 & 803 & 1,183 & 1,691 & 2,524 & 3,863 & 5,438 \\
\hline & 180 & 51.5 & 250 & 224 & & & & & & & & & & \\
\hline & 200 & 55.5 & 300 & 254 & & & & & & & & & & \\
\hline & 225 & 62.5 & 350 & 295 & & & & & & & & & & \\
\hline & 250 & 69.4 & 400 & 313 & & & & & & & & & & \\
\hline & & & 450 & 322 & & & & & & & & & & \\
\hline & & & 500 & 380 & & & & & & & & & & \\
\hline
\end{tabular}

